\title{
An assessment of Southern Ocean water masses and sea ice during 1988-2007 in a suite of inter-annual CORE-II simulations
}

Stephanie M. Downes ${ }^{a, *}$, Riccardo Farneti ${ }^{\text {b, }}$, Petteri Uotila ${ }^{\text {c,d, }}$, Stephen M. Griffies ${ }^{\mathrm{e},}$, Simon J. Marsland $^{\mathrm{c}}$, David Bailey ${ }^{\mathrm{f}}$, Erik Behrens ${ }^{\mathrm{g}, \mathrm{h}}$, Mats Bentsen ${ }^{\mathrm{i}, \mathrm{j}}$, Daohua Bi ${ }^{\mathrm{c}}$, Arne Biastoch ${ }^{\mathrm{g}}$, Claus Böning ${ }^{g}$, Alexandra Bozec ${ }^{\mathrm{k}}$, Vittorio M. Canuto ${ }^{1}$, Eric Chassignet ${ }^{\mathrm{k}}$, Gokhan Danabasoglu ${ }^{\mathrm{f}}$, Sergey Danilov $^{\mathrm{m}}$, Nikolay Diansky ${ }^{\mathrm{n}}$, Helge Drange ${ }^{\mathrm{o}, \mathrm{j}}$, Pier Giuseppe Fogli ${ }^{\mathrm{p}}$, Anatoly Gusev ${ }^{\mathrm{n}}$, Armando

Howard $^{\mathrm{l}}$, Mehmet Ilicak ${ }^{\mathrm{i}, \mathrm{j}}$, Thomas Jung ${ }^{\mathrm{m}}$, Maxwell Kelley ${ }^{\mathrm{l}}$, William G. Large ${ }^{\mathrm{f}}$, Anthony

Leboissetier $^{\mathrm{l}, \mathrm{q}}$, Matthew Long ${ }^{\mathrm{f}}$, Jianhua Lu ${ }^{\mathrm{k}}$, Simona Masina ${ }^{\mathrm{r}, \mathrm{p}}$, Akhilesh Mishra ${ }^{\mathrm{k}}$, Antonio Navarra $^{\mathrm{r}, \mathrm{p}}$, A. J. George Nurser ${ }^{\mathrm{s}}$, Lavinia Patara ${ }^{\mathrm{g}}$, Bonita L. Samuels ${ }^{\mathrm{e}}$, Dmitry Sidorenkom ${ }^{\mathrm{m}}$, Paul Spence $^{\mathrm{t}}$, Hiroyuki Tsujino ${ }^{\mathrm{u}}$, Qiang Wang $^{\mathrm{m}}$, Stephen G. Yeager ${ }^{\mathrm{f}}$

${ }^{a}$ Research School of Earth Sciences and ARC Centre of Excellence for Climate System Science, Australian National University, Acton, Australia

${ }^{b}$ Earth System Physics, International Centre for Theoretical Physics (ICTP), Trieste, Italy

${ }^{c}$ Centre for Australian Weather and Climate Research, a partnership between CSIRO and the Bureau of Meteorology, CSIRO, Aspendale, Australia

${ }^{d}$ Finnish Meteorological Institute, Helsinki, Finland

${ }^{e}$ NOAA/Geophysical Fluid Dynamics Laboratory, Princeton, NJ, USA

${ }^{f}$ National Center for Atmospheric Research (NCAR), Boulder, CO, USA

${ }^{g}$ GEOMAR Helmholtz Centre for Ocean Research Kiel, Kiel, Germany

${ }^{h}$ National Institute of Water and Atmospheric Research (NIWA), Wellington, New Zealand

${ }^{i}$ Uni Climate, Uni Research AS, Bergen, Norway

${ }^{j}$ Bjerknes Centre for Climate Research, Bergen, Norway

${ }^{k}$ Center for Ocean-Atmospheric Prediction Studies (COAPS), Florida State University, Tallahassee, USA

${ }^{l}$ NASA Goddard Institute for Space Studies (GISS), New York, New York, USA

${ }^{m}$ Alfred Wegener Institute (AWI), Bremerhaven, Germany

${ }^{n}$ Institute of Numerical Mathematics, Russian Academy of Sciences, Moscow, Russia

${ }^{\circ}$ University of Bergen, Bergen, Norway

${ }^{p}$ Centro Euro-Mediterraneo sui Cambiamenti Climatici (CMCC), Bologna, Italy

${ }^{q}$ Trinnovim LLC, New York, New York, USA

${ }^{r}$ Istituto Nazionale di Geofisica e Vulcanologia (INGV), Bologna, Italy

${ }^{s}$ National Oceanography Centre Southampton (NOCS), Southampton, UK

${ }^{t}$ ARC Centre of Excellence for Climate System Science, University of New South Wales, Sydney, NSW, Australia

${ }^{u}$ Meteorological Research Institute (MRI), Japan Meteorological Agency, Tsukuba, Japan

\section{Abstract}

We characterize the representation of the Southern Ocean water mass structure and sea ice within a suite of 15 global ocean-ice models run with the Coordinated Ocean-ice Reference Experiment Phase II (CORE-II) protocol. The main focus is the representation of the present (1988-2007) mode and intermediate waters, thus framing an analysis of winter and summer mixed layer depths; temperature, salinity, and potential vorticity structure; and temporal variability of sea ice distributions. We also consider the inter-annual variability over the same 20 year period. Comparisons are made between models as well as to observation-based analyses where available.

*Now at: Antarctic Climate and Ecosystems Cooperative Research Centre, University of Tasmania, 20 Castray Esplanade, Hobart, TAS, Australia 7000

Email address: s.downes@utas.edu.au (Stephanie M. Downes)

Preprint submitted to Ocean Modelling

July 28, 2015

(C) 2015. This manuscript version is made available under the Elsevier user license

http://www.elsevier.com/open-access/userlicense/1.0/ 
The CORE-II models exhibit several biases relative to Southern Ocean observations, including an underestimation of the model mean mixed layer depths of mode and intermediate water masses in March (associated with greater ocean surface heat gain), and an overestimation in September (associated with greater high latitude ocean heat loss and a more northward winter sea-ice extent). In addition, the models have cold and fresh/ warm and salty water column biases centered near $50^{\circ} \mathrm{S}$. Over the 1988-2007 period, the CORE-II models consistently simulate spatially variable trends in sea-ice concentration, surface freshwater fluxes, mixed layer depths, and 200-700 m ocean heat content. In particular, sea-ice coverage around most of the Antarctic continental shelf is reduced, leading to a cooling and freshening of the near surface waters. The shoaling of the mixed layer is associated with increased surface buoyancy gain, except in the Pacific where sea ice is also influential. The models are in disagreement, despite the common CORE-II atmospheric state, in their spatial pattern of the 20-year trends in the mixed layer depth and sea-ice.

Keywords: Southern Ocean, CORE-II experiments, water masses, sea ice, ocean model intercomparison

\section{Introduction}

The Southern Ocean remains poorly sampled by observational programs, compromising a complete understanding of circulation and water mass formation. Thus we rely on climate models to complement observations. Modelling strategies include, but are not limited to, assimilated solutions tightly constrained to observations, varying parameters in individual models, and international multi-model efforts. The Coordinated Ocean-ice Reference Experiments (CORE; Griffies et al. (2009); Danabasoglu et al. (2014)) fall under the latter category. The goal of the second phase of this modelling effort (CORE-II) is to contribute to future model development by investigating the hypothesis that multiple models computing fluxes based on identical bulk formulae and the same prescribed atmospheric state (Large and Yeager, 2009) produce similar ocean and ice representations of the past and present climate. Griffies et al. (2009) evaluated seven ocean-ice models forced with CORE-I Normal Year Forcing (Large and Yeager, 2004), and results were presented from primarily global and/or zonally averaged viewpoints. Here we expand upon the CORE-I effort by evaluating the representation of present and multi-year to decadal observed trends in fifteen CORE-II inter-annually forced models. To capitalize on the CORE-II effort, several regional studies are presently being undertaken, and are contributing to a special issue of Ocean Modelling. For example, Danabasoglu et al. (2014) evaluated the North Atlantic region, Griffies et al. (2014) focussed on sea-level processes, and studies pertaining to the Indian, Pacific and Arctic basins are underway. These publications will provide a detailed model assessment of key circulation, water mass, and sea-ice processes important to global climate modelling.

Given the complex and vast research areas pertaining to Southern Ocean circulation (see Rintoul and Naveira Garabato, 2013, for a review), the CORE-II analysis for this region has been divided into two papers. The first Southern Ocean paper presented here has two foci: i) properties of upper ocean water masses that are key players in the storage and uptake of anthropogenic carbon (c.f., Sabine et al., 2004); and ii) sea-ice concentration and extent, which has a first-order role in ocean surface heat and freshwater fluxes. The companion Southern Ocean paper (Farneti et al., 2015) assesses the Antarctic Circumpolar Current (ACC) transport and meridional overturning circulation of the Southern Ocean, with an emphasis on mesoscale processes.

We discuss here the properties of the three primary water masses forming in the Southern Ocean, namely Sub-Antarctic Mode Water (SAMW), Antarctic Intermediate Water (AAIW), and Antarctic Bottom Water (AABW), as well as the deep seasonal mixed layer depths associated with 
their formation. The subduction of mode and intermediate waters is strongly influenced by the flux of water across the mixed layer base (e.g. Sallée et al., 2010a). The depth of the seasonal mixed layers is governed by overlying wind and buoyancy forcing at the ocean surface, as well as sea ice via both freshwater from melting ice transported equatorward and isolation of the ocean from atmospheric buoyancy fluxes. Strong winter surface buoyancy loss excites vigorous mixing across the mode and intermediate water mass formation regions in the southeast Indian and Pacific basins, resulting in deep mixed layers exceeding $500 \mathrm{~m}$ (de Boyer Montégut et al., 2004; Holte and Talley, 2009). In summer, these mixed layer depths reduce to approximately $100 \mathrm{~m}$ (Sallée et al., 2010b). AABW forms primarily in the Weddell Sea, Ross Sea and along the Adelie coast through the combined diapycnal mixing of southward flowing Circumpolar Deep Waters and the high salinity shelf waters made dense due to brine rejection (c.f., Orsi et al., 1999; Speer et al., 2000; Rintoul and Naveira Garabato, 2013). The companion Southern Ocean CORE-II manuscript by Farneti et al. (2015) addresses the formation, circulation, and associated buoyancy fluxes of AABW.

Observations and models have indicated that most of the ocean surface has warmed and freshened over the past half century (Helm et al., 2011; Durack and Wijffels, 2010), shifting the surface density outcrops poleward. Reduced surface density (increased buoyancy) enhances stratification in the upper ocean and leads to shoaling of the deep winter mixed layers associated with the subduction of mode and intermediate waters (e.g., Downes et al., 2010; Sallée et al., 2010b). In addition, less entrainment of cold deeper water into the mixed layer (due to enhanced upper ocean stratification) can compensate for the negative surface heat flux feedback response to increasing sea surface temperature (Large and Yeager, 2012). Despite a coherent shoaling response to increased greenhouse gases, numerous coarse resolution coupled climate models represent mixed layer depths shallower than observed due to excessive overlying freshwater input (Sallée et al., 2013a). Here we investigate the role of both heat and freshwater fluxes in dictating the mixed layer depth and isopycnal outcropping in models compared to observations.

Two other factors contribute to the surface buoyancy fluxes that influence the mixed layer depths associated with mode and intermediate waters: the surface wind stress; and the salinification and freshening associated with the freezing of sea ice and in-situ thermodynamic melting. The strong westerly winds overlying the ACC induce a northward Ekman transport, driving cooler high latitude waters into the upper ocean water mass mixed layer regions (e.g., Naveira Garabato et al., 2009). Also, between the latitude of the maximum westerlies $\left(\sim 47^{\circ} \mathrm{S}\right)$ and the peak of the easterlies $\left(\sim 73^{\circ} \mathrm{S}\right)$, the winds act to upwell warm, salty and carbon-rich waters from the deep ocean. These winds have strengthened and shifted poleward over the past few decades (e.g., Thompson and Solomon, 2002; Chen and Held, 2007; Thompson et al., 2011), enhancing upwelling and northward surface Ekman transport.

Trends in sea ice are not uniform around the Antarctic continent. Sea-ice concentration has decreased in the Amundsen-Bellingshausen Sea in recent decades (Comiso and Nishio, 2008; Zwally et al., 2002; Simpkins et al., 2013; Abram et al., 2013), associated with increased polar freshening and atmospheric influences (Turner et al., 2009; Holland and Kwok, 2012). Conversely, sea-ice concentration has increased in the Ross Sea and climate models fail to represent these observed trends (Comiso and Nishio, 2008; Zwally et al., 2002; Abram et al., 2013). We investigate the ability of the CORE-II models to represent these distinct regional sea-ice trends, and the resultant influence on upper Southern Ocean water mass properties.

This study assesses whether the CORE-II ocean-ice models are a viable tool for process-based research, by evaluating their representation of the past and present climate mixed layer depths, water masses, and sea ice. We discuss whether differences in the modelled magnitude and spatial distribution of water mass and sea-ice properties are likely to be associated with the common 
CORE-II atmospheric state, or with differences in individual model configurations.

The remainder of this paper is divided as follows. In Section 2, we briefly describe the 15 participating CORE-II models, data, and methodology to be used for model evaluation. In Section 3 we evaluate the 1988-2007 mean, and in Section 4 we describe linear trends over the same years, comparing past and present states with the observation-based data set to be used where available. In Section 5, we provide a summary and schematic representation of our key findings.

\section{Methods, models and data}

\subsection{Models, forcing and analysis periods}

An extensive description of the 15 CORE-II model simulations that have contributed to this study can be found in Danabasoglu et al. (2014). The models generally have a one-degree horizontal grid spacing, with finer meridional spacing in the tropics. They use between 30 and 63 vertical levels. Exceptions are GFDL-MOM025 that has an eddy permitting resolution of $1 / 4^{\circ}$, KIEL05 that has $1 / 2^{\circ}$ resolution, and ICTP that has a coarser $2^{\circ}$ horizontal resolution. GFDL-MOM025 is based on the ocean-ice component of the CM2.5 coupled climate model documented in Delworth et al. (2012). With respect to the vertical coordinate, GFDL-GOLD and BERGEN are isopycnal coordinate models, GISS is a mass coordinate model, INMOM is a terrain following $\sigma$-coordinate model, and FSU has a hybrid coordinate configuration, while the other models use a depth coordinate. The CORE-II models, with the exception of GFDL-MOM025, parameterise mesoscale eddies with variants of the Gent and McWilliams (1990) scheme, using either two dimensional (depth independent) or three-dimensional eddy diffusivities. We refer the reader to Table 1 in Farneti et al. (2015) for further details of individual models' eddy parameterisation configuration and how these choices influence mixing and circulation.

The models are integrated for five cycles of the 60 year CORE-II 1948-2007 interannually varying forcing from Large and Yeager (2009). We focus only on results from the last cycle, treating the earlier cycles as a spin-up phase that allows the models to at least partially equilibrate to the surface forcing. A more detailed discussion of the evolution of CORE-II models over the forcing cycles is given by Danabasoglu et al. (2014) and Griffies et al. (2014). Here we are interested in evaluating model representation of the present climate (average of years 1988-2007) and diagnosing trends over the same final two decades of cycle 5. We note that a 20 -yr period is not likely long enough to differentiate between natural and anthropogenic variability, however this is not the focus of our study. Many figures include the average of 15 CORE-II models, denoted as the multi model mean (MMM).

As explained in Large and Yeager (2009), CORE-II atmospheric states have been adjusted to agree in the mean with a variety of satellite and in situ measurements which were considered more reliable than the corresponding NCEP reanalysis data. After these adjustments were made wind speed increased and humidity was reduced, and the wind direction agreed better with the ship based wind climatologies. Furthermore, radiation prior to 1984 and precipitation before 1979 are given as climatological annual cycles. These adjustments improve the CORE-II climatological air-sea heat and freshwater fluxes. Along with the wind stress changes, they produce a closer agreement to the reanalysis and observation-based implied ocean heat transport estimates. Nonetheless, these fluxes are likely not valid over the whole CORE-II 60 year period, given the absence of satellite-based information before 1979. This caveat is especially relevant in the Southern Ocean, which is very sparsely covered with ship and station based observations. In general, the adjusted atmospheric variables were affected in magnitude more than their inherent decadal variability. Hence, any decadal variability in the CORE-II atmospheric state can at best be considered a measure of relative 
change. We furthermore do not expect that details of the physical drivers prior to incorporation of satellite information are contained in CORE-II atmospheric states.

Despite using the same CORE-II atmospheric state for deriving air-sea fluxes, simulating an ocean in agreement with observations, particularly in the Southern Ocean, remains challenging. The different sea-ice models and treatment of sea surface salinity restoring (see Appendix $\mathrm{C}$ and Table 2 in Danabasoglu et al., 2014) complicate the interpretation of CORE results especially in the Southern Ocean and Arctic. Further, key factors in the forcing are the spatially varying corrections based on mean biases relative to more reliable, but regional and/or short, data sets (Large and Yeager, 2009). For example, the wind speed and direction corrections are based on QuikSCAT measurements over the open ocean, but there is nothing suitable on which to base any corrections over Antarctic sea ice.

Passing of the wind stress to the ocean (and differences in applying the wind stress based on relative versus absolute winds) appears to be influenced by the model sea-ice component for the easterlies circling Antarctica. The maximum of the polar easterlies varies by $0.015 \mathrm{~Pa}$ and over $5^{\circ}$ in latitude, whereas the maximum strength of the westerly wind stress and the position of that maximum vary over $0.05 \mathrm{~Pa}$ with latitudinal spread over $2^{\circ}$ of latitude (see Figure 3 in Farneti et al. $(2015))$.

Also, corrections to other quantities over the open Southern Ocean are more uncertain than elsewhere due to sparse sampling, especially in winter. The Large and Yeager (2009) forcing corrections assume stationary biases, which are most uncertain in the Southern Ocean. Therefore spurious trends in the forcing and simulations are a possibility. This sampling issue also adds to the uncertainty in ocean mean state and variability derived from observations. Another issue, also present in CORE-I (Griffies et al., 2009), is the forcing mismatch expected wherever the model sea ice fails to coincide with the observed.

\subsection{Observational-based analysis products}

The observations chosen for model evaluation of the present climate encompass vast amounts of measurements assembled into gridded products using objective interpolation methods. To compare the model potential vorticity, potential temperature, and salinity, we use the World Ocean Atlas 2009 release (WOA09; Locarnini et al., 2010; Antonov et al., 2010). This climatology (noting a large summer sampling bias) consists of over 9 million profiles sourced from ship, autonomous, pinniped, mooring, and float data collected over recent decades. The quality controlled data are objectively interpolated to 33 standard vertical levels on a 1-degree horizontal grid.

Potential vorticity is used to define mode waters. Using the individual models' density field, potential vorticity is calculated as:

$$
P V=-\frac{f}{\rho_{0}} \frac{\partial \rho}{\partial z}
$$

where $f$ is the Coriolis parameter (negative in the Southern Hemisphere), $\rho_{0}$ is the mean ocean density as estimated in the individual models, $\rho$ is the potential density referenced to the surface, and $z$ is the geopotential coordinate with zero at the surface of a resting ocean and positive upwards.

For the mixed layer depth comparison, we use the de Boyer Montégut et al. (2004) [www.ifremer.fr/cerweb mixed layer depth product. The de Boyer Montégut et al. (2004) analysis extensively tests various density criteria for defining mixed layers across the global ocean, finding a $0.03 \mathrm{~kg} \mathrm{~m}^{-3}$ density criterion to be a robust choice for model evaluation of mixed layers. This global mixed layer depth product incorporates various forms of hydrographic data collected during the 1994 to 2002 period, averaged monthly, and interpolated to a $2^{\circ} \times 2^{\circ}$ grid (latitude $\times$ longitude) 
The sea-ice metrics assessed here are sea-ice concentration and extent. The sea-ice concentration is defined as the area fraction of sea ice (in \%) in each (ocean) grid cell, and can vary from 0-100\%. The sea-ice concentration does not directly depend on the sea-ice thickness. However, grid cells with high ice concentration almost always have a higher ice thickness than grid cells with low ice concentration, and as a result, thickness and concentration correlate positively. The observed seaice concentration is based on the NOAA Optimum Interpolation Sea Surface Temperature V2 data (NOAA OI.v2 SST; Reynolds et al., 2002). The modelled sea-ice concentration was interpolated from model native grids to a common, regular $1^{\circ} \times 1^{\circ}$ grid using a bilinear method to enable the computation of departures of modelled sea-ice concentration from the observed NOAA OI.v2 SST sea-ice concentration. An exception is in Figure 27, where we use the Nimbus-5 Electrically Scanning Microwave Radiometer (ESMR) gridded sea-ice concentration September average from 1973-76 (Zwally et al., 1983; Parkinson et al., 2004). The modelled sea-ice extent is estimated as the sum of the grid cell area where the modelled sea-ice concentration is higher than $15 \%$. The observed sea-ice extent is based on the sea-ice index available from the U.S. National Snow and Ice Data Center (NSIDC, Fetterer et al. (2009)).

\subsection{Correlation calculation}

We are interested in whether the spatial distribution of the large mixed layer depths associated with mode and intermediate waters is influenced by sea ice, surface buoyancy fluxes, and wind stress. For example, do regions where the mixed layers are deepest show a positive correlation with regions where there is greater heat loss to the atmosphere, or correlate with the same longitude bands where the sea ice extends furthest equatorward? We base our analysis on computing correlations between the mixed layer depth and surface winds, buoyancy and sea ice. We identify in how many of the CORE-II models these correlations are significant, and note whether there is uniform agreement in the sign of the correlations across the models.

We define the area spanning grid cells where the March mixed layer depth is greater than $50 \mathrm{~m}$ or where the September mixed layer depth is greater than $300 \mathrm{~m}$. The area where the mixed layer depth is greater than $50 \mathrm{~m} / 300 \mathrm{~m}$ is summed meridionally over the $65^{\circ} \mathrm{S}-45^{\circ} \mathrm{S}$ latitude band (within which the mixed layer depths associated with mode and intermediate water masses are located). We then bin the mixed layer depth area metric in $10^{\circ}$ longitude intervals (given that we are assessing large-scale features), and either average over the 20 years for the mean state, or estimate a linear trend over the 20-year period. The result is a vector, $\mathrm{M}_{i}$, where $i=1: 36$. Regions where $\mathrm{M}_{i}$ is zero (i.e. when the March mixed layer depth is less than $50 \mathrm{~m}$ or the September mixed layer depth is less than $300 \mathrm{~m}$ ) are excluded from the correlation analyses. The mixed layer depth vector $\mathrm{M}_{i}$ is correlated with another index, $\mathrm{S}_{i}$, representative of either the latitudinal location of the sea-ice edge, the maximum wind stress and associated position, or surface heat and freshwater fluxes.

The annual mean heat and freshwater fluxes are interpolated to $1^{\circ}$ longitude bins, and integrated meridionally between $65^{\circ} \mathrm{S}-45^{\circ} \mathrm{S}$ into $10^{\circ}$ bins. We note that in this latitude range, the freshwater flux is dominantly into the ocean, however there are regions of both heat loss and gain. Thus we separate the regions of heat gain and heat loss, that is, we integrate where the heat flux is positive (heat gain) and negative (heat loss) across the Southern Ocean in the $65^{\circ} \mathrm{S}-45^{\circ} \mathrm{S}$ latitude range. We then take the time mean or linear trend over the 20-year period.

For the wind stress, we are interested in both the maximum strength of the westerlies and the position of this maximum for each $10^{\circ}$ bin. The CORE-II models' wind stress maximum is $0.16 \mathrm{~Pa}$, with latitudinal position ranging between $55^{\circ} \mathrm{S}$ and $50^{\circ} \mathrm{S}$ (see Farneti et al. (2015) for further discussion on wind stress in CORE-II models). We use the annual mean wind stress for estimating the wind stress maximum and its latitudinal position, and then take the time mean or 
linear trend over the 20-year period.

The sea-ice edge does not necessarily reach the $65^{\circ} \mathrm{S}-45^{\circ} \mathrm{S}$ latitude range for all longitudes during March and September. However, sea ice can influence buoyancy fluxes, and thus indirectly influence the mixed layer depth. We define the sea ice edge index as the latitudinal location of the northernmost grid cell where the sea-ice concentration is over $15 \%$ for each $10^{\circ}$ longitude bin for March and September in each of the 20 years (1988-2007). We then take the time mean or linear trend over the 20-year period.

\section{Evaluation of the climate over years 1988-2007}

\subsection{March and September mixed layer depth}

Here we evaluate the mixed layer annual cycle by assessing the two months that generally represent the minimum and maximum mixed layer depths, namely March and September. The 1988-2007 multi model mean March mixed layer depth is overall shallower than observed by approximately $50 \mathrm{~m}$ (Figure 1), a result similarly shown in a recent study assessing 21 coupled climate models (Sallée et al., 2013a). However, the model mean features some small regions of deep mixed layer biases that are strongly influenced by few models. For example, the local deep (positive) mixed layer bias in the Indian sector is weighted heavily by biases found in the BERGEN, GISS, ICTP, KIEL05, and NOCS models.

We pay particular attention to the September mixed layer depth biases (Figure 2). The irreversible subduction of upper ocean water masses into the ocean interior, occurring shortly after the deep winter mixed layers begin to shoal in spring, is highly dependent on the late winter mixed layer depth (e.g., Marshall et al., 1993). The deepest mode and intermediate water mass mixed layers are found in the southeast Indian and Pacific basins (Dong et al., 2008; Herraiz-Borreguero and Rintoul, 2011). The models simulate deeper than observed mode and intermediate water mixed layer depths, positioned further south than observed (Figure 2).

Unlike with the March mixed layer biases, the September mixed layer biases vary in sign and spatial distribution. The differing mixed layer biases across the models is associated with differences in, for example, the individual models' interior temperature and salinity field, mixing schemes, grid resolution, and surface heat and freshwater fluxes. Whilst evaluating all these types of differences is beyond the scope of this paper, we can comment on the large variation in the models' surface heat fluxes (Figure 3) and ocean interior temperature and salinity (Figures 4 to 7).

The models with widespread deeper mixed layer depths are ACCESS, BERGEN, FSU, and ICTP. In these four models, the region of Southern Ocean surface heat loss extends further equatorward (Figure 3), and there are larger upper ocean saline biases at high latitudes that dominate the model mean bias (Figures 4 and 5). Dong et al. (2008) noted that mode water mixed layers in the southeastern Pacific basin are preconditioned by the relatively strong cooling and weak stratification from upwelling. The CORE-II models with a shallower than observed mixed layer depth in the southeast Pacific $60^{\circ} \mathrm{S}-50^{\circ} \mathrm{S}$ latitude band (AWI, CMCC, MOM025, GISS, INMOM, KIEL05, and NCAR) have warmer and fresher near surface waters around $45^{\circ} \mathrm{S}$ (Figures 4 and 6).

Several models (ACCESS, BERGEN, FSU, GFDL-GOLD, GFDL-MOM, GISS, ICTP, INMOM, and MRI) have a significantly deeper mixed layer bias in one of the major Antarctic Bottom Water (AABW) formation regions in the Weddell Sea, associated with cold deep ocean biases at high latitudes (Figures 6 and 7). The FSU, GISS and INMOM models in particular have substantial surface heat loss south of $60^{\circ} \mathrm{S}$ (Figure 3) that are associated with these polar ocean interior cold biases. 
South of $50^{\circ} \mathrm{S}$, most models simulate slightly deeper isopycnals than observed (Figure 8). The largest differences exist near the Antarctic continental margin at potential densities (referenced to $2 \mathrm{~km}$ ) greater than $1036.8 \mathrm{~kg} \mathrm{~m}^{-3}$. In particular, the BERGEN, CMCC, ICTP, KIEL05 and NOCS models simulate substantially lighter waters than observed along the continental margin, which may be associated with fresh surface water biases south of $60^{\circ} \mathrm{S}$ (Figure 4) that extend to the ocean floor and are strongest in the Pacific sector (Figure 5). We hypothesize that the CORE-II atmospheric state across the 15 models influences the coherent upper $2 \mathrm{~km} \mathrm{cool} /$ fresh biases south of $50^{\circ} \mathrm{S}$, and the warm/saline biases to the north.

\subsection{Correlations of $M L D$ to boundary forcing}

To assess the likely influence of the spatial pattern of overlying wind stress, surface buoyancy fluxes and sea-ice forcing on the mixed layer depth, we defined an area index as the area where the March and September mixed layer depths exceeded $50 \mathrm{~m}$ and $300 \mathrm{~m}$, respectively, restricted to the upper ocean water mass formation zones $\left(65^{\circ} \mathrm{S}-45^{\circ} \mathrm{S}\right)$. We then correlated this index of deep mixed layer depth with the latitudinal location of high sea ice concentration, heat and freshwater fluxes (integrated over the meridional range of $65^{\circ} \mathrm{S}-45^{\circ} \mathrm{S}$ ), as well as the latitudinal position and strength of the surface westerly wind stress maximum (Figure 9). Using the methodology described in Section 2.3, we diagnose the relationships between mixed layer depths and surface forcing and sea ice. Each symbol (circle or star) in Figure 9 represents the spatial correlation of 36 value pairs $\left(\left(\mathrm{M}_{i}, \mathrm{~S}_{i}\right) ; \mathrm{i}=1: 36\right)$. Our focus is on correlations that are significant at the $90 \%$ level in more than half the assessed CORE-II models (represented by the stars in Figure 9).

The axes labels for buoyancy fluxes/ winds/ sea ice denote the mean state of the variable in association with the mean state of the mixed layer depth area, if the correlation is positive. For example, an area of deeper March mixed layer depth is positively correlated with where the westerly wind stress maxima is positioned further equatorward. Similarly, an area of shallower March mixed layer depth is positively correlated with where the westerly wind stress maxima is positioned further poleward. Conversely, areas of deeper March mixed layer depth are primarily negatively correlated with regions of larger surface heat gain.

The summer (i.e., March) mixed layer depth forms when increased buoyancy input (from surface heating and ice melt increasing surface freshening) strengthens stratification. The correlation in Figure 9 (upper panel) use an area index for where the March mixed layer depth is greater than $50 \mathrm{~m}$. The March mixed layer depth is shallower than observed (Figure 1). We find that models whose March mixed layer depth area index is smallest have a more poleward positioned, but weaker wind stress maximum, larger surface heat gain, and sea ice positioned closer to the Antarctic continent (this would increase surface freshwater). The wind stress strength and position (see Figure 3a in Farneti et al., 2015) and the shallow March mixed layer biases are coherent across the CORE-II models (Figure 1). However there is more pronounced variation between the surface heat fluxes (Figure 3) and sea-ice extent (Section 3.5).

Whilst the March mixed layer across the CORE-II models displays a uniform shallow bias compared to observation, the sign of the bias is not in agreement across the models for the September mixed layer depth (Figure 2). Similarly to the disagreement in the sign of the mixed layer bias across the models, the correlations for where the September mixed layer exceeds $300 \mathrm{~m}$ are not in agreement in sign (Figure 9; lower panel). The deep mixed layers associated with mode and intermediate water mass formation (i.e., in the $65^{\circ}-45^{\circ} \mathrm{S}$ latitude band) form via surface heat loss associated with strong westerlies driving cool polar waters equatorward into the formation zones. Unlike with the March mixed layer depth (Figure 9; upper panel), there is disagreement in the sign and significance of the correlation between the September mixed layer depth and wind stress. Rather, the deeper 
September mixed layer depth is significantly correlated with the surface buoyancy forcing and a more poleward positioned September sea-ice edge.

To interpret the discrepancy in sign for the September mixed layer correlations, we cluster the CORE-II models into four groups. The first group (MRI, GFDL-MOM025, and INMOM models) show insignificant correlations between the deep mixed layer depth areas and winds, buoyancy fluxes and sea ice. The second group (KIEL05 only) indicates that areas where the September mixed layer depth exceeds $300 \mathrm{~m}$ are significantly correlated with larger westerly wind strength maxima, with where the maxima (and sea ice) are positioned further equatorward, and with where there is large freshwater input and heat fluxes (both heat gain and loss). The third group (ACCESS, BERGEN, CMCC, GFDL-GOLD, GISS, ICTP) overall show the opposite relationship with area where the mixed layers are deep. Uotila et al. (2014) similarly showed that in the ACCESS model, ice moves fast northward and then melts, and therefore results in a large freshwater flux between $50^{\circ} \mathrm{S}$ and $60^{\circ} \mathrm{S}$ (see their Figure 6d). Finally, the remaining models (AWI, FSU, GFDL-MOM, NCAR, and ORCA-NOCS) do not exhibit similarities between the signs of the correlations across the diagnostics assessed.

We also assessed the correlation between winds, buoyancy fluxes and sea ice to identify causal relationships between factors influencing mixed layer depth (Figure 10). For example, sea ice is positioned south of the mode and intermediate water mass formation regions, however it has a strong influence on the buoyancy fluxes that are driven equatorward into the formation regions in the Ekman layer. For the CORE-II models, stronger westerly wind stress maxima and a more equatorward positioned wind stress maximum are associated with larger buoyancy fluxes, and a more northward sea ice position. A more northward sea ice position in both March and September is significantly correlated with more freshwater input and larger heat fluxes (both heat loss and gain), likely meaning that regions where sea ice extends further equatorward inhibit polar evaporative processes and influence heat flux exchange at the ocean-atmosphere and ocean-sea ice interfaces. We note that the seasonality of the sea ice position is significantly correlated, meaning that regions of more equatorward March sea ice position are similar to those in September.

The intricate links between surface mechanical and buoyancy forcing reflects the extreme climate of the Southern Ocean, and indicates the high degree of complexity associated with understanding how upper ocean processes impact on the Southern Ocean mean state and trends. We conjecture that the coherent March shallow mixed layer depth biases are likely due to the commonly applied CORE-II atmospheric state (in particular, wind stress), whereas individual model ocean parameterisations, surface buoyancy fluxes, and sea ice appear to be more influential in the representation of the September mixed layer depth. We note that mesoscale parameterisations are not correlated with mixed layer depth properties and that other factors discussed above likely dominate (see also discussion in Farneti et al., 2015).

\subsection{Water mass properties}

We now evaluate the models' representation of the temperature and salinity properties associated with water masses forming in deep mixed layer depth regions, namely Subantarctic Mode Water (SAMW) and Antarctic Intermediate Water (AAIW). In Section 3.4 we discuss how these water masses interact with those adjacent in the water column.

The most widely used observational constraint to identify SAMW is a thick homogenous layer of low potential vorticity (e.g., Hanawa and Talley, 2001; Hartin et al., 2011; Herraiz-Borreguero and Rintoul, 2011; Cerovečki et al., 2013). This low potential vorticity layer is indicative of deep mixed layers in which mode waters form, and can be identified across most of the Southern Ocean around $40^{\circ} \mathrm{S}$ (see for example Figure 2 in Herraiz-Borreguero and Rintoul, 2011). Here we are interested in 
the model representation of the low potential vorticity layer across the Southern Ocean (Figures 11 and 12). Overall, the CORE-II models compare well with observations (WOA09) in terms of depth and magnitude of the low potential vorticity cell in the Indian Ocean. However, few are able to simulate the very weak stratification of the SAMW cell in the Pacific basin. Only NCAR and NOCS simulate a low potential vorticity cell of similar magnitude and around $500 \mathrm{~m}$ thick in the Pacific. ACCESS, BERGEN, FSU, GFDL-MOM, ICTP, and KIEL05 represent a potential vorticity minimum with similar magnitude to observed, but with a deeper extending low potential vorticity layer. Sloyan and Kamenkovich (2007) found that eight coarse resolution Coupled Model Intercomparison Project Phase 3 models have a thinner and less defined low potential vorticity layer associated with mode water in the Pacific basin (see their Figure 8). Here, the poor representation of the low potential vorticity layer in the Pacific basin is reflected in the shallow mixed layer biases south of this region in Figure 2, whereas the lower than observed potential vorticity in the Indian sector corresponds with deep winter mixed layer biases south of $40^{\circ} \mathrm{S}$.

AAIW, mostly forming south of SAMW, is identified by a salinity minimum (see the 34.4 contour in the upper left panel of Figure 4) that extends below $1000 \mathrm{~m}$ (e.g. Hanawa and Talley, 2001). This distinct salinity minimum is produced by freshwater input (precipitation) in the intermediate water formation regions that is subducted into the ocean interior at densities similar to and denser than mode waters (c.f., Hartin et al., 2011; Sloyan and Kamenkovich, 2007). Overall, the modelled salinity minimum is fresher than observed and does not extend as far into the ocean as found in observations. The overly fresh salinity minimum in models may in part be due to less than observed sea ice, particularly in March (see Section 3.5). Namely, the low sea ice, and associated low levels of brine rejection, allows for more open ocean areas whereby precipitation biases the salinity low. The salinity minimum is displaced poleward and/or does not extend deep enough into the ocean interior in the ACCESS, BERGEN, GFDL-GOLD, GFDL-MOM, GFDL-MOM025, ICTP and INMOM models. Models that adequately represent the salinity minimum associated with intermediate water are BERGEN, KIEL05, MRI, NCAR and NOCS.

We compared the zonally averaged density structure across the CORE-II models, finding a favourable agreement between the multi model mean and observations (Figure 8). However, the CORE-II models are biased warm north of $50^{\circ} \mathrm{S}$, with the exceptions being the GFDL-GOLD and GISS models (see $6^{\circ} \mathrm{C}$ isotherms in Figure 6). The overall favourable agreement in the density structure of the CORE-II models is due to counteracting warm and salty biases north of $\sim 50^{\circ} \mathrm{S}$ and the cool and fresh biases to the south (Figures 4 and 6). These Southern Ocean temperature and salinity bias patterns centered around $50^{\circ} \mathrm{S}$ are restricted to the upper $2 \mathrm{~km}$; for deeper regions, the models show an overall cold and fresh bias across all latitudes (Figures 5 and 7 ).

\subsection{Water mass formation processes}

Here we describe the water mass budget for the CORE-II models in the region south of $30^{\circ} \mathrm{S}$, using methods stemming from Walin (1982), and subsequently applied in several multi-model analyses (c.f., Downes et al., 2011; Sallée et al., 2013b). The rate of change in the volume of a density layer (summed zonally) from its high latitude outcrop to $30^{\circ} \mathrm{S}$ is a balance between three components, namely (1) the lateral diapycnal flux across its outcrop arising from heat and freshwater fluxes at the ocean-atmosphere and ocean-sea ice interfaces, (2) the transport across the $30^{\circ} \mathrm{S}$ boundary, and (3) the diapycnal fluxes arising from interior mixing (see for example Figure 2 and associated equations in Downes et al., 2011). Here we concentrate on the first two components, which we term as the water mass transformation rates by surface buoyancy fluxes, and the volume transport across $30^{\circ} \mathrm{S}$.

The northward volume transport across $30^{\circ} \mathrm{S}$ (i.e., the export of volume from a density layer from 
the Southern Ocean), averaged over years 1988 to 2007, is illustrated by the gray bars in Figure 13. Water mass layers are defined by the direction of transport; thermocline waters (TW) and deep waters (DW) are imported from northern origins, whereas mode/intermediate waters (MW) and bottom waters (BW) form in the Southern Ocean and are exported equatorward. Thus the volume and densities bounding these water mass layers are different for each model. As has been shown in previous studies that evaluate coarse resolution climate models (e.g., Gnanadesikan et al., 2004; Downes et al., 2011; Sallée et al., 2013b), the CORE-II models exhibit a stronger upper, and weaker lower, overturning circulation at $30^{\circ} \mathrm{S}$ compared with observationally based estimates (grey bars versus white bars in Figure 13).

Talley (2008) (white bars in Figure 13) concludes that the majority of the deep waters of northern origin flowing southward into the Southern Ocean return equatorwards as bottom waters. On the other hand, the models indicate that the majority of the incoming deep waters upwell and contribute to lighter mode and intermediate waters. The isopycnal coordinate model, GFDL-GOLD, best represents the lower cell volume transports across $30^{\circ} \mathrm{S}$ among the CORE-II models. The GFDLMOM025, ICTP, KIEL05, and MRI models have particularly small bottom water export.

The tendency for strong upper ocean overturning and weak lower overturning transports in CORE-II models relative to observations cannot simply be attributed to biases in the atmospheric forcing. Firstly, these common volume transport biases have been depicted in past studies as mentioned above, which include fully coupled climate models and assimilated solutions. Secondly the observations may miss key downwelling and entrainment processes in the AABW layer associated with sea ice. These observations are estimated from inverse methods and sparse Southern Ocean observations, with no sea-ice processes represented. Additionally, models likely misrepresent smallscale mixing process, for example, associated with the entrainment of deep waters into the bottom water layer.

The surface water mass transformation is influenced by sea ice, buoyancy and air-sea and icesea stress that combine to alter the surface density. The transformation rate for a density layer, $\rho_{k}$ (bound by $\rho_{k}$ and $\rho_{k+1}$ ) fluctuates widely over the seasonal cycle, and thus we use monthly fields for the calculation. The surface transformation is an integration over the entire outcrop region, and is estimated as (following Downes et al., 2011):

$$
F\left(\rho_{k}\right)=-\frac{1}{\left(\rho_{k+1}-\rho_{k}\right)} \iint_{A}\left\{\frac{\alpha Q_{n e t}}{C_{p}}\right\} d A+\frac{1}{\left(\rho_{k+1}-\rho_{k}\right)} \iint_{A}\left\{\rho_{0} \beta S\left(F W_{n e t}\right)\right\} d A,
$$

where the first term represents the transformation due to the net heat flux into the ocean $\left(Q_{n e t}\right)$ and its associated thermal expansion and heat capacity coefficients ( $\alpha$ and $C_{p}$, respectively). The second term represents the net contribution from the freshwater flux into the ocean $\left(F W_{n e t}\right)$, including precipitation, evaporation, run-off and sea ice melt (where available), and associated haline contraction coefficient $(\beta)$, surface salinity $(S)$, and reference ocean density $\left(\rho_{0}=1035 \mathrm{~kg} \mathrm{~m}^{-3}\right)$. We choose density referenced to 2000 dbar as we are assessing water mass transformation over the entire water column. Previous Southern Ocean model water mass transformation studies have used a variety of density coordinates, including density referenced to the surface or 2000 dbar or neutral density (e.g., Marsh et al., 2000; Downes et al., 2011; Cerovečki et al., 2013; Sallée et al., 2013b). We conjecture that our choice of density coordinate will not qualitatively impact identification of the dominant buoyancy fluxes influencing the surface transformation.

We compare the transformation at the ocean-atmosphere and ocean-sea ice interfaces, arising from surface heat and freshwater fluxes. In Figure 14, we show the resultant multi model mean (MMM) transformation curves for heat, freshwater and their sum, as well as an interpretative guide to water mass transformation (WMT) diagrams in density space. Positive WMT implies conversion 
of water masses from lower to higher density classes, with the buoyancy loss resulting from overlying cooling and/or evaporative processes. Conversely, negative WMT implies water mass conversion to lower density classes, and a buoyancy gain due to warming and/or freshening at the surface. Formation in a water mass layer occurs when $\mathrm{WMT}_{\sigma_{k}}-\mathrm{WMT}_{\sigma_{k+1}}>0$ (where $\sigma$ here refers to potential density referenced to 2000 dbar, i.e., $\left.\sigma_{2}\right)$, and the discrete label $k$ labels density layers with $k$ increasing downwards. A negative difference implies destruction of the water mass as it is mixed into adjacent density layers. Note that the formation diagnostic assumes waters are stably stratified with respect to $\sigma_{2}$, so that $\sigma_{k+1}>\sigma_{k}$.

Figure 15 shows the MMM and individual model water mass transformation from the COREII models. Across all models, the water mass transformation at the ocean surface is coherently dominated by heat fluxes north of $\sim 45^{\circ} \mathrm{S}$ (red curves) that coincides with the zonally averaged outcrop latitude for $\sigma_{2} \sim 1035 \mathrm{~kg} \mathrm{~m}^{-3}$; a net heat gain in the tropics (negative transformation rate) and heat loss in the subtropics. Cooling and freshening (the latter dominating) contribute to the surface transformation in the CORE-II models between $1035 \mathrm{~kg} \mathrm{~m}^{-3}$ and $1037 \mathrm{~kg} \mathrm{~m}^{-3}$. In this density range, the net surface transformation (black curves) migrates from a region of buoyancy loss to gain, corresponding to the formation of mode waters via the destruction of intermediate waters. We note that the two models with the strongest water mass transformation due to heat loss at the ocean surface in the $\sigma_{2}=1036.5-1037 \mathrm{~kg} \mathrm{~m}^{-3}$ range (FSU and ICTP) also exhibit the deepest September mixed layer biases (Figure 2). Upwelled deep waters $\left(\sigma_{2}=1036.5-1037 \mathrm{~kg} \mathrm{~m}^{-3}\right)$ are destroyed through freshening and converted to lighter intermediate waters, and denser bottom waters. The formation of bottom waters $\left(\sigma_{2}>1037 \mathrm{~kg} \mathrm{~m}^{-3}\right)$ is via both cooling and brine rejection at the surface.

The combination of heat and freshwater fluxes driving Southern Ocean water mass transformation has previously been identified using both reanalyses products and models (e.g., Speer et al., 2000; Downes et al., 2011; Sallée et al., 2013b). In particular, Downes et al. (2011) showed very similar surface formation rates for three fully coupled models with similar ocean-ice configurations, whereas Sallée et al. (2013b) showed that 21 different fully coupled models varied considerably in their formation rates. In the present study, the magnitude of formation rates varies considerably across the CORE-II models. For example, the formation of mode waters (taken as the difference between the maximum transformation near $\sigma_{2}=1034.5 \mathrm{~kg} \mathrm{~m}^{-3}$ and the minimum near $\sigma_{2} \sim=1036 \mathrm{~kg} \mathrm{~m}^{-3}$ ) varies by more than approximately $10 \mathrm{~Sv}$ across the thirteen illustrated models. The transformation differences between the CORE-II models imply that the different ocean model configurations, in particular their density field and mixing parameterisations, are more likely to influence the surface water mass transformation over the whole water column than the common Large and Yeager (2009) atmospheric state.

\subsection{Sea-ice properties}

The Antarctic sea ice can significantly influence water mass formation throughout the water column via changes in upper ocean buoyancy driven by sea-ice melting and freezing. Here we evaluate the representation of the ice concentration and extent in comparison with satellite-based observations where available. Sea-ice extent box plots in March and September from 1988-2007 are shown in Figure 16. In March, all models have, on average, lower sea-ice extent than observed (the MMM is $4.4 \times 10^{6} \mathrm{~km}^{2}$; Figure 16 lower panel), with GFDL-MOM025 having the closest to observed mean sea-ice extent of $4.1 \times 10^{6} \mathrm{~km}^{2}$, then NOCS of $2.7 \times 10^{6} \mathrm{~km}^{2}$, and finally GISS having the lowest mean sea-ice extent of $0.9 \times 10^{6} \mathrm{~km}^{2}$.

In September, the modelled sea-ice extent ranges from $13-24 \times 10^{6} \mathrm{~km}^{2}$, with FSU having the least amount of ice, on the average $16.4 \times 10^{6} \mathrm{~km}^{2}$ from 1988-2007, and GFDL-MOM025 having 
the largest average ice extent of $22.9 \times 10^{6} \mathrm{~km}^{2}$, while the observed mean is $18.8 \times 10^{6} \mathrm{~km}^{2}$. Modelled September sea-ice extent is spread relatively evenly around the observed sea-ice extent. Nine models (ACCESS, CMCC, GFDL-GOLD, GFDL-MOM, GFDL-MOM025, GISS, ICTP, KIEL05 and NOCS) have higher sea-ice extent than the observed, while six models (AWI, BERGEN, FSU, INMOM, NCAR and MRI) have a lower sea-ice extent than the observed. All models, except FSU, GFDL-MOM025, GISS and NOCS, have the mean September sea-ice extent relatively close to the observed ranging from $18.0-19.6 \times 10^{6} \mathrm{~km}^{2}$.

The modelled sea-ice appears less realistic in March than in September. The expansion of sea ice in austral autumn is driven by large-scale atmospheric circulation and thermodynamic processes which are relatively well captured by the CORE-II forcing and ocean-ice models. The summer minimum sea-ice extent, on the other hand, is likely to be controlled by smaller scale processes which are less realistically represented in the forcing, such as the oceanic heat flux, topographically guided atmospheric flow and storms, and the portion of shortwave radiation penetrating the ice (dependent on different parameterisations and albedo values) (c.f., Stössel et al., 2011). Such summertime processes may require both high resolution ocean models and a higher resolution wind forcing that incorporates the effects of katabatic winds at the Antarctic continental margin (Barthélemy et al., 2012; Mathiot et al., 2010; Stössel et al., 2011).

The observed sea-ice concentration based on NOAA OI.v2 SST data set for March is shown in the first panel of Figure 17, and the deviations of modelled sea-ice concentration from the observed are shown in the remaining panels. The sea-ice concentration is high in the western Weddell Sea where sea ice remains thick in summer, and where models show lower ice concentrations than observed indicating that the modelled sea ice is too thin in the area. AWI has the smallest sea-ice concentration biases, while, for example FSU, along with GFDL-GOLD, GISS, and MRI, show large negative biases in the western Weddell Sea, in the Bellingshausen and Amundsen Seas, and in the Ross Sea. GFDL-MOM, and GFDL-MOM025 models have particularly high positive biases in the eastern Weddell Sea and Ross Sea regions.

In September, sea-ice extends much further north than in March and many models show high positive or negative biases in concentration at the northern boundary of sea ice related to the unrealistic position of the sea-ice edge (Figure 18). Many models simulate sea-ice extending too far north in the Australian sector (approximately from $90^{\circ} \mathrm{E}$ to $150^{\circ} \mathrm{E}$ ), apparent as positive sea-ice concentration biases along $60^{\circ} \mathrm{S}$. Exceptions are INMOM, KIEL05 and MRI, which display very small departures from the observed. This discrepancy between the observed and modelled seaice concentration across many models implies that the September sea-ice concentration biases are related to the common atmospheric forcing, possibly the large scale wind transport that is important for the advection of sea ice in autumn.

Elsewhere, such as in the northern Weddell Sea, negative concentration biases are common (see for example ACCESS, GFDL-GOLD, GFDL-MOM, INMOM, and MRI in Figure 18) indicating that there too little sea ice is advected northward. GFDL-MOM025 displays positive sea-ice concentration biases practically everywhere contributing to its high sea-ice extent. Biases such as these vary from model to model and are likely to be due to the ability of an individual model to simulate sea-ice thermodynamics, ocean-ice exchange processes and ocean currents. Whilst the March sea-ice concentration negative bias patterns are similar across the CORE-II models, the September regional biases vary in sign and magnitude between models.

The location of the sea-ice edge can be characterised by the latitudinal location of the northernmost grid cell around Antarctica where the sea-ice concentration is greater than 15\%. Statistics of the sea-ice edge (mean latitude and standard deviation from 1988-2007) are shown in Figures 19 and 20. In March, the modelled sea-ice edge is mostly too far south, except in GFDL-MOM025, 
particularly in the Ross Sea and in the Amundsen-Bellingshausen Sea $\left(170^{\circ} \mathrm{E}\right.$ to $\left.300^{\circ} \mathrm{E}\right)$. In the Weddell Sea, the inter-model variability is large, with, for example, the location of the sea-ice edge varying from $73^{\circ} \mathrm{S}$ (MRI and FSU) to $65^{\circ} \mathrm{S}$ (GFDL-MOM025, NCAR and KIEL05) at $340^{\circ} \mathrm{E}$ (Figure 19).

In September, the location of the modelled sea-ice edge follows relatively closely to observations, except being too northward around the East Antarctic and the Ross Sea, from $90^{\circ} \mathrm{E}$ to $180^{\circ} \mathrm{E}$ (Figure 19; see also Figure 18). In the Amundsen Sea, from $210^{\circ} \mathrm{E}$ to $280^{\circ} \mathrm{E}$, the inter-model variability is high with the southernmost mean sea-ice edge simulated by FSU and the northernmost sea-ice edge simulated by GFDL-MOM025. In the Weddell Sea, between $310^{\circ} \mathrm{E}$ and $20^{\circ} \mathrm{E}$, the modelled sea-ice edge remains too far south, on the average, which is consistent with Figure 18.

Modelled inter-annual variability, in terms of standard deviation of the location of sea-ice edge appears to be in good agreement with the observed variability. In March, the modelled variability in terms of multi-model mean, follows closely the observed in the Ross Sea and in the Amundsen Sea, but shows too high variability in the Bellingshausen Sea and in the western Weddell Sea. In September, FSU shows too high variability in the Weddell Sea and in the Ross Sea (Figure 20), and the sea-ice edge of INMOM has a very high interannual variability at the Antarctic Peninsula, $300^{\circ} \mathrm{E}$.

In general, the modelled and observed variability is particularly high in the Ross Sea and in the Bellingshausen Sea, where the inter-annual variability of the large-scale atmospheric circulation modes, such as Southern Annular Mode (SAM), El Niño Southern Oscillation (ENSO) and the Zonal Wave 3 (ZW3) results in variability of cyclonicity and further in variability of sea ice (Pezza et al., 2012).

\section{Evaluation of 20 year trends (1988-2007)}

\subsection{Mixed layer depth trends}

The linear trends over years 1988-2007 in the modelled mixed layer depth are shown in Figures 21 and 22. There is no record of observed multi-decadal mixed layer depth trends to use for comparison with the modelled trends presented here. However, over the last decade, Sallée et al. (2010b) showed that the response of the mixed layer depth is zonally asymmetric, as demonstrated here over a 20 year period. In addition, CMIP5 coupled climate models overall project $21^{\text {st }}$ century trends that are the same sign as the trends modelled here (Sallée et al., 2013a, see their Figure 10). We find that the CORE-II models simulate a coherent spatial pattern for the mixed layer trends, indicating that the CORE-II forcing strongly influences the temporal variation in both the summer and winter mixed layer depths.

For the 20 year mean period, the regions of deepest mixed layers are in the southeast Pacific and southeast Indian basins (Figures 1 and 2). Over the 20 year period, the March mixed layer depth increases in the southeast Pacific, and decreases in the southeast Indian, with a magnitude of approximately $\pm 3 \mathrm{~m} \mathrm{yr}^{-1}$ (Figure 21). The strongest March trends are found in the BERGEN, GFDL-GOLD, KIEL05 and NOCS models in particular, with weaker changes in the ACCESS, AWI, GFDL-MOM, GFDL-MOM025 and ICTP models. These mixed layer depth trends are unlikely associated with trends in upper ocean temperature (Figure 23), given that the temperature is warming in the southeast Pacific where the March mixed layer has deepened, and vice versa for the southeast Indian basin. The increases in the southeast Pacific March mixed layer depth is more likely associated with increased sea ice extent (Figure 24), and thus increased brine rejection.

The CORE-II models vary in the magnitude of their September mixed layer depth trends (Figure 22), however the sign and spatial pattern of these trends across the Southern Ocean is similar. 
The most striking mixed layer trend is in the Pacific basin, where September mixed layers decrease in the southeast region, and increase in the southwest region (latitude range $60^{\circ} \mathrm{S}-50^{\circ} \mathrm{S}$ ). The simulated decreases in September mixed layer depth in the southeast Pacific region are associated with upper ocean warming, and increases in the mixed layer depth in the southwest Pacific with upper ocean cooling (see Figure 23). Decreasing September mixed layer depth in the Indian basin, in regions of deep mixed layers are likely associated with mid-latitude freshening (figure not shown).

The region of decreasing September mixed layer depths in the southeast Pacific is adjacent to one of increasing to the south, implying a possible shift in the deep mixed layer regions. The increases in the September mixed layer depth south of $60^{\circ} \mathrm{S}$ is likely associated with sea ice changes. The September sea ice retreats poleward by approximately $0.02^{\circ}$ of latitude per year (Figure 24), providing a larger domain for surface buoyancy fluxes and wind stress to influence the winter southeast Pacific mixed layer depths. Models simulating the largest increases in the September polar mixed layer depth (FSU, the three GFDL models, ICTP and INMOM) also exhibited the deepest mixed layer biases compared to observations for the 20 year averaged period (Figure 2).

Using the methodology described in Section 2.3, we correlated the 20 year trends of the areas where the mixed layer depth exceeds $50 \mathrm{~m}$ (March)/ $300 \mathrm{~m}$ (September) with surface forcing and sea ice (Figure 25). Overall, we found that the trend in the mixed layer depths is not uniformly correlated (in terms of sign) with the spatial distribution of external forcing trends across the CORE-II models. We found that the deepening of the September mixed layer depth (i.e., increase of the mixed layer area greater than $300 \mathrm{~m}$ ) is significantly correlated with changes in surface heat loss in more than half the CORE-II models, however the sign of these correlations was not coherent across the models. In addition, we were not able to coherently cluster the models into the sign of their correlations.

Changes in wind stress strength and position were significantly correlated with changes in the mixed layer depth in few models. Wind changes are best interpreted through the Southern Annular Mode (SAM), which is the principal mode of variability in the Southern Hemisphere extratropical atmospheric circulation, and computed as the difference in normalized zonal mean sea level pressure at $40^{\circ} \mathrm{S}$ and $65^{\circ} \mathrm{S}$ (Marshall, 2003). The SAM has a zonally symmetric or annual structure, with synchronous anomalies of opposite signs in Antarctica and the midlatitudes. Over the past 60 years, a clear upward trend in the SAM index has been observed, and is well represented in the CORE-II forcings (Figure 26). The SAM is believed to drive and influence the large-scale variability of both mean and eddy flows in the Southern Ocean, and a detailed investigation of its effect on the CORE-II models is given in Farneti et al. (2015). A positive SAM index means that sea-level pressure over Antarctica is relatively low compared to the midlatitudes. A positive trend in the SAM index (increasing strength of westerlies) was sustained until the 1980's, at which point the trend diminished with the index remaining in a positive state. Hence, although winds have been shown to strengthen and shift polewards across the entire Southern Ocean over the past 60 years, the trend has weakened considerably from the 1990's onwards. Since the trend analysis presented here covers the 1988-2007 period, the reduction in strengthening of westerly winds over the same period might partly explain the absence of a coherent significant correlation with mixed layer trends across the CORE-II models.

\subsection{Sea ice trends}

In the last three decades, the Antarctic sea-ice extent has slightly increased as a result of opposite regional trends including a decrease of sea ice in the Amundsen Sea and an increase in the Ross Sea (e.g., Comiso and Nishio, 2008; Zwally et al., 2002; Abram et al., 2013). These observed regional trends are statistically most significant in autumn and spring (Turner et al., 2009). In March, 
both observed and modelled trends are more variable than in September (Figure 24). Models fail to reproduce the observed decrease of sea ice in the Amundsen-Bellingshausen Sea, which is partly due to the already low modelled sea-ice extent in the region. Elsewhere, trends look variable without clear directions.

The September NOAA OI.v2 SST sea-ice edge location shows a slight increase from $45^{\circ} \mathrm{E}$ to $220^{\circ} \mathrm{E}$ and a small decrease between $220^{\circ} \mathrm{E}$ and $270^{\circ} \mathrm{E}$. Only one model, FSU, shows a very strong decline of sea ice in the Ross Sea and in the Weddell Sea which appears unrealistic. The MMM captures the decrease of sea ice in the Amundsen Sea, but not the increase in the Ross Sea. The decrease of sea ice is driven by warming of western Antarctica due to increased large-scale atmospheric heat transport from the mid-latitudes, and compensating equatorward oceanic heat transport anomalies (Farneti et al., 2010). In contrast, the Ross Sea cooling, driven by strong cold southerly winds blowing to the north from the Antarctic interior, increases sea-ice cover there. A realistic simulation of the cold southerly winds requires a high resolution topography and polar specific physical parameterisations, which are not in the CORE-II atmospheric state. The erroneous wind and temperature fields could be reasons why models do not reproduce the observed increase of sea ice in the Ross Sea (Barthélemy et al., 2012; Mathiot et al., 2010; Stössel et al., 2011). Another possibility is that upper ocean freshening from increases in Antarctic runoff that has been proposed as a mechanism for the Ross Sea sea-ice increases (Bintanja et al., 2013) are not captured in the CORE forcing which uses a climatological value for Antarctic runoff.

\subsection{Are there simulated polynas in the Weddell Sea?}

The Weddell Polynya was a distinct feature of Antarctic sea ice in the mid-1970s (Carsey, 1980). Its occurrence and movement has to some extent been explained by ocean stratification and convection, and topographical features (Martinson et al., 1981; Marsland and Wolff, 2001). No other polynyas of this magnitude have been observed, and it is unclear whether it will occur again. We do not expect that details of the physical drivers (e.g., wind stress divergences) are contained in the CORE-II atmospheric state, particularly since this period of the dataset is prior to incorporation of satellite information. Nonetheless, we investigate how sea ice in the CORE-II simulations responds during the $1970 \mathrm{~s}$.

For the analysis, we looked at the minimum monthly ice concentration for each of the models and the Nimbus-5 ESMR data in September 1974-76 when the Weddell Polynya occurs according to the observational Nimbus-5 ESMR data (Figure 27). The observed location of the Weddell Polynya is between $70^{\circ} \mathrm{S}$ and $60^{\circ} \mathrm{S}$ and approximately from $330^{\circ} \mathrm{E}$ to $10^{\circ} \mathrm{E}$, where the ice concentration stays below $10 \%$ throughout winter, and is surrounded by dense pack ice with ice concentration above 90\%. As evident from Figure 27, no CORE-II model simulates the Weddell Polynya realistically. Three models, ACCESS, GFDL-MOM and MRI, show areas of ice concentration less than $10 \%$ in the Weddell Sea, but this area is less extensive than the Weddell Polynya and it is located too far west. A majority of models - BERGEN, CMCC, FSU, GFDL-GOLD, GFDL-MOM025, GISS, ICTP, INMOM and NCAR, show a moderate decrease in sea-ice concentration within the proximity of the Weddell Polynya, but not as much as observed. Finally, three models, AWI, KIEL05, and NOCS, do not indicate any polynya type of features in the Weddell Sea.

De Lavergne et al. (2014) found that among the present generation of climate models, deep convection is common in the Southern Ocean under pre-industrial conditions, but weakens and ceases under a climate change scenario owing to surface freshening. We also inspected the minimum September ice concentrations for CORE-II models from the full 1948-2007 period of the last cycle to see whether distinct polynyas develop during other periods than in 1974-76. We found that models that do not display polynyas in the Weddell Sea in 1974-76 (AWI, KIEL05 and NOCS), also do 
not display polynyas during the full 1948-2007 period. However, some models (BERGEN, CMCC, GFDL-MOM, GISS and MRI) that indicate polynya type features in 1974-76, also indicate more distinct polynyas outside these years, while the remaining CORE-II models (ACCESS, FSU, GFDLGOLD, GFDL-MOM025, ICTP, INMOM and NCAR) indicate approximately similar polynya type features in the Weddell Sea in 1974-76 as outside these years. Hence, it appears that the modelled polynyas were not specifically related to the years 1974-1976. This result is perhaps expected, given that the CORE-II atmospheric state in this region is based on climatology prior to the advent of satellite information in 1979 .

Because none of the CORE-II models are able to simulate the Weddell Polynya as it appeared, we can not provide a comprehensive reasoning for its formation. Since the CORE-II atmospheric state is identical across the models, inter-model differences in polynya formation arise from the simulation of oceanic processes and topography. We conjecture that differences between model simulations do not arise from sea-ice processes, since sea ice over these relatively local spatial scales, away from coastal regions, is largely driven by atmospheric and oceanic conditions.

\subsection{Subsurface temperature trends}

Given the potential for sea-level rise associated with melting land ice, there are concerns about changes in ocean temperature for waters interacting with ice shelves around Antarctica. We therefore present trends in the 200-700 m averaged temperatures (Figure 23). Most models indicate no coherent pattern near the coast, particularly in the Weddell Sea. This disagreement between models is also evident in the September MLD trend in the same region (Figure 22). However, the GFDL-MOM025, GISS, ICTP, INMOM, and KIEL05 models show overall polar warming. This warming pattern that circles the Antarctic coast is also seen in idealized wind perturbation experiments using the same GFDL-MOM025 configuration (Spence et al., 2014), and is likely associated with a combination of wind and surface buoyancy fluxes. The warming in GFDL-MOM025 relates to shoaling of the relatively warm coastal current around Antarctica, associated with a weakening of Ekman downwelling next to the coast. Representing the dynamics of this current, along with its fluctuations and trends, generally requires fine resolution in both the ocean and the atmospheric winds.

\section{Summary and Conclusions}

We evaluated the representation of the Southern Ocean mixed layer depth, sea ice, and water mass properties in 15 global ocean-ice models participating in the CORE-II effort. Our analysis is in part driven by the hypothesis that the common atmospheric state applied to these models results in a similar representation of Southern Ocean water mass and sea-ice features for the 1988-2007 period. Results that were coherent across the CORE-II models for the 20 year mean are schematized in Figure 28. The following conclusions can be drawn from this study.

- The March (summertime) mixed layer depth is overall shallower than observed in mode and intermediate water mass formation regions. The uniform shallow bias across the CORE-II models indicates the CORE-II atmospheric state largely dictates the summer mixed layer, in particular the wind stress strength and position. Conversely, the September (winter) mixed layers differ significantly across the models. However, most models represented the mode and intermediate water mass September mixed layer depths deeper than observed and positioned further poleward. The CORE-II models with considerably deeper than observed September mixed layer depth biases also showed large regions of surface heat loss, large saline biases north of $50^{\circ} \mathrm{S}$ in the upper $200 \mathrm{~m}$, deeper than observed Sub-Antarctic Mode Water (SAMW) low 
potential vorticity layers in the Pacific, and a more poleward displaced Antarctic Intermediate Water (AAIW) salinity minimum layer. Examples are the ACCESS, BERGEN, FSU, and ICTP models.

- Significant spatial correlations between regions of deep mixed layers and wind stress, surface buoyancy fluxes and sea ice indicate that shallower March mixed layers are associated with weaker and more poleward positioned westerlies. Spatial correlations varied in sign for the September mixed layers, however the majority of significant spatial correlations showed that deeper September mixed layer depth areas are associated with larger surface heat and freshwater input, and sea ice positioned further poleward.

- Whilst the models represent similar spatial patterns for the March and September 20 year mixed layer depth trends, the association of these trends with surface buoyancy, wind stress, and sea-ice is incoherent. In addition, the spatial pattern in the September mixed layer depth biases varies both in sign and magnitude for the 1988-2007 period.

- Below $200 \mathrm{~m}$, the CORE-II models have a cold/fresh bias south of $\sim 50^{\circ} \mathrm{S}$, and warm/salty bias to the north, with biases largest in the Pacific sector. These biases lead to a favourable density structure compared with observations. However, these temperature and salinity biases result in deeper than observed mode and intermediate water mass mixed layer depths, and shallower than observed polar mixed layers.

- The surface water mass transformation rates, driven by heat and freshwater fluxes, vary widely between models. The volume transport across $30^{\circ} \mathrm{S}$ implies a stronger than observed upper ocean overturning cell, and weaker than observed deep flow. We conjecture that this transport bias is less likely linked to common CORE-II atmospheric state. Rather, it is more likely linked to weak bottom water formation and overturning inherent in coarse resolution level coordinate ocean climate models.

- The March sea-ice concentration was lower than observed around the Antarctic continent, and neither the mean or linear trend in sea-ice extent were similarly depicted across the models. The September sea-ice concentration biases are both positive and negative around the Antarctic continent, with little agreement in sign and magnitude across the models. While the models captured the decreased sea ice in the West Antarctic (1988-2007), they failed to coherently represent an increase in the Ross Sea, and this failure is likely linked to biases in wind stress over the Antarctic continent. The modelled September sea-ice retreat north of the Ross Sea can indirectly influence the simulated increase in September mixed layer depths in the southwest Pacific. Sea-ice retreat increases the ocean surface area available for heat loss via atmosphere-ocean fluxes.

We found that the NCAR and NOCS models performed best in terms of their representation of the SAMW low potential vorticity and AAIW salinity minimum layers, and shallower seasonal mixed layer depth biases and temperature and salinity biases (south of $40^{\circ} \mathrm{S}$ ) compared with other CORE-II models. We did not find the model vertical coordinate (four of the models use an isopycnal or hybrid coordinate) to be a contributing factor to model differences in ocean and ice representation. Model resolution (focusing on GFDL-MOM025) also did not improve most of the Southern Ocean metrics presented here, however the summertime sea ice was better captured by GFDL-MOM025. Both GFDL-MOM and GFDL-MOM025 have similar seasonal mixed layer depth biases, transformation rates, and a smaller than observed salinity minimum layer. 
Details of the models' ocean-sea ice configurations, including the treatment and strength of surface salinity restoration, do influence their water mass exchange and interior transformation. However, there is sizable coherence in representing sea-ice trends, mixed layer depths, and surface buoyancy across the Southern Ocean, both regionally and in a zonal mean. This result suggests, at least tentatively, that the CORE-II approach offers a useful means to uncover mechanisms for Southern Ocean climate over the years 1988-2007. This upbeat conclusion must be caveated by a huge degree of uncertainty both in the atmospheric state in the Southern Ocean, and the observational record for use in evaluating simulations.

\section{Acknowledgements}

The CLIVAR Ocean Model Development Panel (OMDP) is responsible for organising the Coordinated Ocean-sea ice Reference Experiments, with support from international CLIVAR and U.S. CLIVAR project offices, particularly Anna Pirani. We are grateful for the efforts of modellers who have contributed to the simulation and processing of the CORE-II experiments. S. M. Downes was supported by the ARC Centre of Excellence for Climate System Science (grant CE110001028). The ACCESS model is supported by the Australian Government Department of the Environment, the Bureau of Meteorology and CSIRO through the Australian Climate Change Science Programme. AWI is a member of the Helmholtz Association of German Research Centers. Q. Wang and D. Sidorenko are funded by the Helmholtz Climate Initiative REKLIM (Regional Climate Change) project. The GEOMAR model integrations were built on developments in the DRAKKAR collaboration, were performed at the North-German Supercomputing Alliance (HLRN), and were supported by the Cluster of Excellence 'The Future Ocean'. The BERGEN contribution is supported by the Research Council of Norway through the EarthClim (207711/E10) and NOTUR/NorStore projects, as well as the Centre for Climate Dynamics at the Bjerknes Centre for Climate Research. The CMCC contribution received funding from the Italian Ministry of Education, University, and Research and the Italian Ministry of Environment, Land, and Sea under the GEMINA project. NCAR is sponsored by the U. S. National Science Foundation (NSF). S. G. Yeager was supported by the NOAA Climate Program Office under Climate Variability and Predictability Program Grant NA09OAR4310163. We thank Carolina Dufour and Adele Morrison for their useful comments on earlier drafts, and two anonymous reviewers for their constructive comments, all of which helped improve the paper. 


\section{References}

Abram, N. J., Mulvaney, R., Wolff, E. W., Triest, J., Kipfstuhl, S., Trusel, L. D., Vimeux, F., Fleet, L., Arrowsmith, C., 2013. Acceleration of snow melt in an Antarctic Peninsula ice core during the twentieth century. Nat. Geosci. 6 (5), 404-411.

Antonov, J. I., Seidov, D., Boyer, T. P., Locarnini, R. A., Mishonov, A. V., Garcia, H. E., Baranova, O. K., Zweng, M. M., Johnson, D. R., 2010. World Ocean Atlas 2009, Volume 1: Temperature. NOAA Atlas NESDIS 68, U.S. Government Printing Office, Washington, D.C., 184 pp.

Barthélemy, A., Goosse, H., Mathiot, P., Fichefet, T., 2012. Inclusion of a katabatic wind correction in a coarse-resolution global coupled climate model. Ocn. Modell. 48, 45-54.

Bintanja, R., van Oldenborgh, G. J., Drijfhout, S. S., Wouters, B., Katsman, C. A., 052013. Important role for ocean warming and increased ice-shelf melt in antarctic sea-ice expansion. Nat. Geosci. 6 (5), 376-379.

Carsey, F. D., 1980. Microwave observation of the Weddell Polynya. Mon. Weath. Rev. 108, 20322044.

Cerovečki, I., Talley, L. D., Mazloff, M. R., Maze, G., 2013. Subantarctic Mode Water formation, destruction, and export in the eddy-permitting Southern Ocean State Estimate. J. Phys. Oceanogr. 43, 1485-1511.

Chen, G., Held, I. M., 2007. Phase speed spectra and the recent poleward shift of Southern Hemisphere surface westerlies. Geophys. Res. Lett. 34 (21).

Comiso, J. C., Nishio, F., 2008. Trends in the sea ice cover using enhanced and compatible AMSR-E, SSM/I, and SMMR data. J. Geophys. Res. 113, c02S07, doi:10.1029/2007JC004257.

Danabasoglu, G., Yeager, S. G., Bailey, D., Behrens, E., Bentsen, M., Bi, D., Biastoch, A., Bning, C., Bozec, A., Canuto, V. M., Cassou, C., Chassignet, E., Coward, A. C., Danilov, S., Diansky, N., Drange, H., Farneti, R., Fernandez, E., Fogli, P. G., Forget, G., Fujii, Y., Griffies, S. M., Gusev, A., Heimbach, P., Howard, A., Jung, T., Kelley, M., Large, W. G., Leboissetier, A., Lu, J., Madec, G., Marsland, S. J., Masina, S., Navarra, A., Nurser, A. G., Pirani, A., y Mlia, D. S., Samuels, B. L., Scheinert, M., Sidorenko, D., Treguier, A.-M., Tsujino, H., Uotila, P., Valcke, S., Voldoire, A., Wang, Q., 2014. North Atlantic simulations in Coordinated Ocean-ice Reference Experiments Phase II (CORE-II). Part I: Mean states. Ocean Modell. 73 (0), 76 -107.

de Boyer Montégut, C., Madec, G., Fischer, A. S., Lazar, A., Iudicone, D., 2004. Mixed layer depth over the global ocean: An examination of profile data and a profile-based climatology. J. Geophys. Res. 109 (C12).

De Lavergne, C., Palter, J. B., Galbraith, E. D., Bernardello, R., Marinov, I., 2014. Cessation of deep convection in the open Southern Ocean under anthropogenic climate change. Nat. Clim. Chang. 4, 278-282, doi:10.1038/nclimate2132.

Delworth, T. L., Rosati, A., Anderson, W., Adcroft, A. J., Balaji, V., Benson, R., Dixon, K., Griffies, S. M., Lee, H.-C., Pacanowski, R. C., Vecchi, G. A., Wittenberg, A. T., Zeng, F., Zhang, R., 2012. Simulated climate and climate change in the GFDL CM2.5 high-resolution coupled climate model. J. Clim. 25, 2755-2781. 
Dong, S., Sprintall, J., Gille, S. T., Talley, L., 2008. Southern Ocean mixed-layer depth from Argo float profiles. J. Geophys. Res. 113 (C6), 2156-2202.

Downes, S. M., Bindoff, N. L., Rintoul, S. R., 2010. Changes in the subduction of Southern Ocean water masses at the end of the twenty-first century in eight IPCC models. J. Clim. 23, 6526-6541.

Downes, S. M., Gnanadesikan, A., Griffies, S. M., Sarmiento, J. L., 2011. Water mass exchange in the Southern Ocean in coupled climate models. J. Phys. Oceanogr. 41, 1756-1771.

Durack, P. J., Wijffels, S. E., 2010. Fifty-year trends in global ocean salinities and their relationship to broad-scale warming. Journal of Climate 23 (16), 4342-4362.

Farneti, R., Delworth, T. L., Rosati, A. J., Griffies, S. M., Zeng, F., 2010. The role of mesoscale eddies in the rectification of the Southern Ocean response to climate change. J. Phys. Oceanogr. 40 (7), 1539-1557.

Farneti, R., Downes, S. M., Griffies, S. M., Marsland, S. J., Bailey, D., Behrens, E., Bentsen, M., Bi, D., Biastoch, A., Böning, C., Bozec, A., Chassignet, E., Danabasoglu, G., Danilov, S., Diansky, N., Drange, H., Fogli, P. G., Gusev, A., Hallberg, R. W., Howard, A., Kelley, M., Illicak, M., Large, W. G., Leboissetier, A., Long, M., Lu, J., Masina, S., Mishra, A., Navarra, A., Nurser, A. J. G., Patara, L., Samuels, B. L., Sidorenko, D., Tsujino, H., Uotila, P., Yeager, S. G., Wang, Q., 2015. An assessment of antarctic circumpolar current and southern ocean overturning circulation in a suite of interannual core-ii simulations. Ocean Modelling, Submitted.

Fetterer, F., Knowles, K., Meier, W., Savoie, M., 2009. Sea ice index. Tech. Rep. Digital media, National Snow and Ice Data Center, Boulder, Colorado, USA.

Gent, P. R., McWilliams, J. C., 1990. Isopycnal mixing in ocean circulation models. J. Phys. Oceanogr. 20, 150-155.

Gnanadesikan, A., Dunne, J. P., Key, R. M., Matsumoto, K., Sarmiento, J. L., Slater, R. D., Swathi, P. S., 2004. Oceanic ventilation and biogeochemical cycling: Understanding the physical mechanisms that produce realistic distributions of tracers and productivity. Global Biogeochem. Cy. 18 (4).

Griffies, S. M., Biastoch, A., Böning, C., Bryan, F., Danabasoglu, G., Chassignet, E. P., England, M. H., Gerdes, R., Haak, H., Hallberg, R. W., Hazeleger, W., Jungclaus, J., Large, W. G., Madec, G., Pirani, A., Samuels, B. L., Scheinert, M., Gupta, A. S., Severijns, C. A., Simmons, H. L., Treguier, A. M., Winton, M., Yeager, S., Yin, J., 2009. Coordinated Ocean-ice Reference Experiments (COREs). Ocn. Modell. 26, 1-46.

Griffies, S. M., Yin, J., Durack, P. J., Goddard, P. B., Bates, S. C., Behrens, E., Bentsen, M., Bi, D., Biastoch, A., Boning, C., Bozec, A., Chassignet, E., Danabasoglu, G., Danilov, S., Domingues, C., Drange, H., Farneti, R., Fernandez, E., Greatbatch, R. J., Holland, D. M., Ilicakf, M., Lu, J., Marsland, S. J., Mishra, A., Lorbacher, K., Nursern, A. J. G., y Melia, D. S., Palter, J. B., Samuels, B. L., Schroter, J., Schwarzkopf, F. U., Sidorenko, D., Treguierq, A. M., Tseng, Y., Tsujino, H., Uotila, P., Valcke, S., Aurore, A., Wang, Q., Winton, M., Zhang, X., 2014. An assessment of global and regional sea level for years 1993-2007 in a suite of interannual CORE-II simulations. Ocean Modell., in press, dpi: 10.1016/j.ocemod.2014.03.004.

Hanawa, K., Talley, L. D., 2001. Mode Waters, In: Ocean circulation and climate. Academic Press. 
Hartin, C. A., Fine, R. A., Sloyan, B. M., Talley, L. D., Chereskin, T. K., Happell, J., 2011. Formation rates of Subantarctic mode water and Antarctic intermediate water within the South Pacific. Deep-Sea Res. I 58, 524-534.

Helm, K. P., Bindoff, N. L., Church, J. A., 2011. Observed decreases in oxygen content of the global ocean. Geophys. Res. Lett. 38 (23).

Herraiz-Borreguero, L., Rintoul, S. R., 2011. Subantarctic mode water: distribution and circulation. Ocn. Dyn. 61, 103-126.

Holland, P. R., Kwok, R., 2012. Wind-driven trends in Antarctic sea-ice drift. Nat. Geosc. 5, 1-4, doi:10.1038/ngeo1627.

Holte, J., Talley, L., 2009. A new algorithm for finding mixed layer depths with applications to argo data and subantarctic mode water formation. J. Atmos. Oceanic Technol. 26 (9), 1920-1939.

Large, W., Yeager, S. G., 2004. Diurnal to decadal global forcing for ocean and sea-ice models: the datasets and flux climatologies. Tech. Rep. NCAR Technical Note: NCAR/TN-460+STR, CGD Division of the National Centre for Atmospheric Research, Colorado, USA.

Large, W., Yeager, S. G., 2009. The global climatology of an interannually varying air-sea flux data set. Clim. Dyn. 33 (5682), 341-364.

Large, W. G., Yeager, S. G., 2012. On the observed trends and changes in global sea surface temperature and air-sea heat fluxes (1984-2006). J. Clim. 25, 6123-6135.

Locarnini, R. A., Mishonov, A. V., Antonov, J. I., Boyer, T. P., Garcia, H. E., Baranova, O. K., Zweng, M. M., Johnson, D. R., 2010. World Ocean Atlas 2009, Volume 1: Temperature. NOAA Atlas NESDIS 68, U.S. Government Printing Office, Washington, D.C., 184 pp.

Marsh, R., Nurser, A. J. G., Megann, A. P., New, A. L., 2000. Water mass transformation in the Southern Ocean of a global isopycnal coordinate GCM. J. Phys. Oceanogr. 30, 1013-1045.

Marshall, G. J., 2003. Trends in the Southern Annular Mode from observations and reanalyses. J. Clim. 16, 4134-4143.

Marshall, J. C., Nurser, A. J. G., Williams, R. G., 1993. Inferring the subduction rate and period over the North Atlantic. J. Phys. Oceanogr. 23, 1315-1329.

Marsland, S. J., Wolff, J.-O., 2001. On the sensitivity of Southern Ocean sea ice to the surface freshwater flux: a model study. J. Geophys. Res. 106 (C2), 2723-2741.

Martinson, D., Killworth, P., Gordon, A., 1981. A convective model for the Weddell Polynya. J. Phys. Oceanogr. 11, 466-488.

Mathiot, P., Barnier, B., Gallée, H., Molines, J. M., Sommer, J. L., Juza, M., Penduff, T., 2010. Introducing katabatic winds in global ERA40 fields to simulate their impacts on the Southern Ocean and sea-ice. Ocn. Modell. 35, 146-160.

Naveira Garabato, A. C., Jullion, L., Stevens, D. P., Heywood, K. J., King, B. A., 2009. Variability of Subantarctic mode water and Antarctic intermediate water in the Drake Passage during the late-twentieth and early-twenty-first centuries. J. Clim. 22 (13), 3661-3688. 
Orsi, A., Johnson, G., Bullister, J., 1999. Circulation, mixing, and production of Antarctic Bottom Water. Progr. Oceanogr. 43, 55-109.

Parkinson, C. L., Comiso, J. C., Zwally, H., 2004. Nimbus-5 ESMR Polar Gridded Sea Ice Concentrations. Boulder, Colorado USA: NASA DAAC at the National Snow and Ice Data Center.

Pezza, A. B., Rashid, H. A., Simmonds, I., 2012. Climate links and recent extremes in Antarctic sea ice, high-latitude cyclones, Southern Annular Mode and ENSO. Clim. Dyn. 38, 57-73, doi:10.1007/s00382-011-1044-y.

Reynolds, R. W., Rayner, N., Smith, T., Stokes, D., Wang, W., 2002. An improved in situ and satellite SST analysis for climate. J. Clim. 15, 1609-1625.

Rintoul, S. R., Naveira Garabato, A. C., 2013. Chapter 18 - Dynamics of the Southern Ocean circulation. In: Gerold Siedler, Stephen M. Griffies, J. G., Church, J. A. (Eds.), Ocean Circulation and Climate A 21st Century Perspective. Vol. 103 of International Geophysics. Academic Press, pp. $471-492$.

Sabine, C. L., Feely, R. A., Gruber, N., Key, R. M., Lee, K., Bullister, J. L., Wanninkhof, R., Wong, C. S., Wallace, D. W. R., Tilbrook, B., Millero, F. J., Peng, T.-H., Kozyr, A., Ono, T., Rios, A. F., 2004. The oceanic sink for anthropogenic $\mathrm{CO}_{2}$. Science 305 (5682), 367-371.

Sallée, J.-B., Shuckburgh, E., Bruneau, N., Meijers, A. J. S., Bracegirdle, T. J., Wang, Z., 2013a. Assessment of Southern Ocean mixed-layer depths in CMIP5 models: Historical bias and forcing response. J. Geophys. Res., 1845-1862.

Sallée, J.-B., Shuckburgh, E., Bruneau, N., Meijers, A. J. S., Bracegirdle, T. J., Wang, Z., Roy, T., 2013b. Assessment of Southern Ocean water mass circulation and characteristics in CMIP5 models: Historical bias and forcing response. J. Geophys. Res., 1830-1844.

Sallée, J.-B., Speer, K., Rintoul, S., Wijffels, S., 2010a. Southern Ocean thermocline ventilation. J. Phys. Oceanogr. 40 (3), 509-529.

Sallée, J. B., Speer, K. G., Rintoul, S. R., 2010b. Zonally asymmetric response of the Southern Ocean mixed-layer depth to the Southern Annular Mode. Nat. Geosci. 3 (4), 273-279.

Simpkins, G. R., Ciasto, L. M., England, M. H., 2013. Observed variations in multidecadal Antarctic sea ice trends during 1979-2012. Geophys. Res. Lett. 40, doi:10.1002/grl.50715.

Sloyan, B. M., Kamenkovich, I. V., 2007. Simulation of Subantarctic mode and Antarctic intermediate waters in climate models. J. Clim. 20, 5061-5080.

Speer, K., Guilyardi, E., Madec, G., 2000. Southern Ocean transformation in a coupled model with and without eddy mass fluxes. Tellus 52A, 554-565.

Spence, P., van Sebille, E., Saenko, O. A., England, M. H., 2014. Using Eulerian and Lagrangian approaches to investigate wind-driven changes in the Southern Ocean abyssal circulation. J. Phys. Oceanogr. 44, 662-675.

Stössel, A., Zhang, Z., Vihma, T., 2011. The effect of alternative real-time wind forcing on Southern Ocean sea-ice simulations. J. Geophys. Res. 116, 1-54. 
Talley, L. D., 2008. Freshwater transport estimates and the global overturning circulation: Shallow, deep and throughflow components. Progress in Oceanography 78 (4), 257 - 303.

Thompson, D. W. J., Solomon, S., Kushner, P. J., England, M. H., Grise, K. M., Karoly, D. J., 2011. Signatures of the Antarctic ozone hole in Southern Hemisphere surface climate change. Nat. Geosc. 4, 741-749, doi:10.1038/NGEO1296.

Thompson, D. W. L., Solomon, S., 2002. Interpretation of recent Southern Hemisphere climate change. Science 296, 895-899.

Turner, J., Comiso, J. C., Marshall, G. J., Lachlan-Cope, T. A., Bracegirdle, T. J., Maksym, T., Meredith, M. P., Wang, Z., , Orr, A., 2009. Non-annular atmospheric circulation change induced by stratospheric ozone depletion and its role in the recent increase of Antarctic sea ice extent. Geophys. Res. Lett. 36, 57-73, doi:10.1029/2009GL037524.

Uotila, P., Holland, P. R., Vihma, T., Marsland, S. J., Kimura, N., 2014. Is realistic Antarctic sea-ice extent in climate models the result of excessive ice drift? Ocean Modell. 79, 33-42, doi:10.1016/j.ocemod.2014.04.004.

Zwally, H. J., Comiso, J. C., Parkinson, C. L., Campbell, W. J., Carsey, F. D., Gloersen, P., 1983. Antarctic Sea Ice, 1973-1976: Satellite Passive-Microwave Observations. NASA SP-459, National Aeronautics and Space Administration, Washington, D.C.

Zwally, H. J., Comiso, J. C., Parkinson, C. L., Cavalieri, D. J., Gloersen, P., 2002. Variability of Antarctic sea ice 19791998. J. Geophys. Res. 107, 3041, doi:10.1029/2000JC000733. 
${ }_{956}$ 6. TABLES 


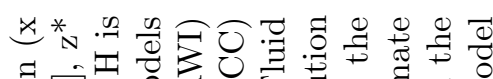

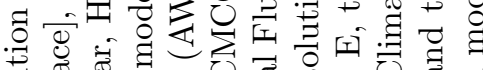

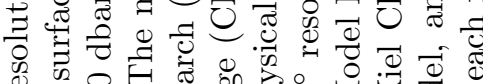
क क ${ }^{\mathrm{W}}$.

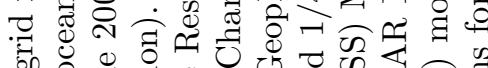

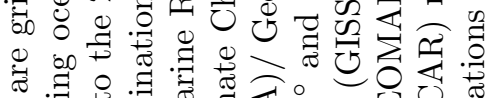

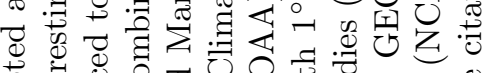

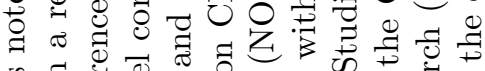

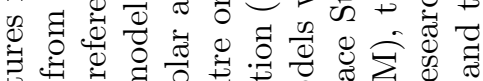

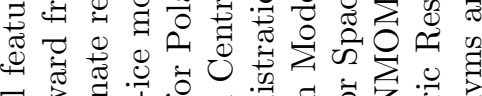

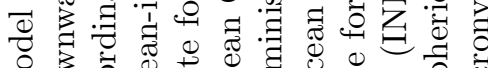
范

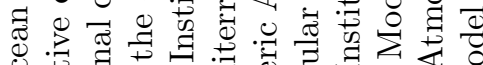

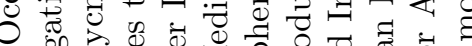

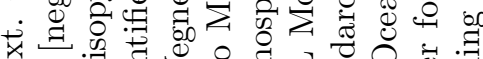

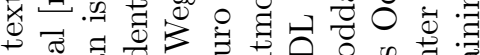

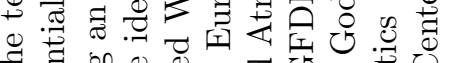
若

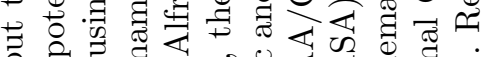

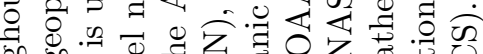
son

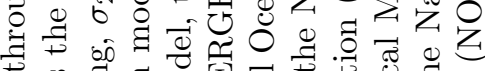
. . .

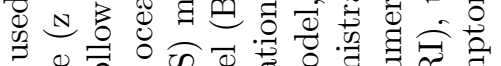
记

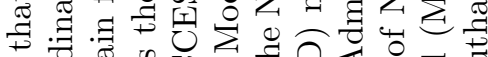
क

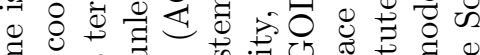
氜

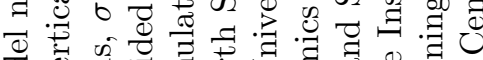

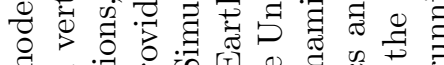

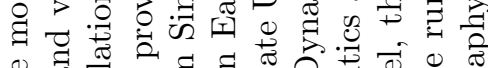

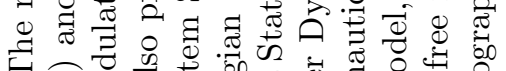

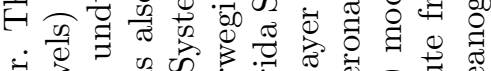

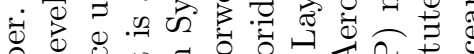

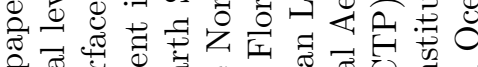

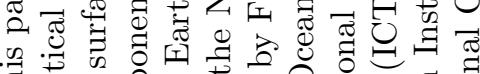

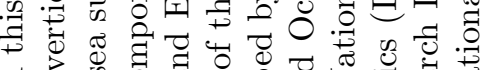

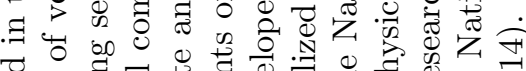

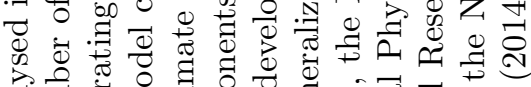

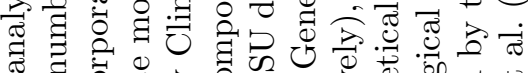
సี ప

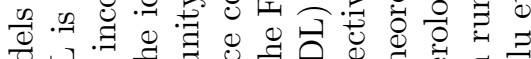

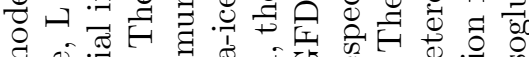

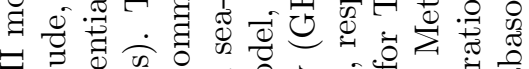

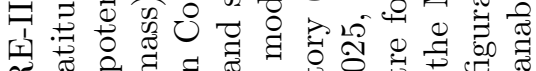

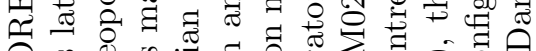

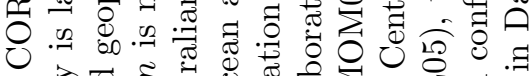

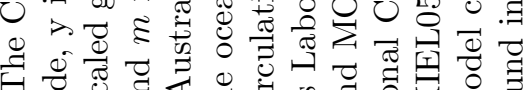
E

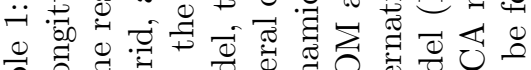

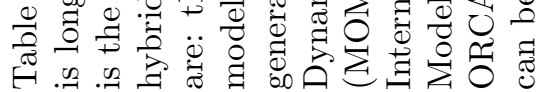

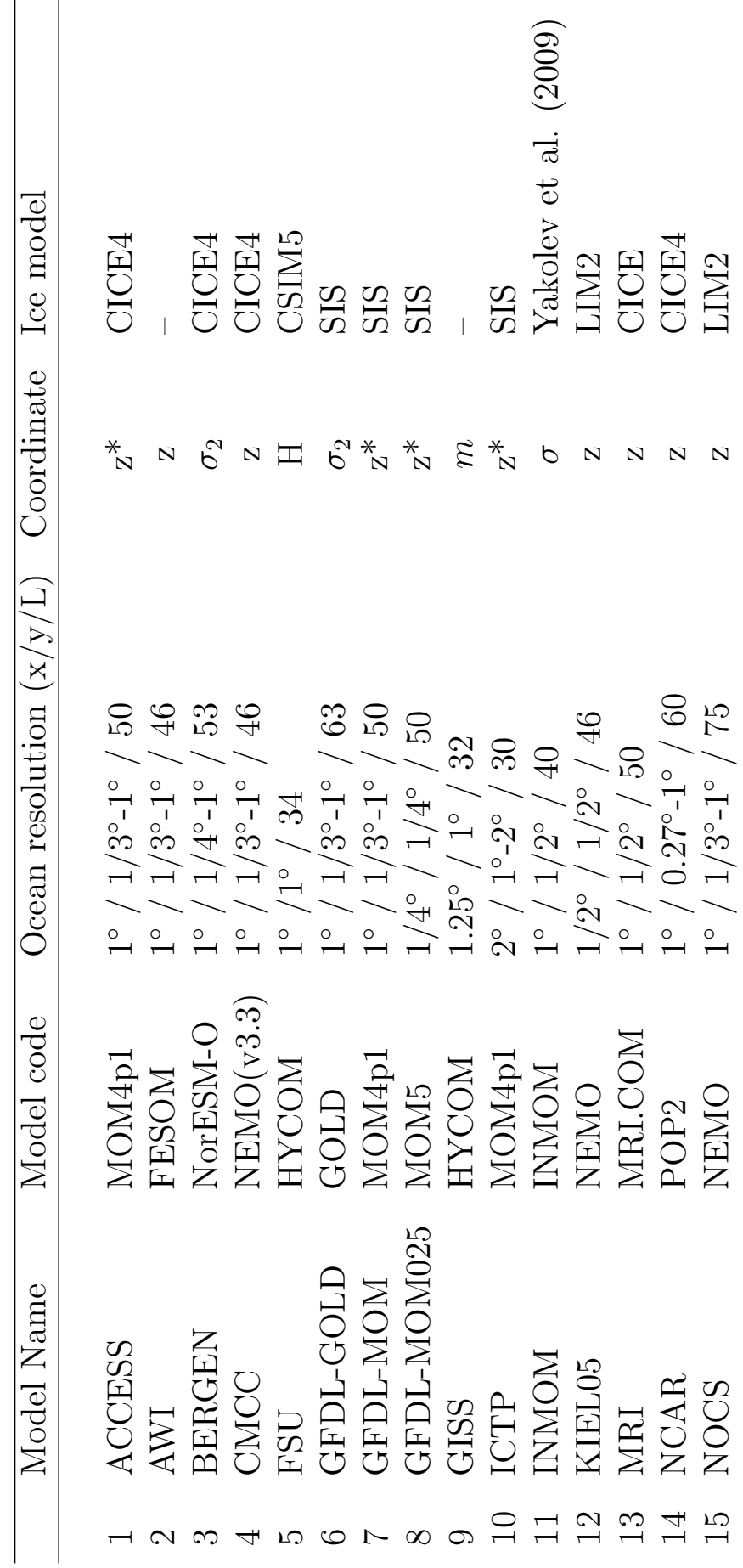


${ }_{957}$ 7. FIGURES 

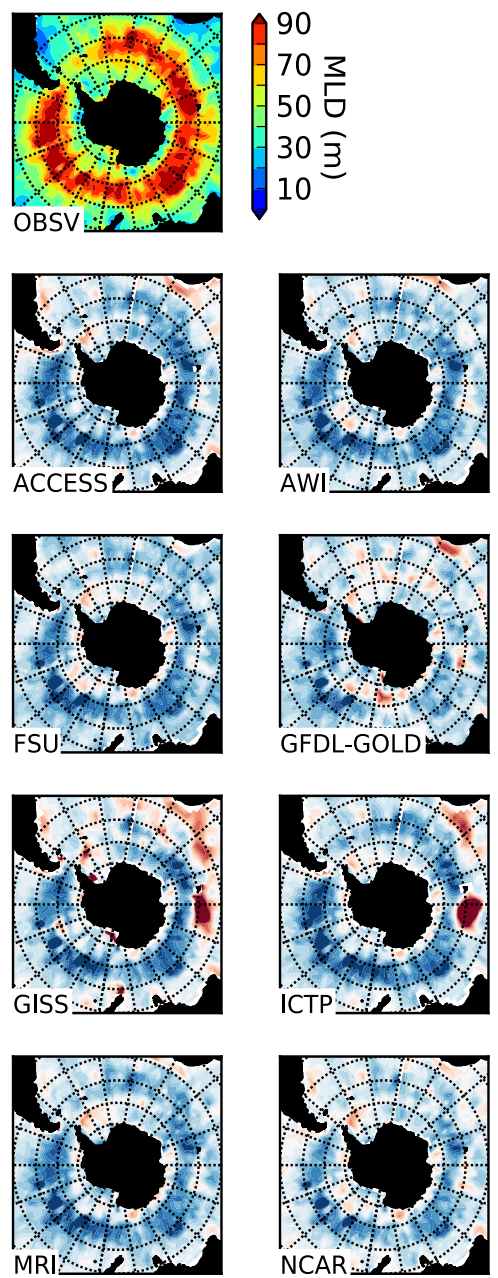
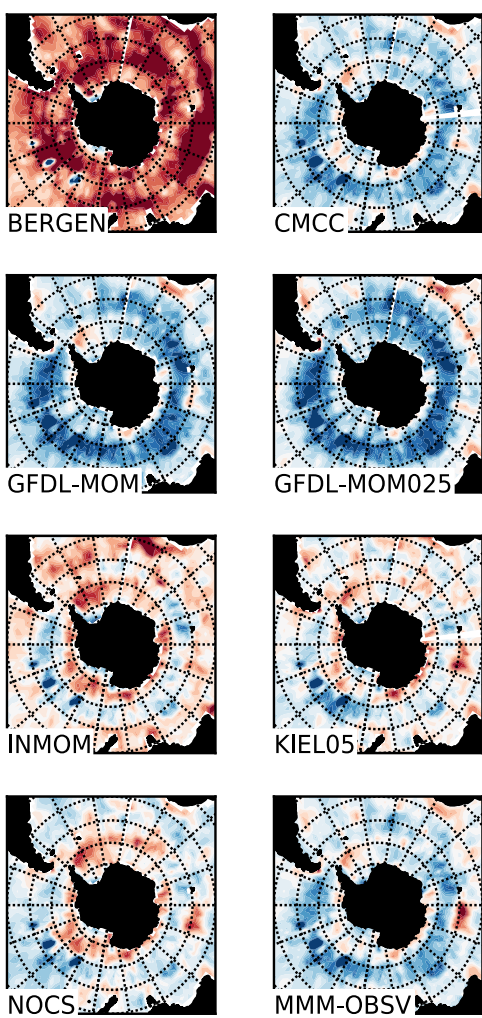

Figure 1: First two top row panels: observed (de Boyer Montégut et al., 2004, OBSV) and multi-model mean (MMM) March mixed layer depth (m), defined as using a $0.03 \mathrm{~kg} \mathrm{~m}^{-3}$ criterion. Remaining panels (associated color scale at bottom of figure): individual models and multi model mean (1988-2007 average) minus observations. Polar grid (black lines) shows latitude (radials; $70^{\circ}-40^{\circ} \mathrm{S}$ by $10^{\circ}$ ) and longitude (rays; clockwise $10^{\circ}-350^{\circ} \mathrm{E}$ by $20^{\circ}$ ). Note: the color bar in the top row represents the mean states of the observations and multi model mean, whereas the color bar at the bottom of the figure is for the remaining rows (the biases from observations). The models generally underestimate the summer mixed layer depth in the Southern Ocean, particularly in the mode and intermediate water mass formation regions. 

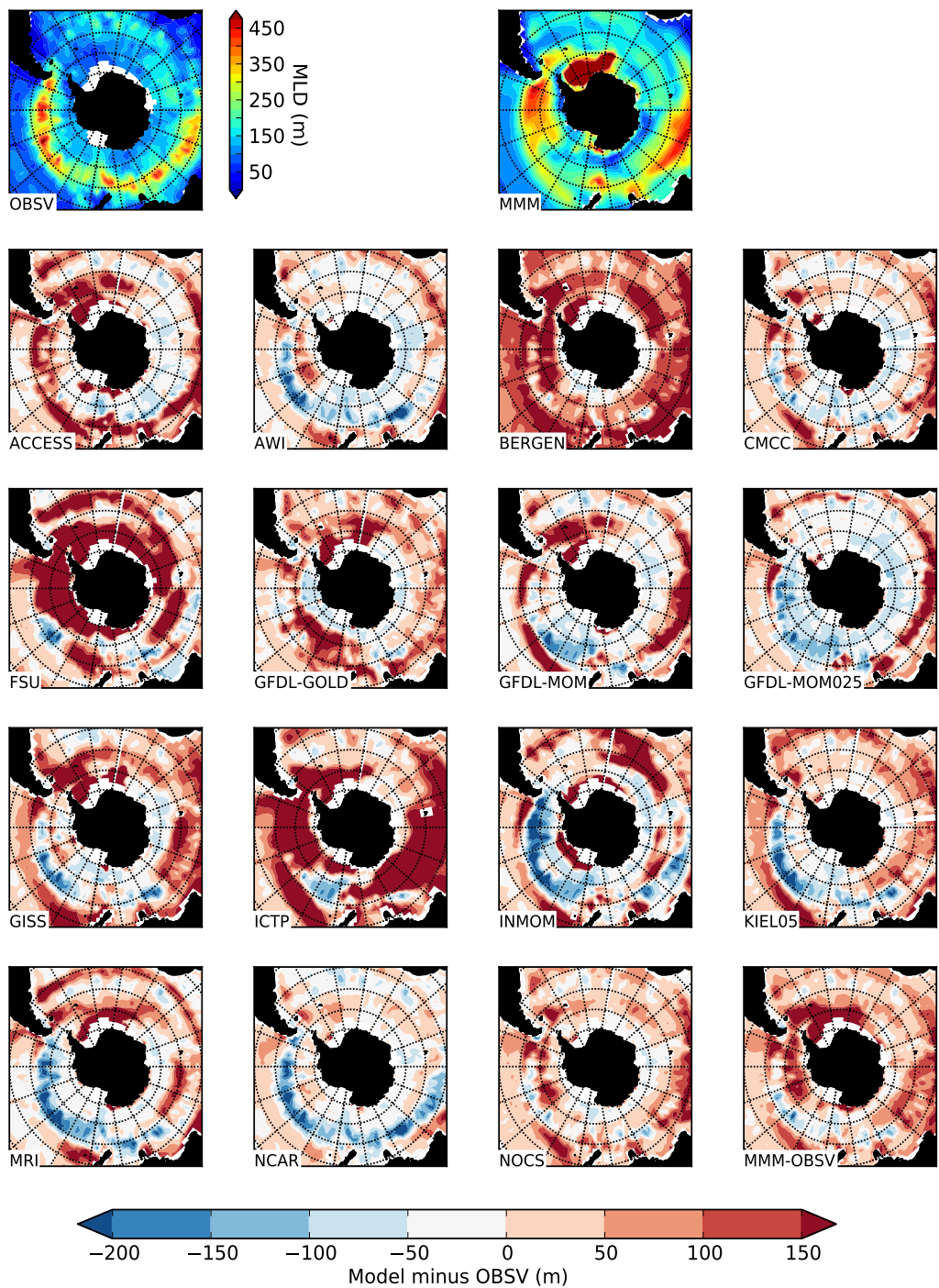

Figure 2: First two top row panels: observed (de Boyer Montégut et al., 2004, OBSV) and multi-model mean (MMM) September mixed layer depth $(\mathrm{m})$, defined as using a $0.03 \mathrm{~kg} \mathrm{~m}^{-3}$ criterion. Remaining panels (associated color scale at bottom of figure): individual models and multi model mean (1988-2007 average) minus observations. Geographic grid (black lines) as in Figure 1. Note: the color bar in the top row represents the mean states of the observations and multi model mean, whereas the color bar at the bottom of the figure is for the remaining rows (the biases from observations). The models generally overestimate the winter mixed layer depth in the Southern Ocean. 


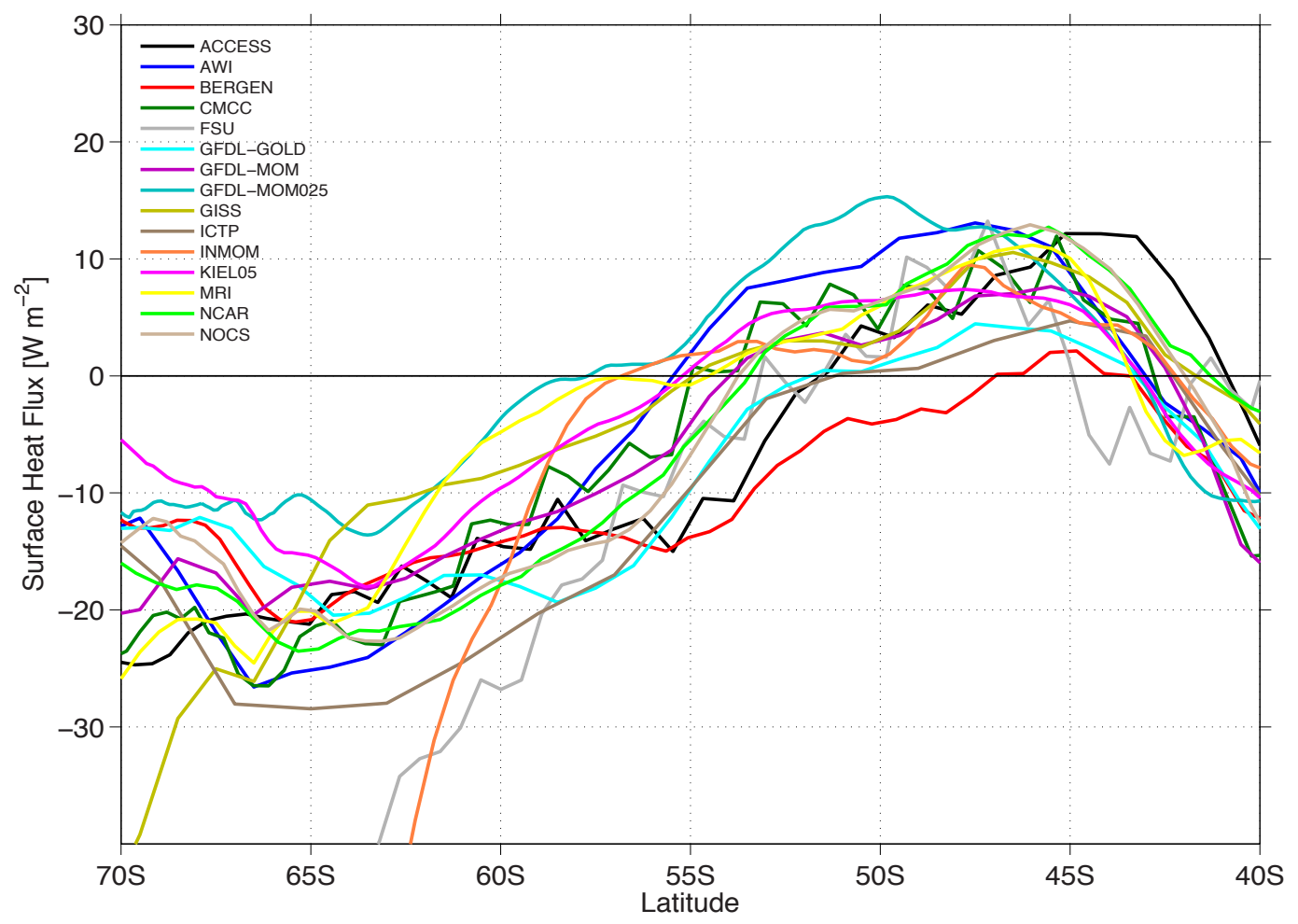

Figure 3: Zonally averaged surface heat flux ( $\mathrm{W} \mathrm{m}^{-2}$; positive associated with heat gain to the ocean) in the individual CORE-II models for the 1988-2007 mean period. Note that the FSU and INMOM simulations fall below the lower scale south of roughly $62^{\circ} \mathrm{S}$, and the GISS model does so south of $69^{\circ} \mathrm{S}$. 


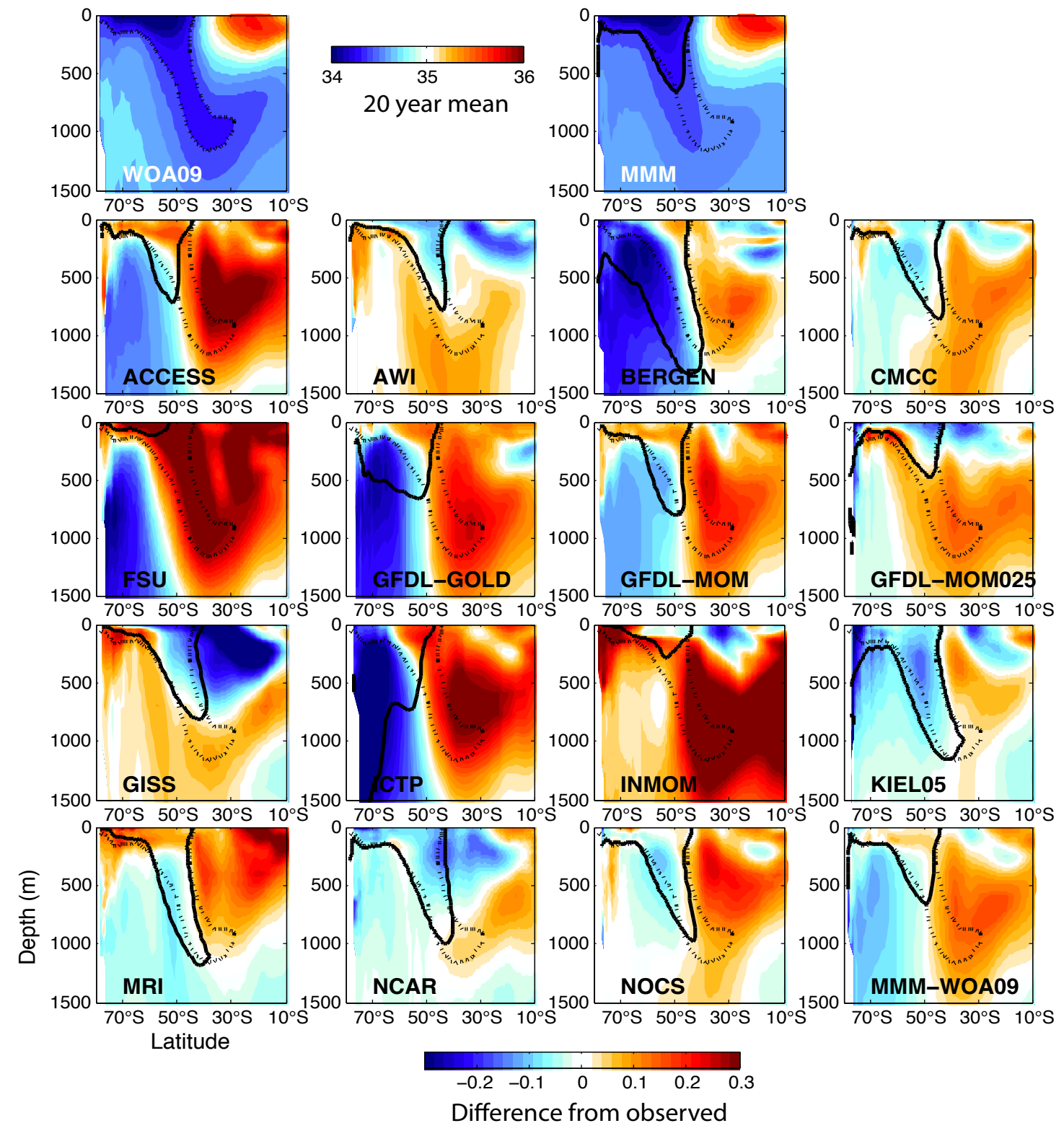

Figure 4: Top row panels: zonally averaged salinity for the averaged 1988-2007 period for observations (WOA09; Antonov et al., 2010) and the multi model mean (MMM). Remaining panels (associated color scale at bottom of figure): model difference from observations, where blue shades denote the model is fresher than observed, and reds more saline than observed. The solid black contour is the model 34.4 isohaline, and dashed is the 34.4 observed isohaline. Note: the color bar in the top row represents the mean states of the observations and multi model mean, whereas the color bar at the bottom of the figure is for the remaining rows (the biases from observations). The MMM generally shows a fresh bias south of $50^{\circ} \mathrm{S}$ and salty bias to the north. 

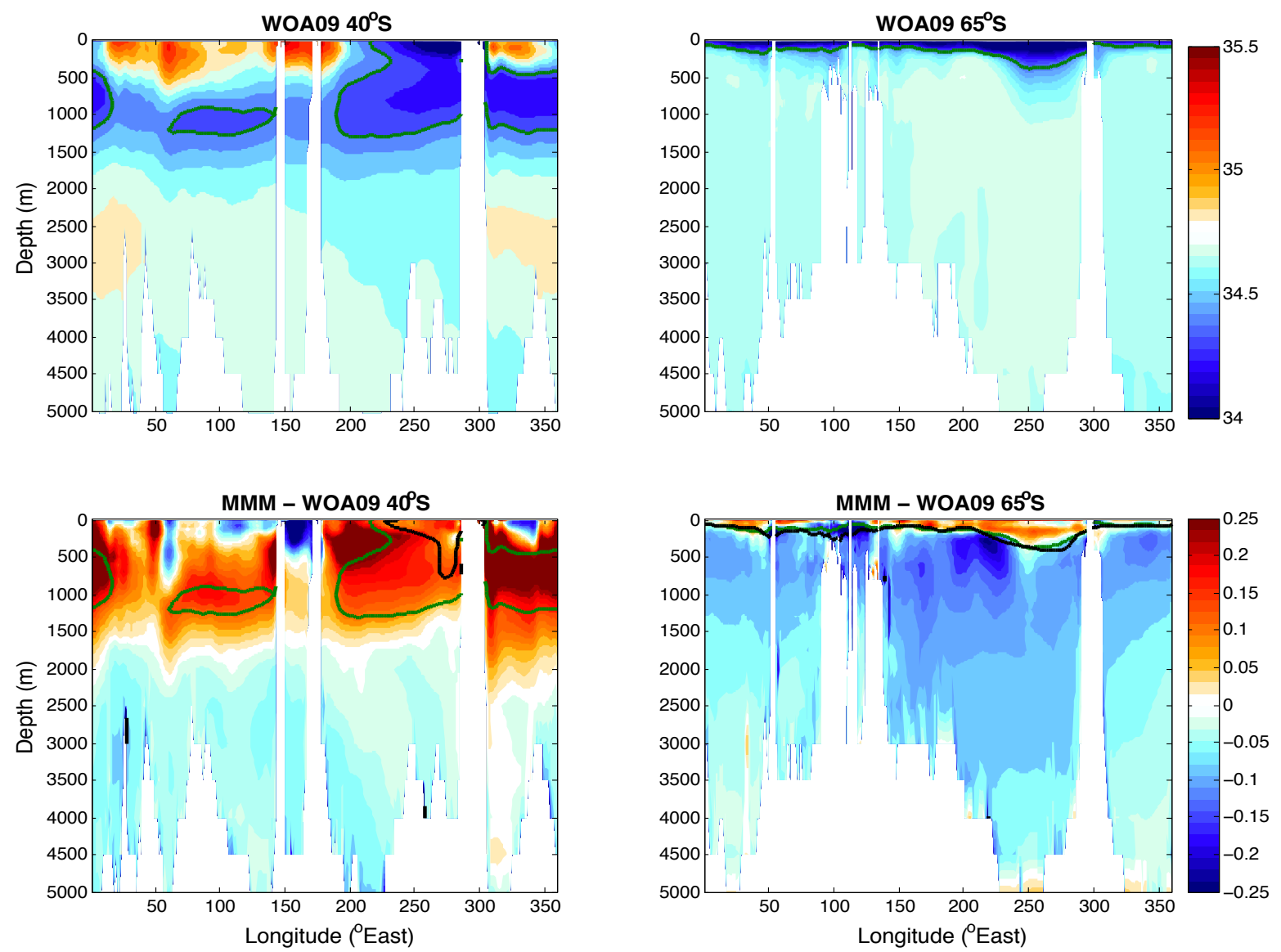

Figure 5: Salinity at $40 \mathrm{~S}^{\circ}$ and $65^{\circ} \mathrm{S}$ for observations (WOA09; Locarnini et al., 2010, top panels) and the multi model mean biases (MMM minus WOA09; bottom panels). The MMM is the averaged 1988-2007 period. Color scales to the right are for each row. The solid green (WOA09)/black (MMM) contours are the 34.4 isohaline. The MMM generally shows a salty bias in the upper $1500 \mathrm{~m}$ at $40^{\circ} \mathrm{S}$, whereas at $65^{\circ} \mathrm{S}$ there is a salty bias near the surface overlying a fresh bias, particularly in the Pacific sector. 

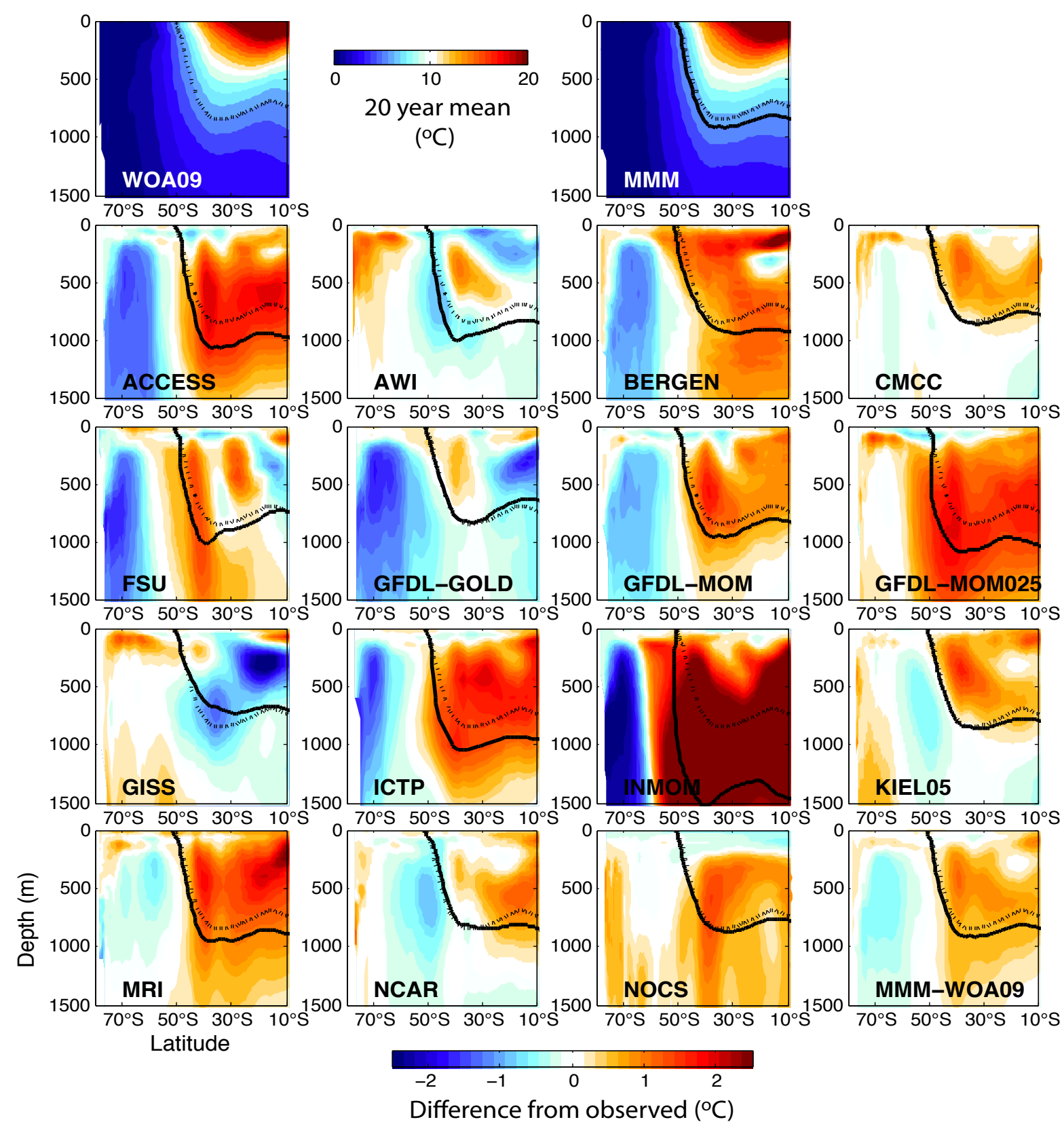

Figure 6: Top row panels: zonally averaged temperature $\left({ }^{\circ} \mathrm{C}\right)$ for the averaged $1988-2007$ period for observations (WOA09; Locarnini et al., 2010) and the multi model mean (MMM). Remaining panels (associated color scale at bottom of figure): model difference from observations, where blue shades denote model temperature is cooler than observed, reds for warmer than observed. The solid black contour is the model $6^{\circ} \mathrm{C}$ isotherm, and dashed is the observed $6^{\circ} \mathrm{C}$ isotherm. Note: the color bar in the top row represents the mean states of the observations and multi model mean, whereas the color bar at the bottom of the figure is for the remaining rows (the biases from observations). The MMM generally shows a cool bias south of $50^{\circ} \mathrm{S}$ and a warm bias to the north. The temperature bias renders a rough density compensating bias with the salinity bias shown in Figure 4. 

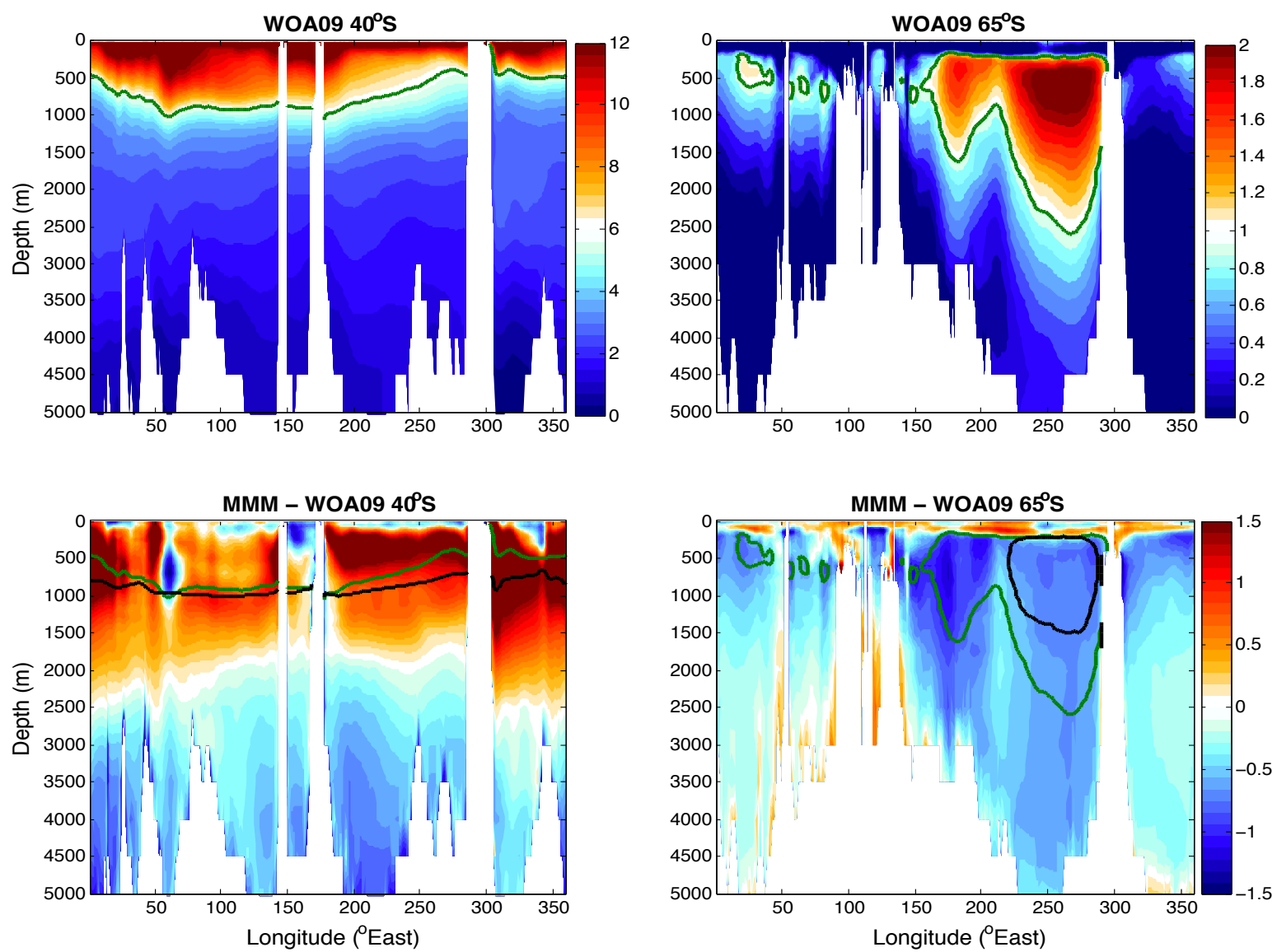

Figure 7: Temperature $\left({ }^{\circ} \mathrm{C}\right.$ ) at $40 \mathrm{~S}^{\circ}$ and $65^{\circ} \mathrm{S}$ for observations (WOA09; Locarnini et al., 2010, top panels) and the multi model mean biases (MMM minus WOA09; bottom panels). The MMM is the averaged 1988-2007 period. The bottom right color scale applies to both bottom panels. The solid green (WOA09)/black (MMM) contours are the $6^{\circ} \mathrm{C}$ isotherm $\left(40^{\circ} \mathrm{S}\right.$ section) and $1^{\circ} \mathrm{C}$ isotherm $\left(65^{\circ} \mathrm{S}\right.$ section). The MMM generally shows a warm bias in the upper $1500 \mathrm{~m}$ at $40^{\circ} \mathrm{S}$, whereas at $65^{\circ} \mathrm{S}$ there is a warm bias near the surface overlying a cool bias, particularly in the Pacific sector. The temperature bias renders a rough density compensating bias with the salinity bias shown in Figure 5 . 

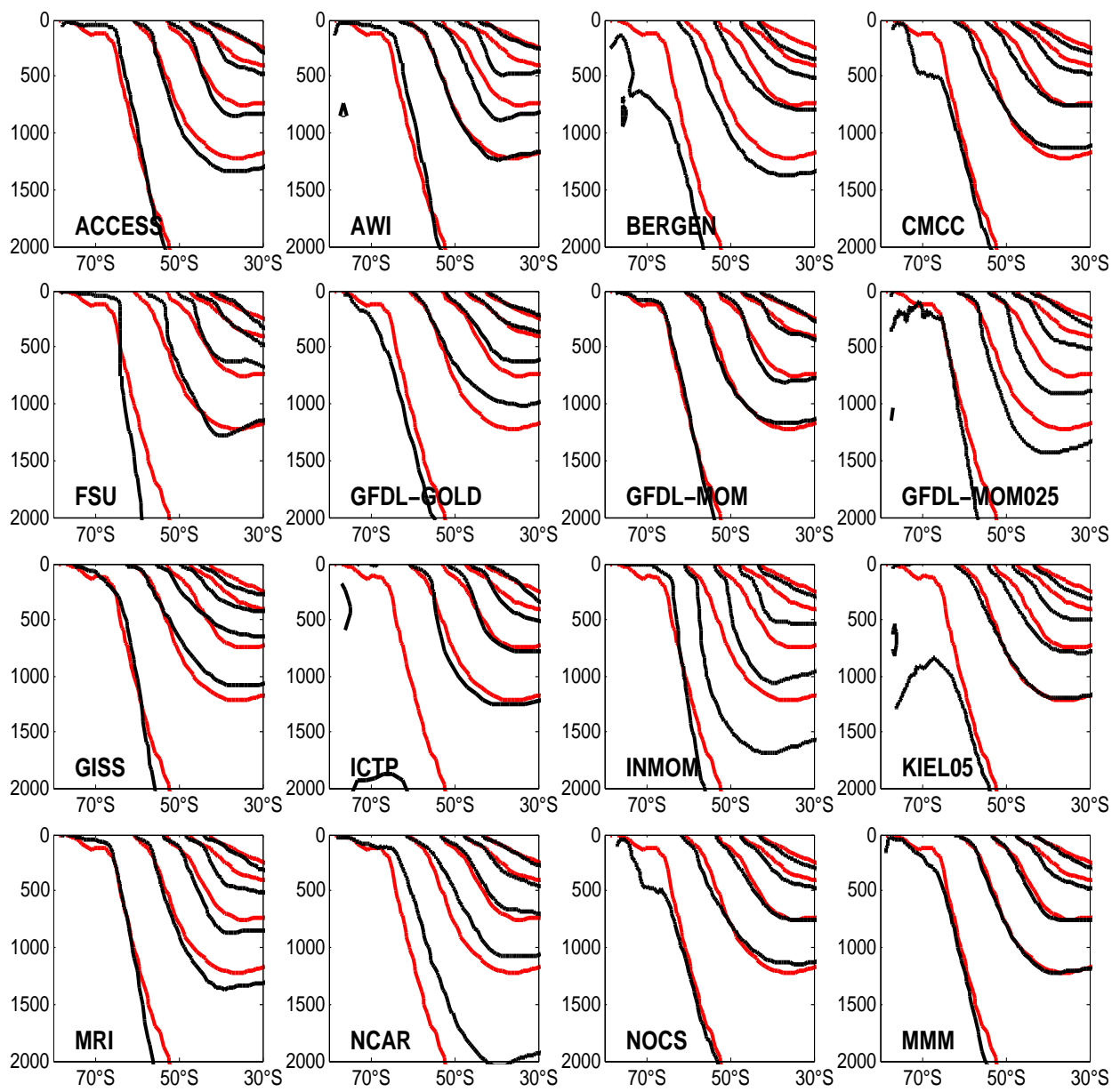

Figure 8: Zonally averaged potential density referenced to $2000 \mathrm{~m}\left(\sigma_{2} ; \mathrm{kg} \mathrm{m}^{-3}\right)$ in the observations (WOA09; all panels; red), and the multi model mean and CORE-II models (black; remaining panels). The $\sigma_{2}$ contours (from top to bottom of the water column) are: 1035.0, 1035.5, 1036.0, 1036.5, and $1037.0 \mathrm{~kg} \mathrm{~m}^{-3}$. The MMM density contours are closely aligned with the observational estimates, largely due to the density compensated biases of temperature and salinity shown in Figure 4 and 6. 

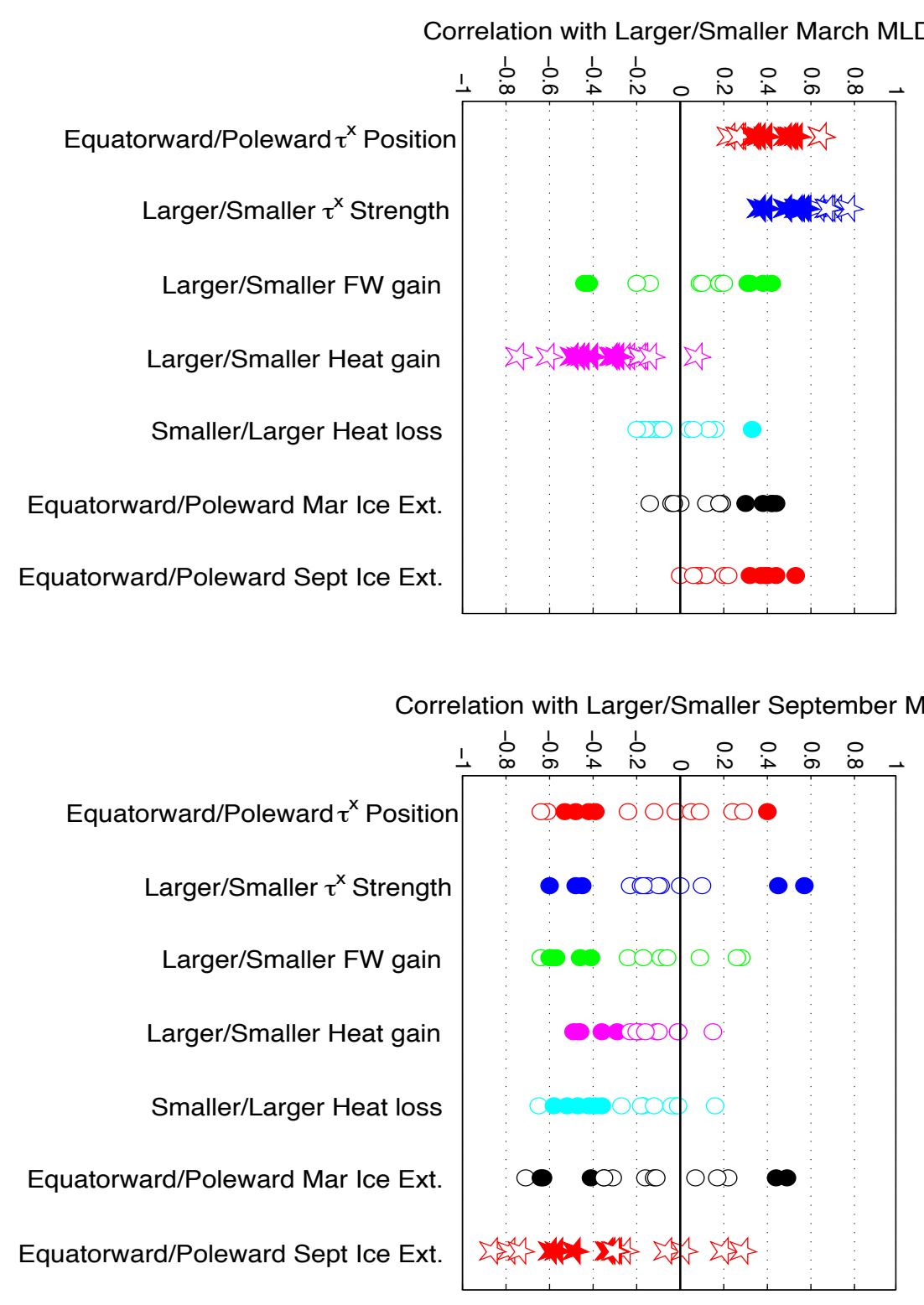

Figure 9: Correlation coefficients for the mean 20 year period (1988-2007) describing the relationship between the March (top) and September (bottom) mixed layer depth regions exceeding $50 \mathrm{~m}$ and $300 \mathrm{~m}$, and the westerly wind stress $\left(\tau^{x}\right)$ position (red), westerly wind stress strength (blue), freshwater flux into the ocean (green), heat gain to the ocean (magenta; the integral over positive heat fluxes), heat loss to the ocean (cyan; the integral over negative heat fluxes), March sea-ice edge (black), and September sea-ice edge (red). Each symbol represents one of the 15 CORE-II models. Solid symbols represents a correlation significant at the $90 \%$ level; open symbols are insignificant correlations. Stars represent relationships where more than half the CORE-II models indicated a significant relationship; circles represent cases where less than half the models indicated a significant relationship. See text for interpretation of the sign of the correlations. 

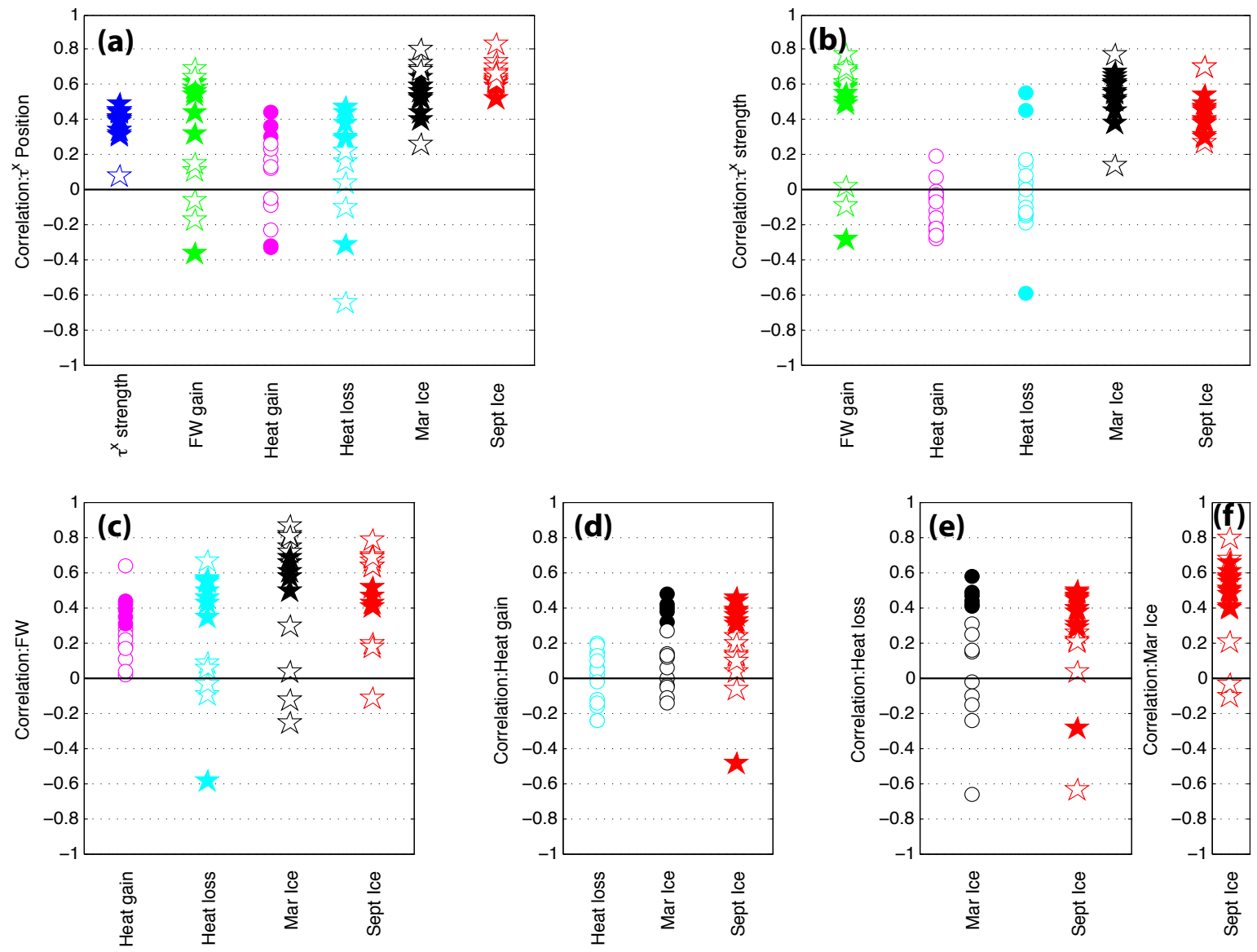

Figure 10: Correlation coefficients for the mean 20 year period (1988-2007) describing the relationship between the (a) maximum westerly wind stress position ( $\tau^{x}$ position), (b) maximum westerly wind stress strength $\left(\tau^{x}\right.$ strength), (c) freshwater flux into the ocean (FW gain), (d) heat gain to the ocean (Heat gain), (e) heat loss to the ocean (Heat loss), (f) March sea-ice edge (Mar Ice), and September sea-ice edge (Sept Ice). Each symbol represents one of the 15 CORE-II models. Solid symbols represents a correlation significant at the 90\% level; open symbols are insignificant correlations. Stars represent relationships where more than half the CORE-II models indicated a significant relationship; circles represent cases where less than half the models indicated a significant relationship. Interpretation of each variable is similar to Figure 9. 

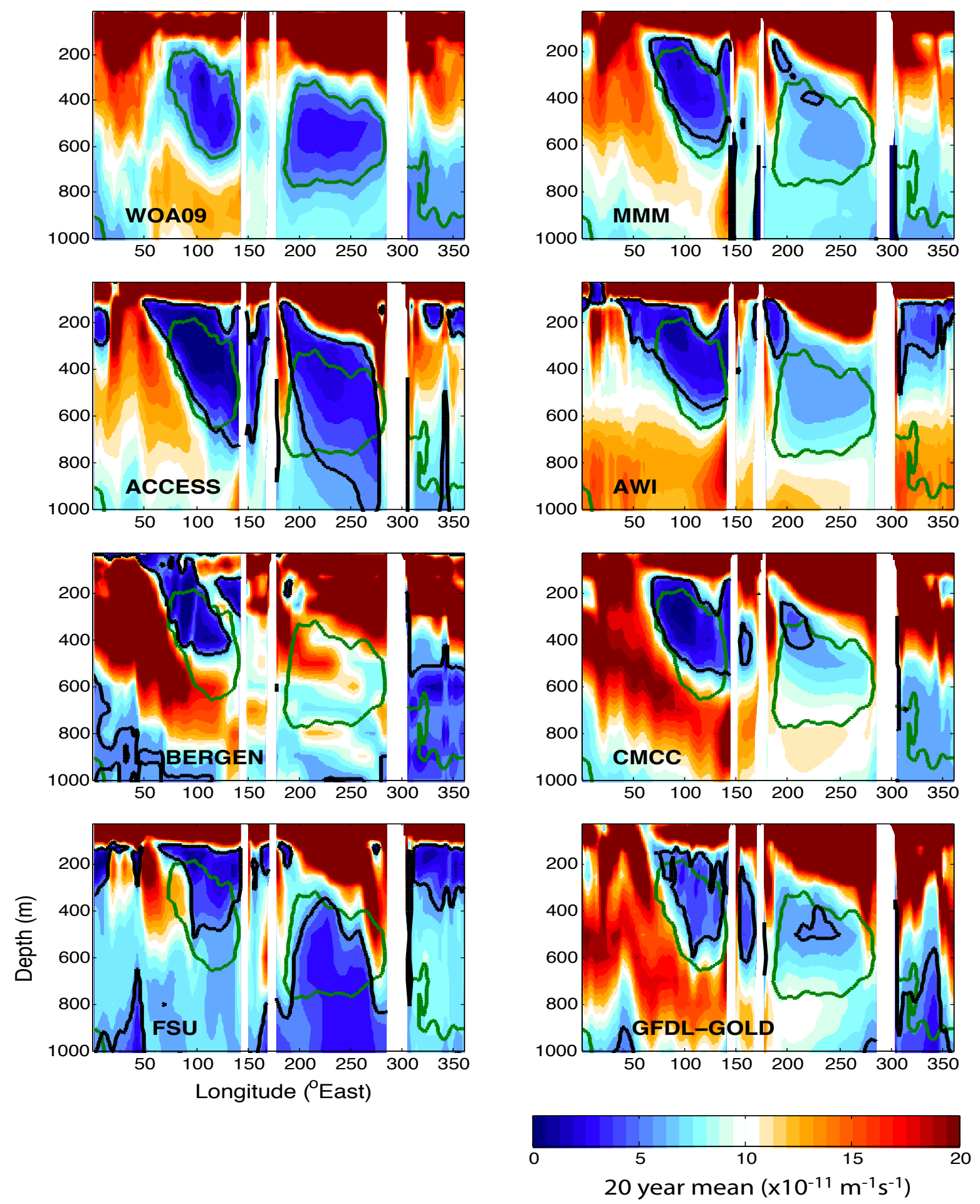

Figure 11: Potential vorticity $\left(\times 10^{-11} \mathrm{~m}^{-1} \mathrm{~s}^{-1}\right)$ across $45^{\circ} \mathrm{S}$ for the averaged 1988-2007 period for observations (WOA09; top left), the multi model mean (MMM; top right), and six of the CORE-II models (remaining panels). Potential vorticity is defined in equation 1 . Overlaid are the $6 \times 10^{-11} \mathrm{~m}^{-1} \mathrm{~s}^{-1}$ contours for WOA09 (green) and the models (black). 

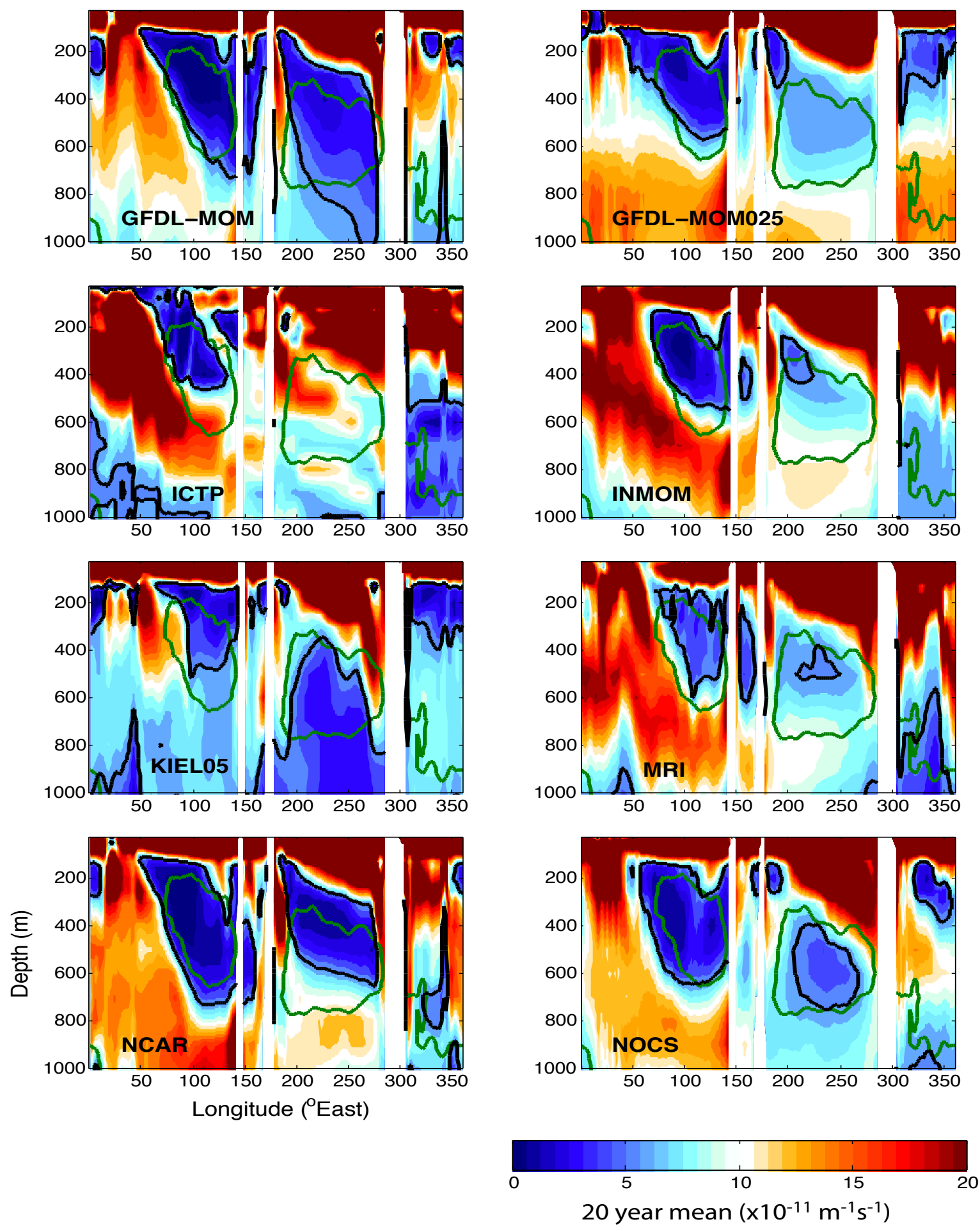

Figure 12: Potential vorticity $\left(\times 10^{-11} \mathrm{~m}^{-1} \mathrm{~s}^{-1}\right)$ across $45^{\circ} \mathrm{S}$ for the averaged 1988-2007 period for eight of the CORE-II models. Overlaid are the $6 \times 10^{-11} \mathrm{~m}^{-1} \mathrm{~s}^{-1}$ contours for observations (WOA09; green) and the models (black). The GISS model is missing from this figure as the diagnostics were unavailable. 

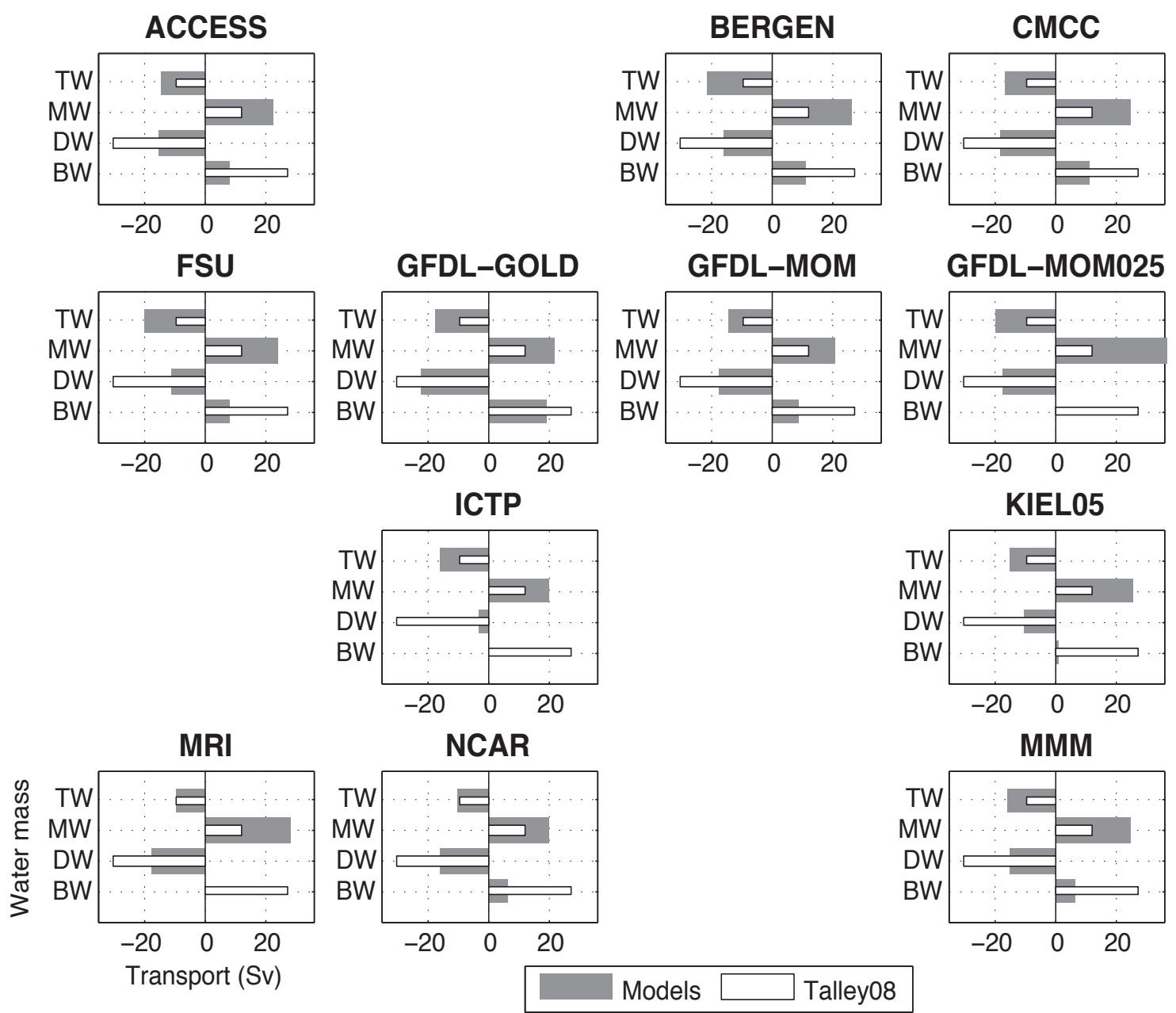

Figure 13: Total seawater volume transport across $30^{\circ} \mathrm{S}(\mathrm{Sv})$ in the CORE-II models. Positive values indicate export from the Southern Ocean (i.e. northward flow). White bars are observationally based estimates from Talley (2008). Grey bars are CORE-II model transports averaged over the 1988-2007 period. Transports are grouped in water mass density layers that are unique to each model: southward flowing thermocline waters (TW) and deep waters (DW); northward flowing mode/intermediate waters (MW) and bottom waters (BW). AWI, GISS, INMOM and NOCS models are missing from this figure as their diagnostics were unavailable. The model transports include contributions from both the resolved advective velocity plus that from the parameterised eddy-induced velocity (for those models using such parameterisations). Note the the MMM generally overestimates the transport of TW and $\mathrm{MW}$, and underestimates the transport of DW and BW. 


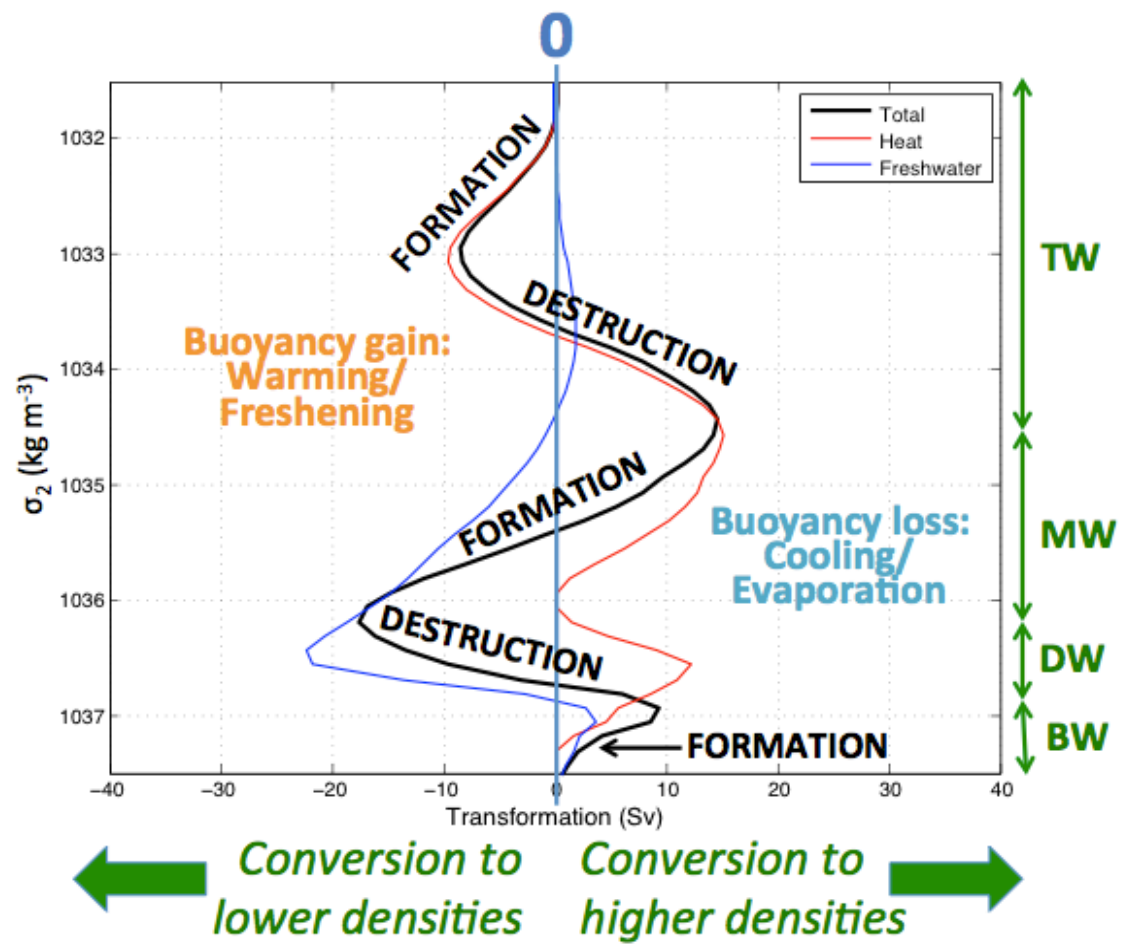

Figure 14: Water mass transformation (WMT) interpretation figure, where transformation (units of Sv) is plotted versus potential density referenced to $2000 \mathrm{dbar}\left(\sigma_{2} ; \mathrm{kg} \mathrm{m}^{-3}\right)$. The black curve used as an example here is the multi model mean total water mass transformation due to buoyancy fluxes at the ocean-atmosphere interface, also shown in Figure 15. The red and blue curves are the surface water mass transformation due to heat and freshwater fluxes, respectively, as defined in equation 2. Positive WMT implies conversion of water masses from lower to higher density classes, and that the overlying buoyancy loss is a result of cooling or evaporative processes. Conversely, negative WMT implies water mass conversion to lower density classes, and a buoyancy gain due to warming and freshening at the surface. Formation in a water mass layer is indicated when $\mathrm{WMT}_{\sigma_{k}}-\mathrm{WMT}_{\sigma_{k+1}}>0$ (where $\sigma$ here refers to potential density referenced to 2000 dbar, i.e., $\sigma_{2}$ ), and the discrete label $k$ represents density layers with $k$ increasing downwards. A negative difference implies destruction of the water mass as it is mixed into adjacent density layers. Note that the formation diagnostic assumes waters are stably stratified with respect to $\sigma_{2}$, so that $\sigma_{k+1}>\sigma_{k}$. The water mass layers (TW, MW, DW and BW) are those used in Figure 13, and the associated density classes are defined here by the points of inflection in the total surface WMT black curve. 

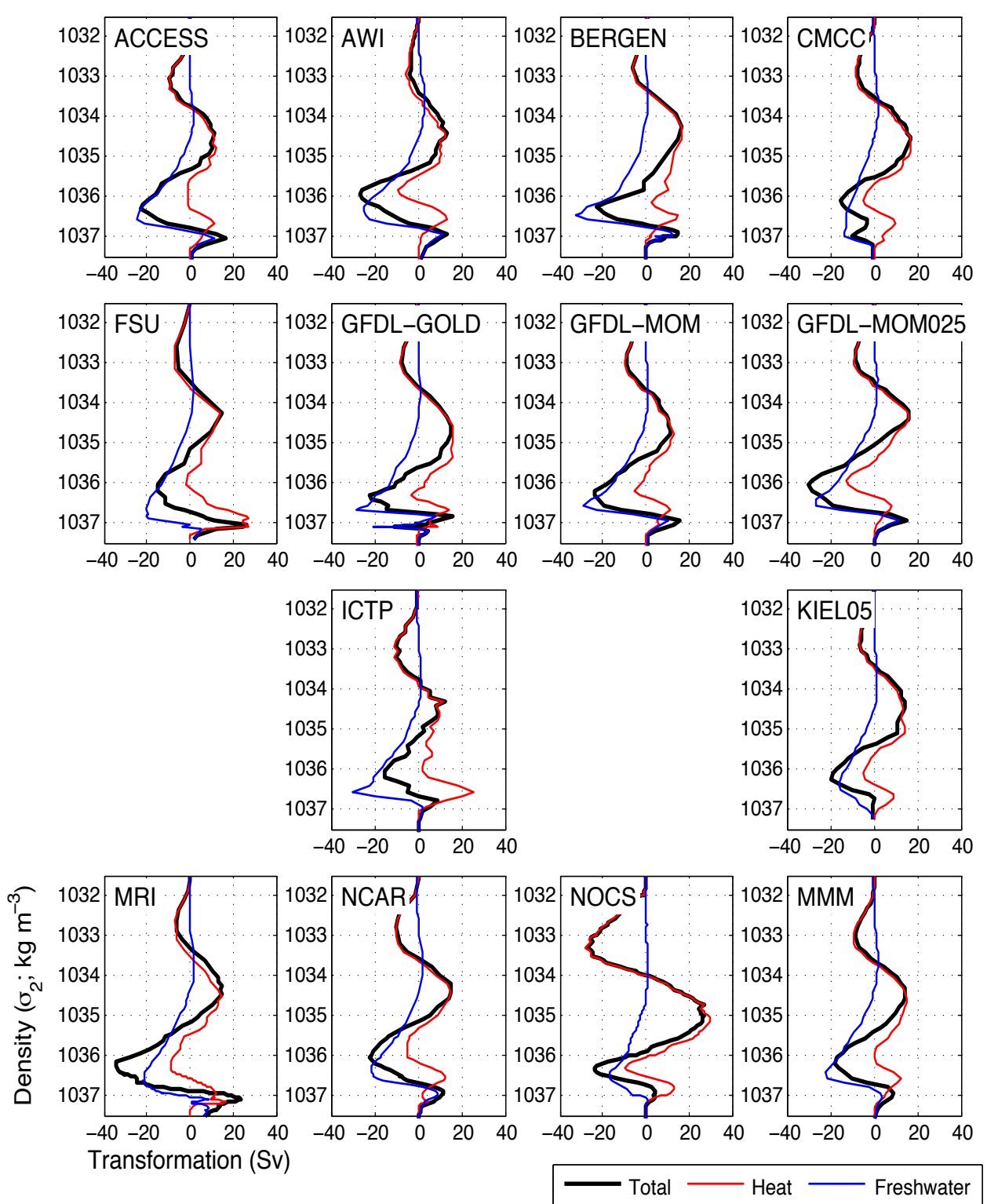

Figure 15: Water mass transformation (units of $\mathrm{Sv}$ ) at the ocean-atmosphere interface arising from heat (red), freshwater (blue) and total buoyancy (black) fluxes in the CORE-II models. The y-axis is density referenced to $2000 \mathrm{dbar}\left(\mathrm{kg} \mathrm{m}^{-3}\right)$. Positive transformation arises from surface buoyancy loss, that is, from cooling and evaporation, and vice versa for negative transformation. GISS and INMOM are missing from this figure as its diagnostics were unavailable. 

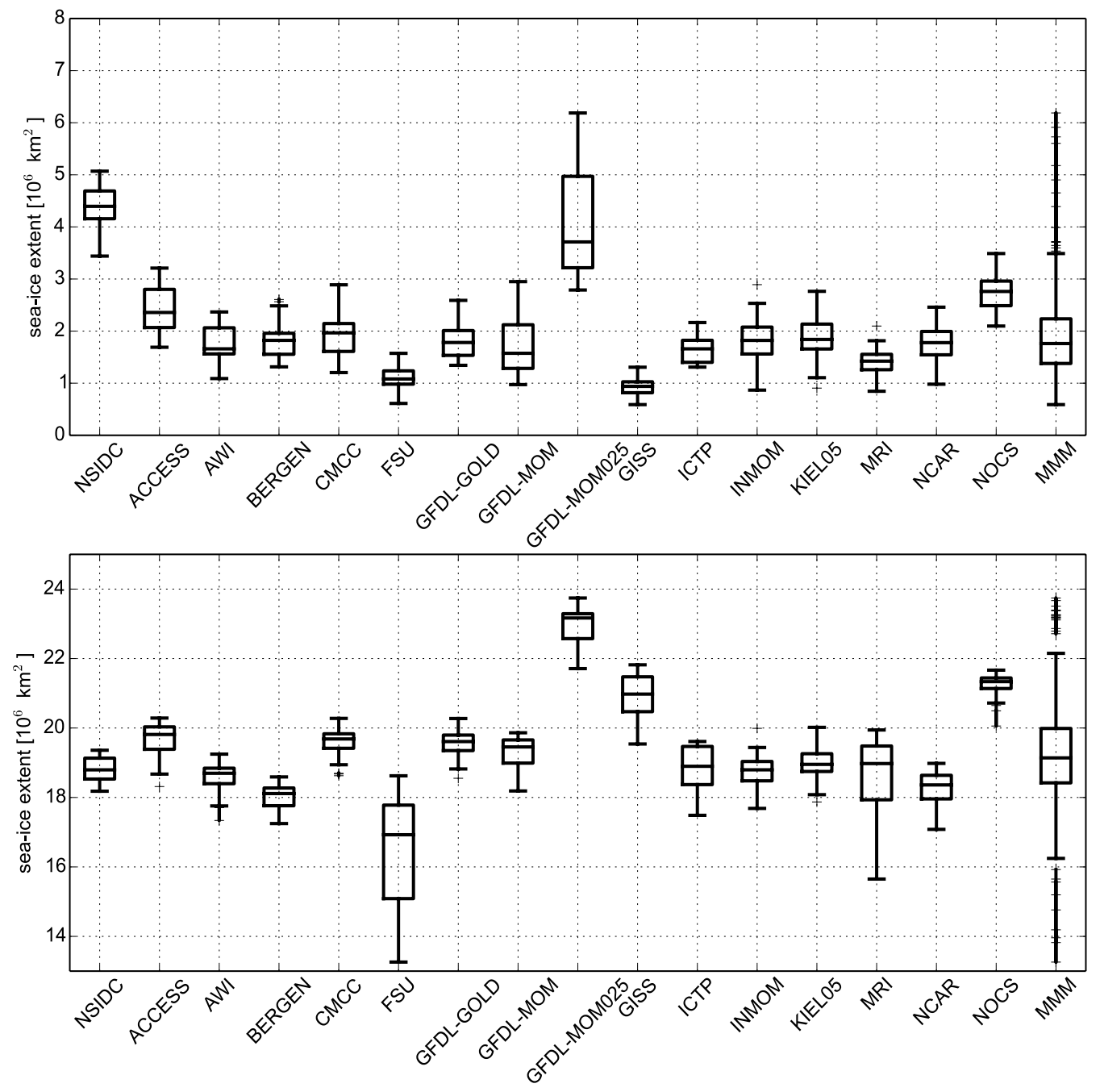

Figure 16: Boxplots of (upper panel) the Antarctic March sea-ice extent and (lower panel) the Antarctic September sea-ice extent for the period 1988-2007 inclusive versus observations (National Snow and Ice Data Center; NSIDC; Fetterer et al. (2009)). Boxes extend from the lower to upper quartile values of the data over the interquartile range, with a line at the median. Sea ice extent units are $10^{6} \mathrm{~km}^{2}$. Note that the MMM contains values from all models, resulting in a large spread and several outliers. 


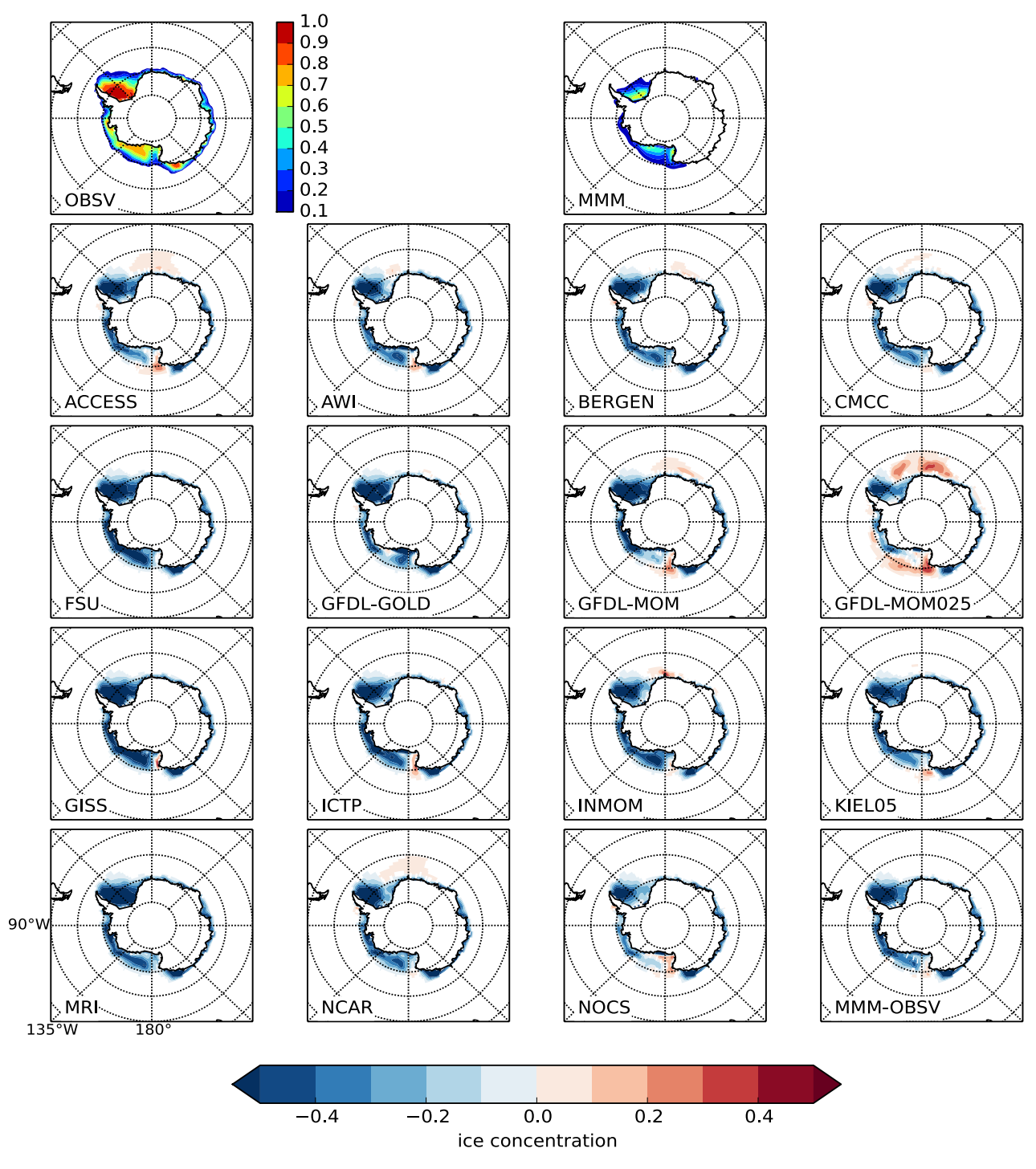

Figure 17: First two top row panels: March observed (NOAA OI.v2 SST) and multi model mean sea-ice concentration, averaged over the 1988-2007 period. Remaining panels (associated color scale at bottom of figure): departures of multi model mean and individual models from observations. The CORE-II models exhibit weaker concentration in the west Antarctic and Weddell Sea regions where sea ice concentration is largest. Polar grid (black lines) shows latitude (radials; $70^{\circ}-40^{\circ} \mathrm{S}$ by $10^{\circ}$ ) and longitude (rays; clockwise $0^{\circ}-315^{\circ} \mathrm{E}$ by $45^{\circ}$ ). Note: the color bar in the top row represents the mean states of the observations and multi model mean, whereas the color bar at the bottom of the figure is for the remaining rows (the biases from observations). The simulations generally underestimate the summer Southern Ocean sea-ice extent. 


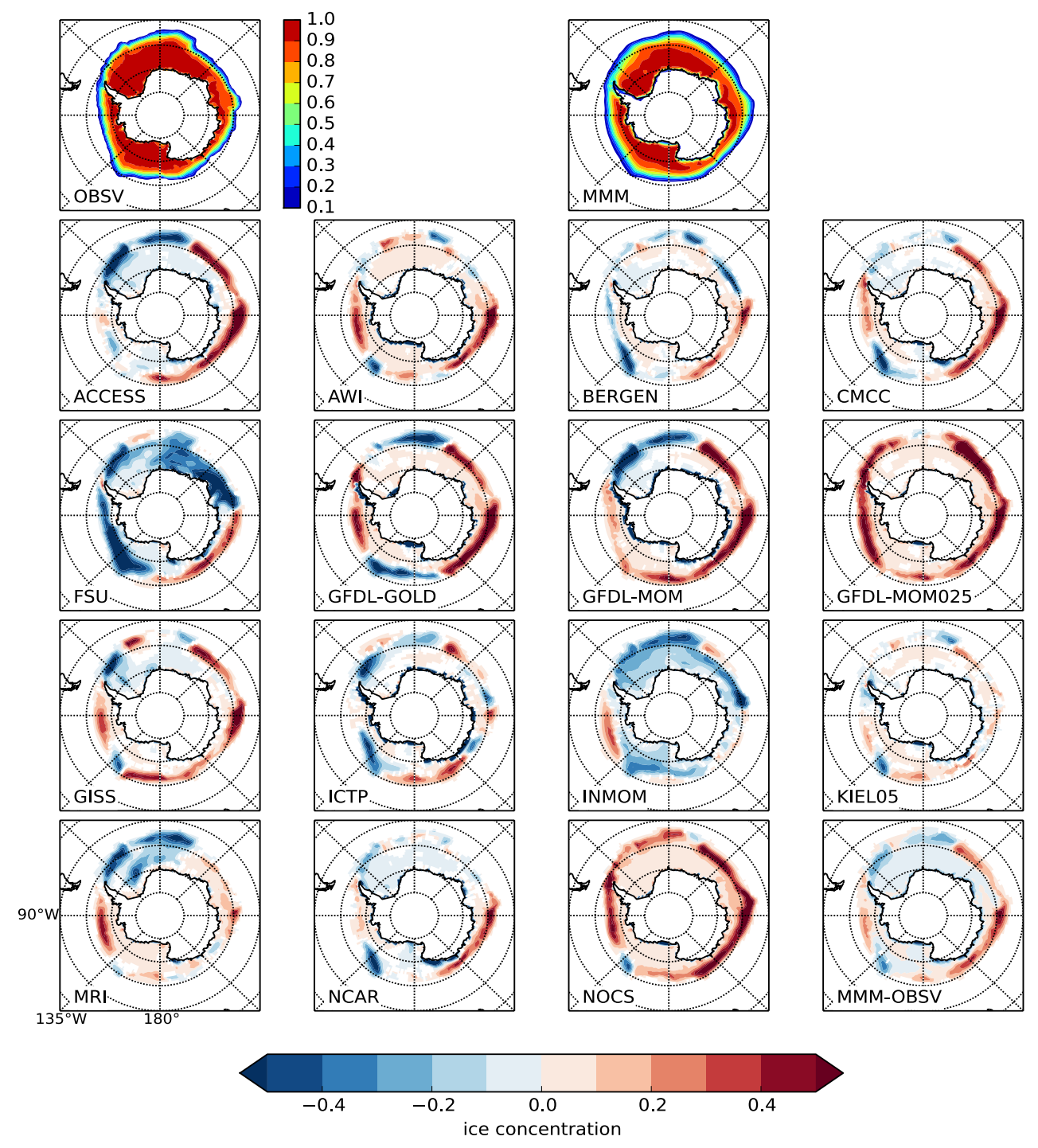

Figure 18: First two top row panels: September observed (NOAA OI.v2 SST) and multi model mean sea-ice concentration, averaged over the 1988-2007 period. Remaining panels (associated color scale at bottom of figure): departures of multi model mean and individual models from observations. Geographic grid (black lines) as in Figure 17. Note: the color bar in the top row represents the mean states of the observations and multi model mean, whereas the color bar at the bottom of the figure is for the remaining rows (the biases from observations). The simulations show a diverse spread in biases for winter Southern Ocean sea-ice extent, with the MMM showing some regions of positive and some with negative biases. 

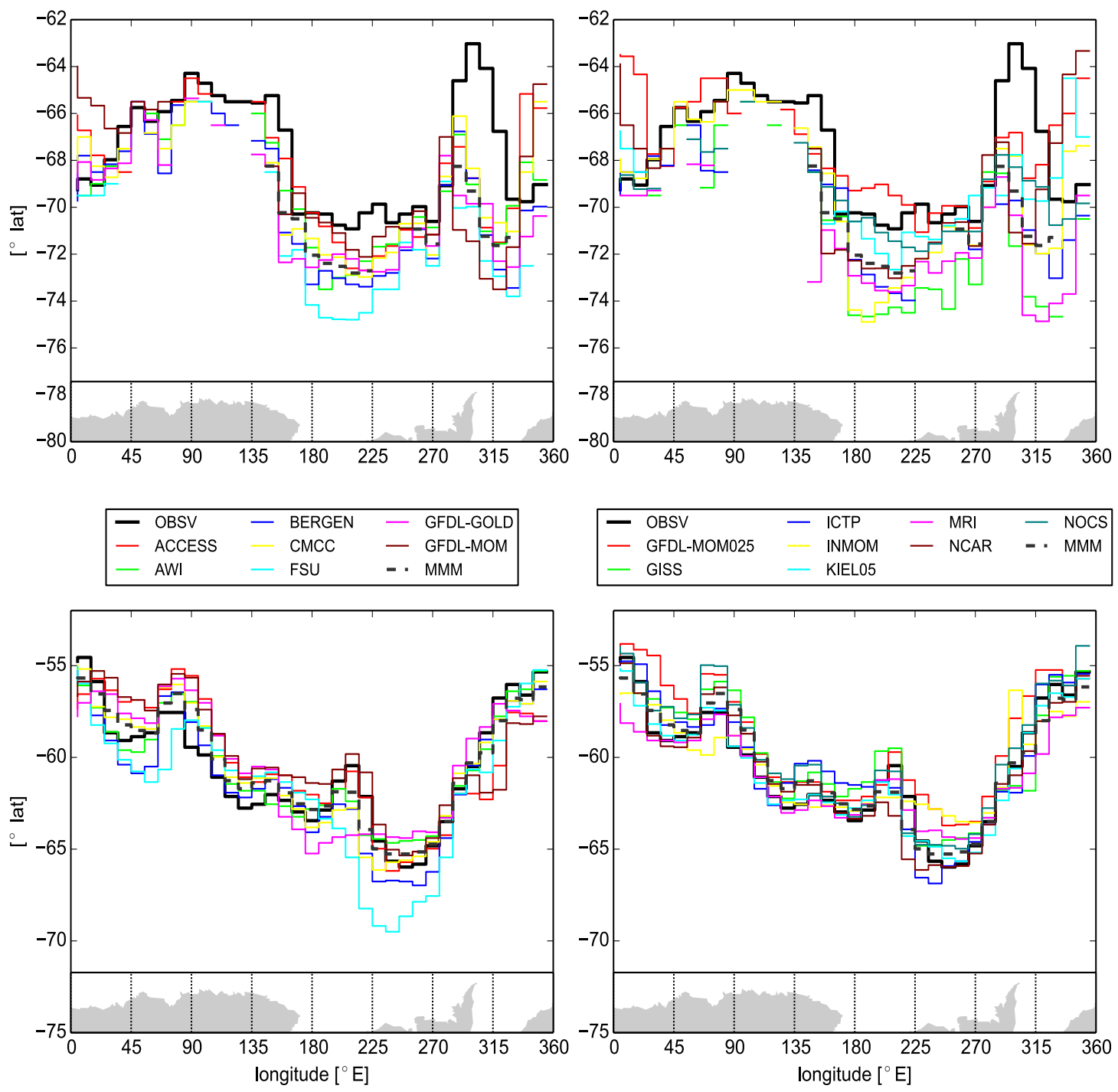

Figure 19: March (upper panels) and September (lower panels) latitudinal location of the northernmost grid cell where the sea-ice concentration is over $15 \%$ for each $10^{\circ}$ longitude bin from 1988-2007. MMM is the multi model mean (black dashed curves). Observations are the NOAA OI.v2 SST product (back solid curves). 

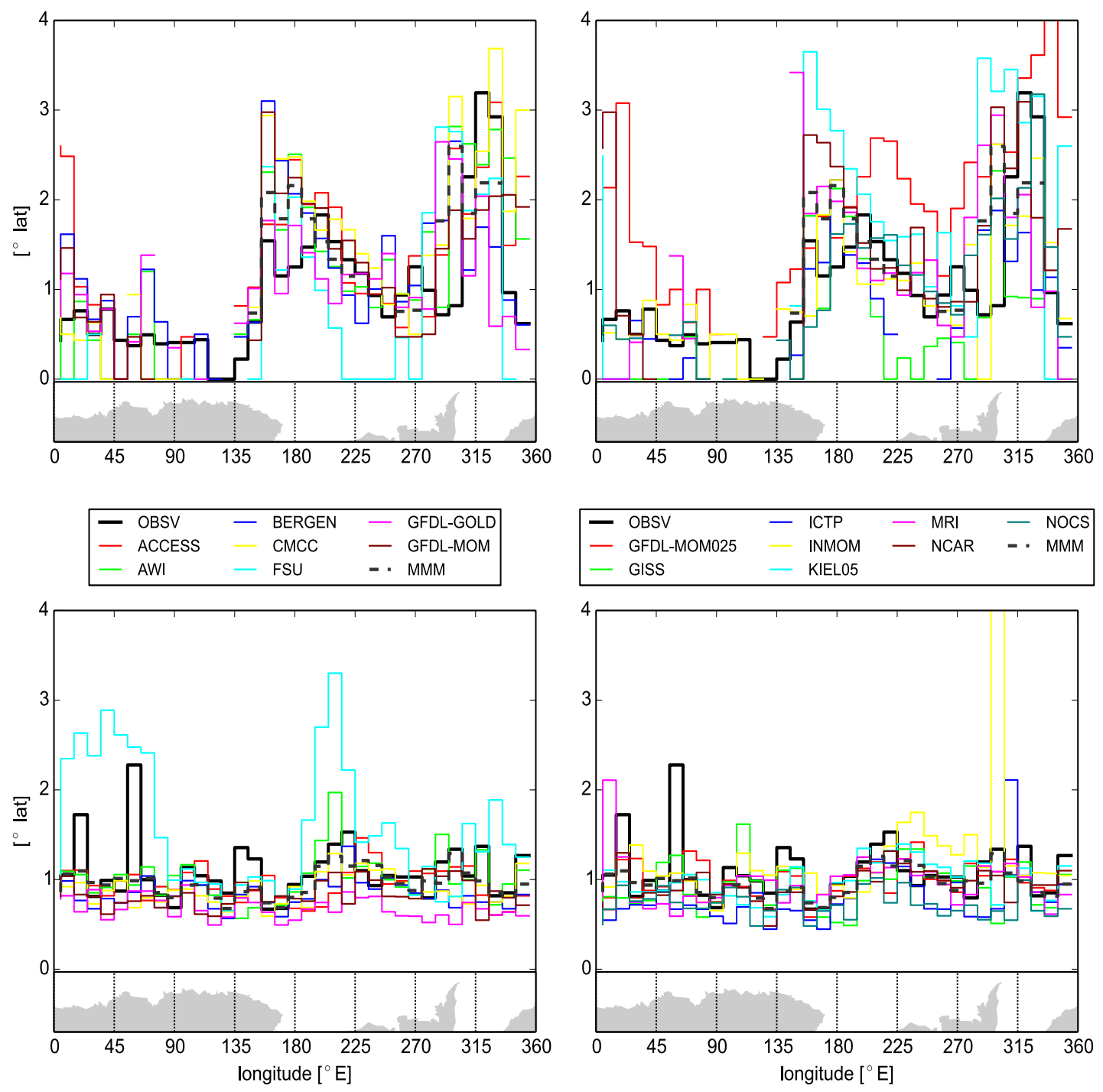

Figure 20: Standard deviation in the March (upper panels) and September (lower panels) latitudinal location of the northernmost grid cell where the sea-ice concentration is over $15 \%$ for each $10^{\circ}$ longitude bin from 1988-2007. MMM is the multi model mean (black dashed curves). Observations are the NOAA OI.v2 SST product (black solid curves). 

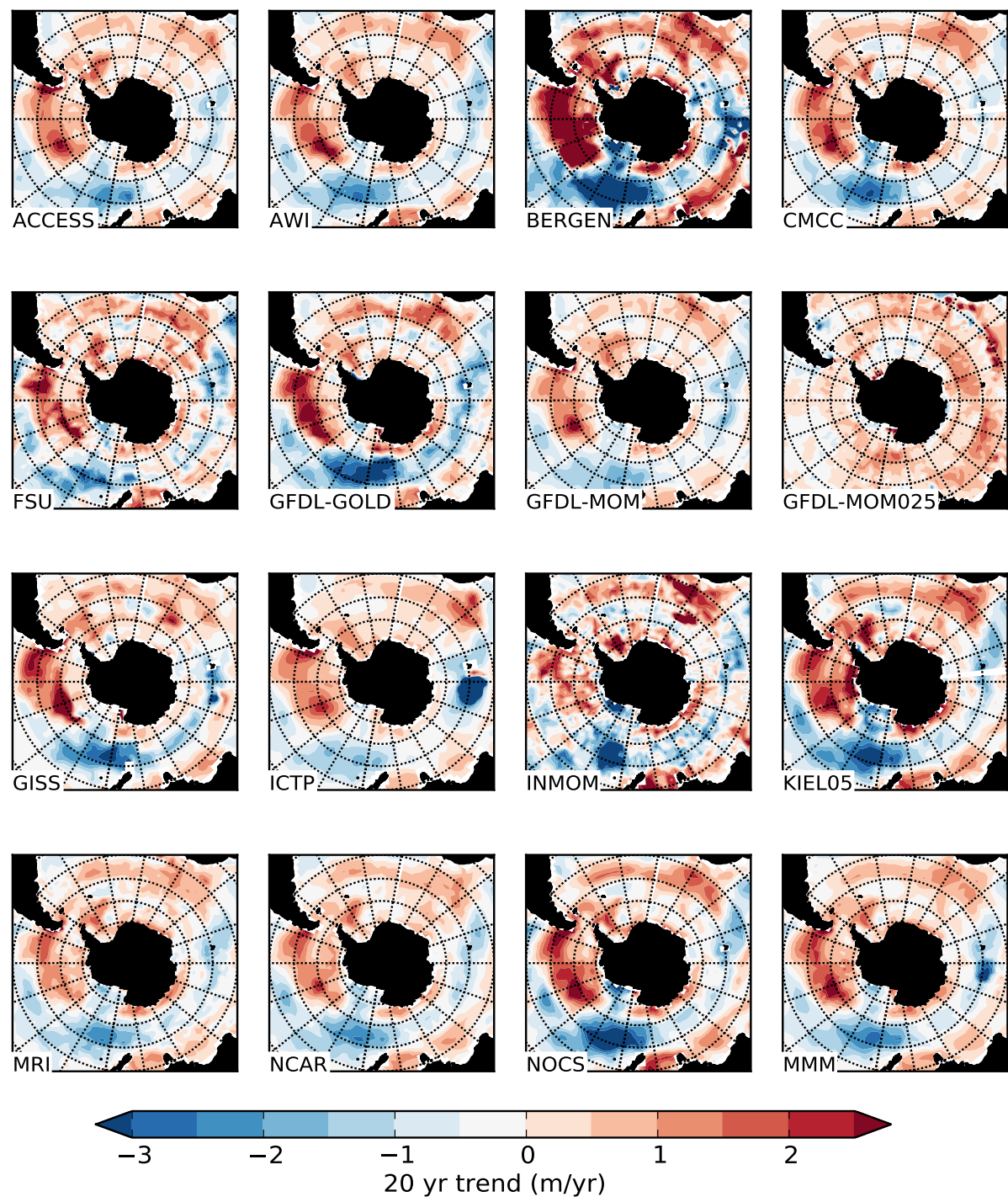

Figure 21: Trend in the March mixed layer depth $\left(\mathrm{m} \mathrm{yr}^{-1}\right)$ for the 1988-2007 period. The multi-model mean (MMM) is displayed in the bottom right panel. Geographic grid (black lines) as in Fig 1. The MMM generally shows a trend towards increases in the March mixed layer depth across the Atlantic and southeast Pacific sectors, and decreases in the mixed layer in the Indian and southwest Pacific sectors. 

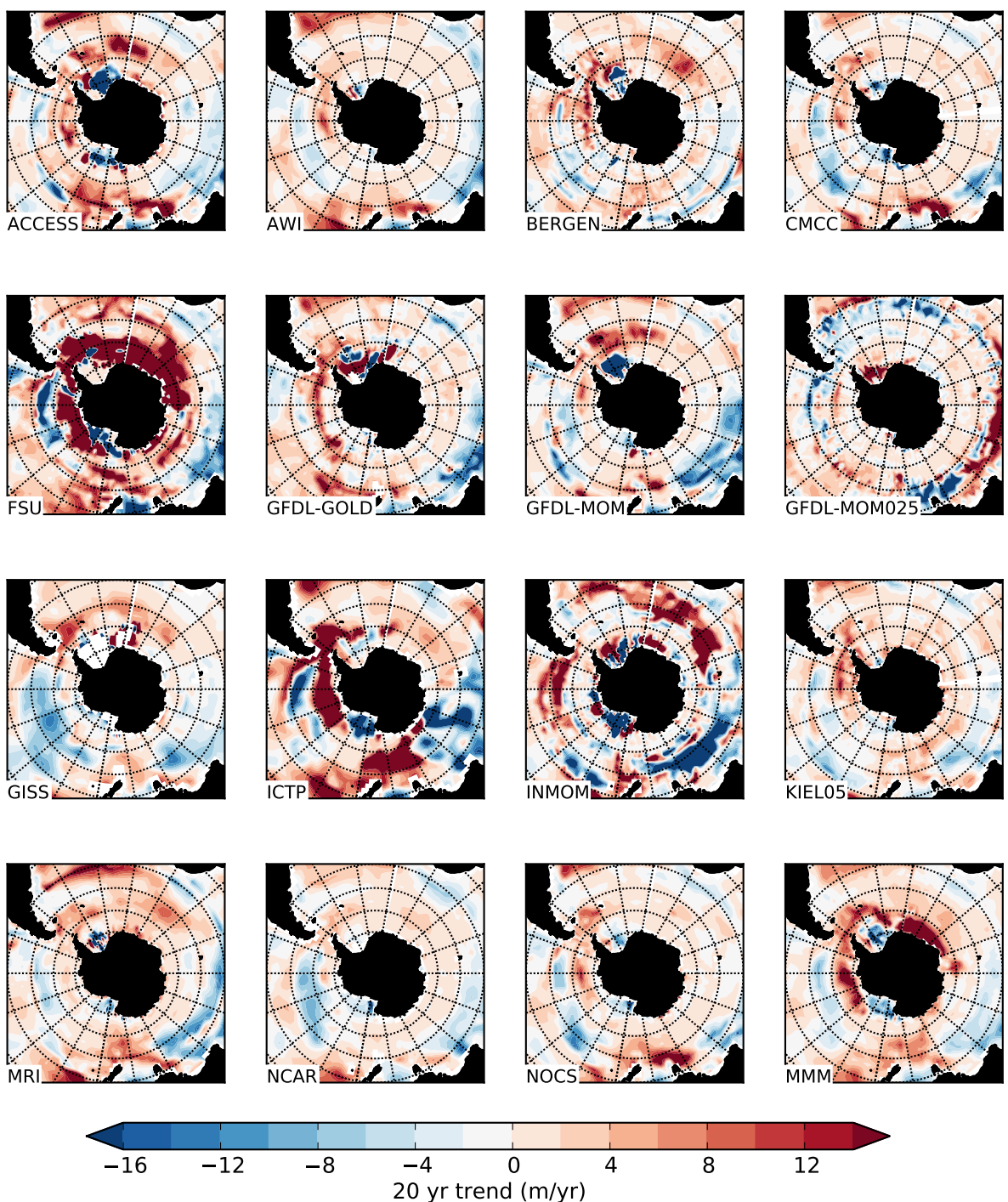

Figure 22: Trend in the September mixed layer depth $\left(\mathrm{m} \mathrm{yr}^{-1}\right)$ for the 1988-2007 period. The multi-model mean (MMM) is displayed in the bottom right panel. Geographic grid (black lines) as in Fig 1. The MMM generally shows a trend towards deepening of the September mixed layer depths throughout most of the Southern Ocean. 

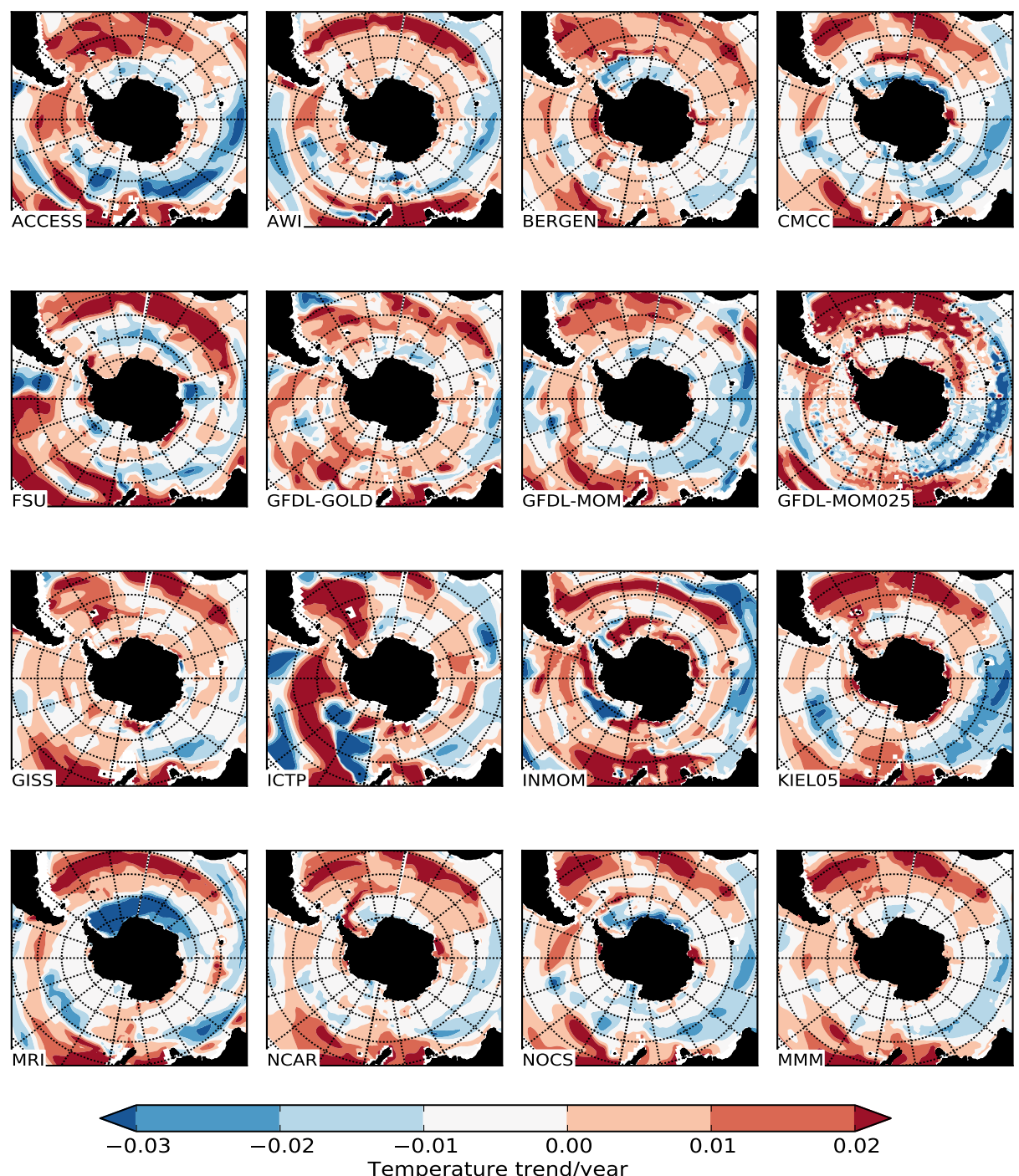

Figure 23: Trend in the $200 \mathrm{~m}$ to $700 \mathrm{~m}$ averaged temperature $\left({ }^{\circ} \mathrm{C} \mathrm{yr}^{-1}\right)$ for the $1988-2007$ period. The multi model mean (MMM) is displayed in the bottom right panel. Geographic grid (black lines) as in Fig 1. The MMM generally shows a warming trend in the South Atlantic and South Pacific regions, with modest cooling in the Indian. Additionally, some of the models, notably the finest resolution models (KIEL05 and GFDL-MOM025) show patches of warming reaching towards the Antarctic continent margins. 

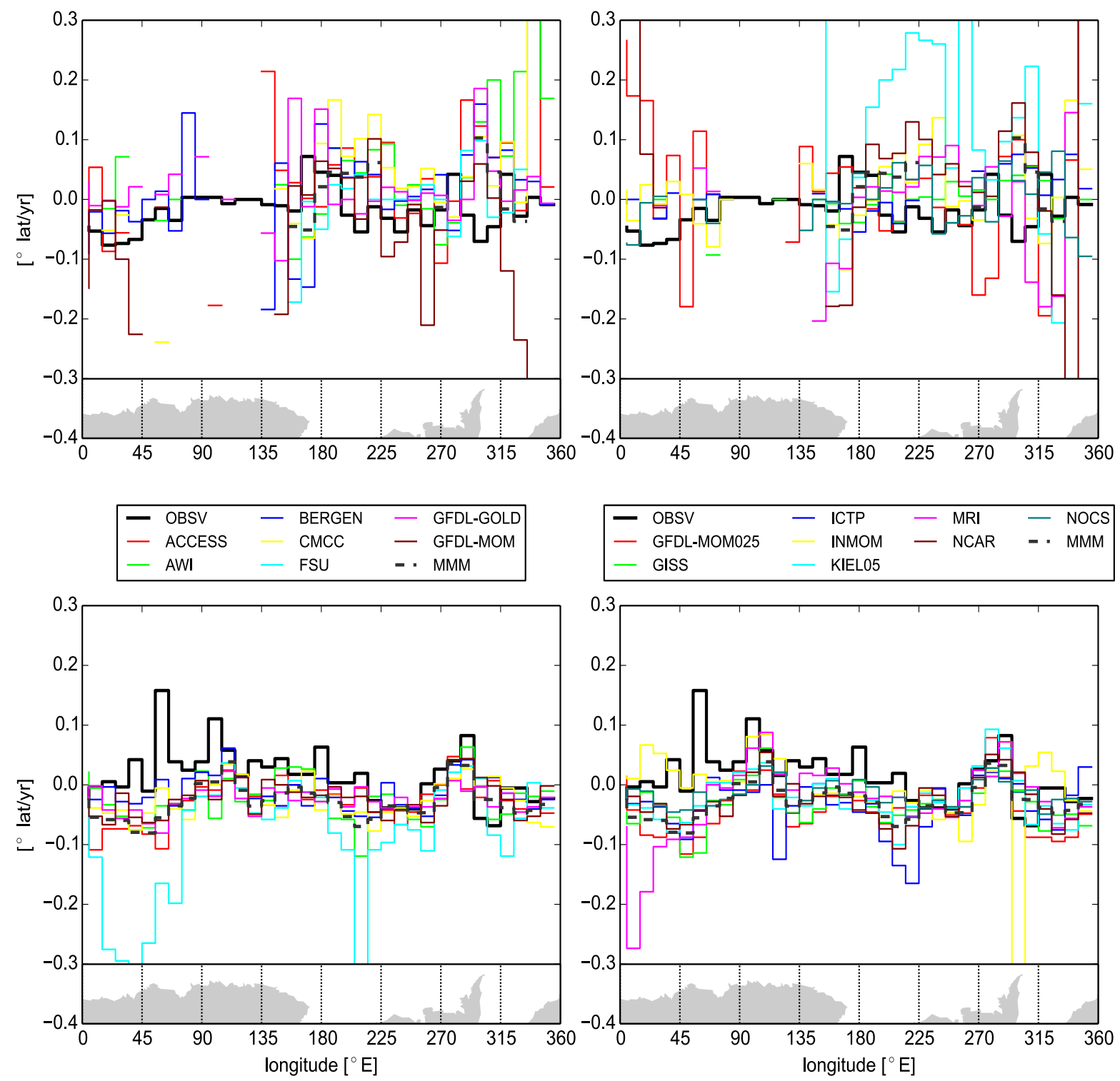

Figure 24: Twenty year trend (1988-2007) in the March (upper panel) and September (lower panel) latitudinal location of the northernmost grid cell, where the sea-ice concentration is over $15 \%$ for each $10^{\circ}$ longitude bin. MMM is the multi model mean (black dashed curves). Observations are the NOAA OI.v2 SST product (black solid curves). Overall the observed sea-ice margin has extended northward over the past 20 years, though the models exhibit a smaller or negative (retreating) trend in sea ice. 

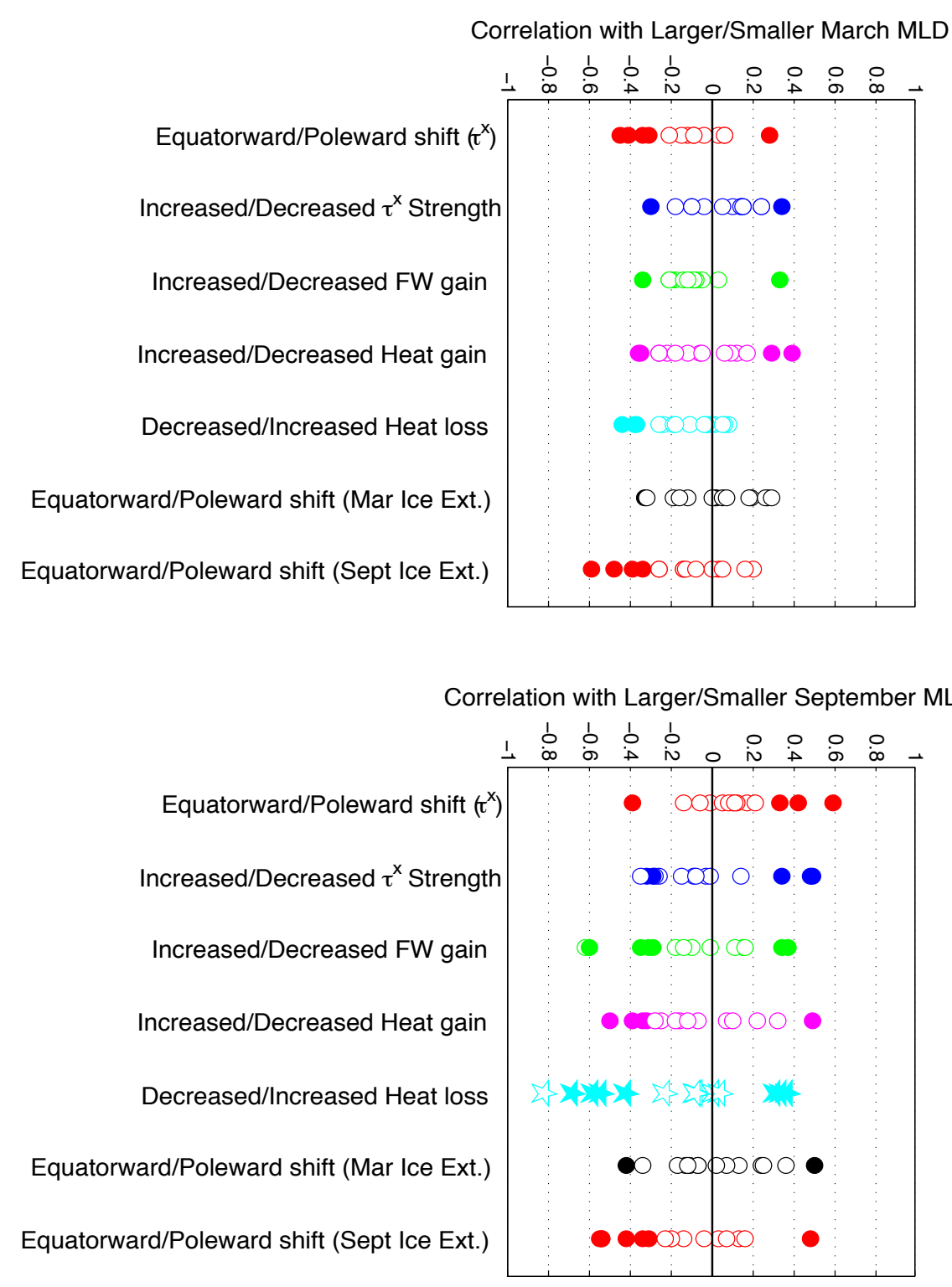

Figure 25: Correlation coefficients for the trend over the 20 year period (1988-2007) describing the relationship between the March (top) and September (bottom) mixed layer depth regions exceeding $50 \mathrm{~m}$ and $300 \mathrm{~m}$, and the westerly wind stress $\left(\tau^{x}\right)$ position (red), westerly wind strength (blue), freshwater flux into the ocean (green), heat flux into the ocean (magenta), heat loss to the ocean (cyan), March sea-ice edge (black), and September sea-ice edge (red). Each symbol represents one of the 15 CORE-II models. Solid symbols represents a correlation significant at the 90\% level; open symbols are insignificant correlations. Stars represent relationships where more than half the CORE-II models indicated a significant relationship; circles represent cases where less than half the models indicated a significant relationship. See text for interpretation of the sign of the correlations. 


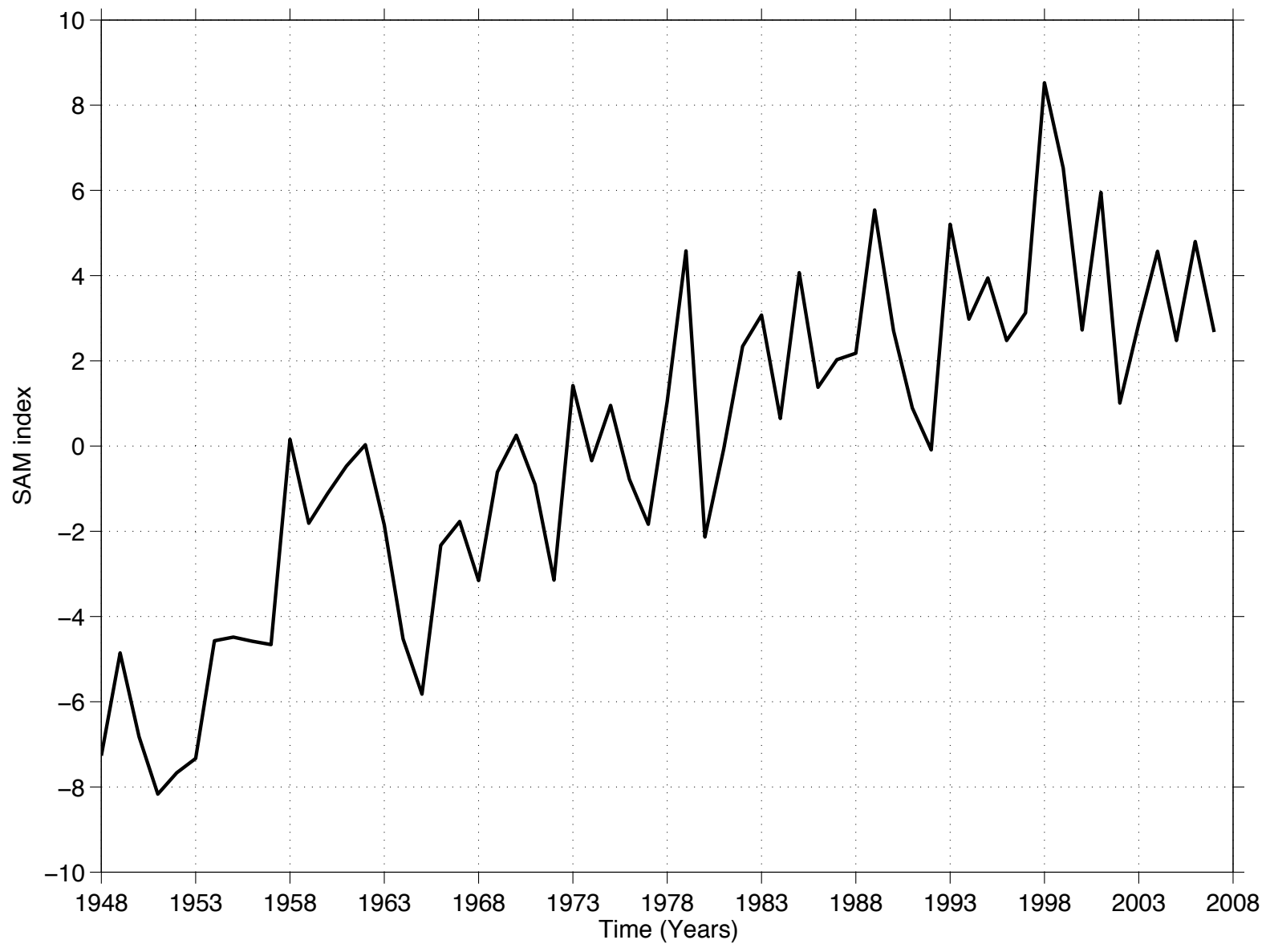

Figure 26: Southern Annular Mode (SAM) index computed as the difference in normalized annual-mean zonal mean sea-level pressure at $40^{\circ} \mathrm{S}$ and $65^{\circ} \mathrm{S}$ (Marshall, 2003) from the CORE-II forcing for the entire cycle (1948-2007). The relative flattening of the trend during the final 20 years may explain the modest role of wind trends on mixed layer depth trends in the CORE-II simulations. 

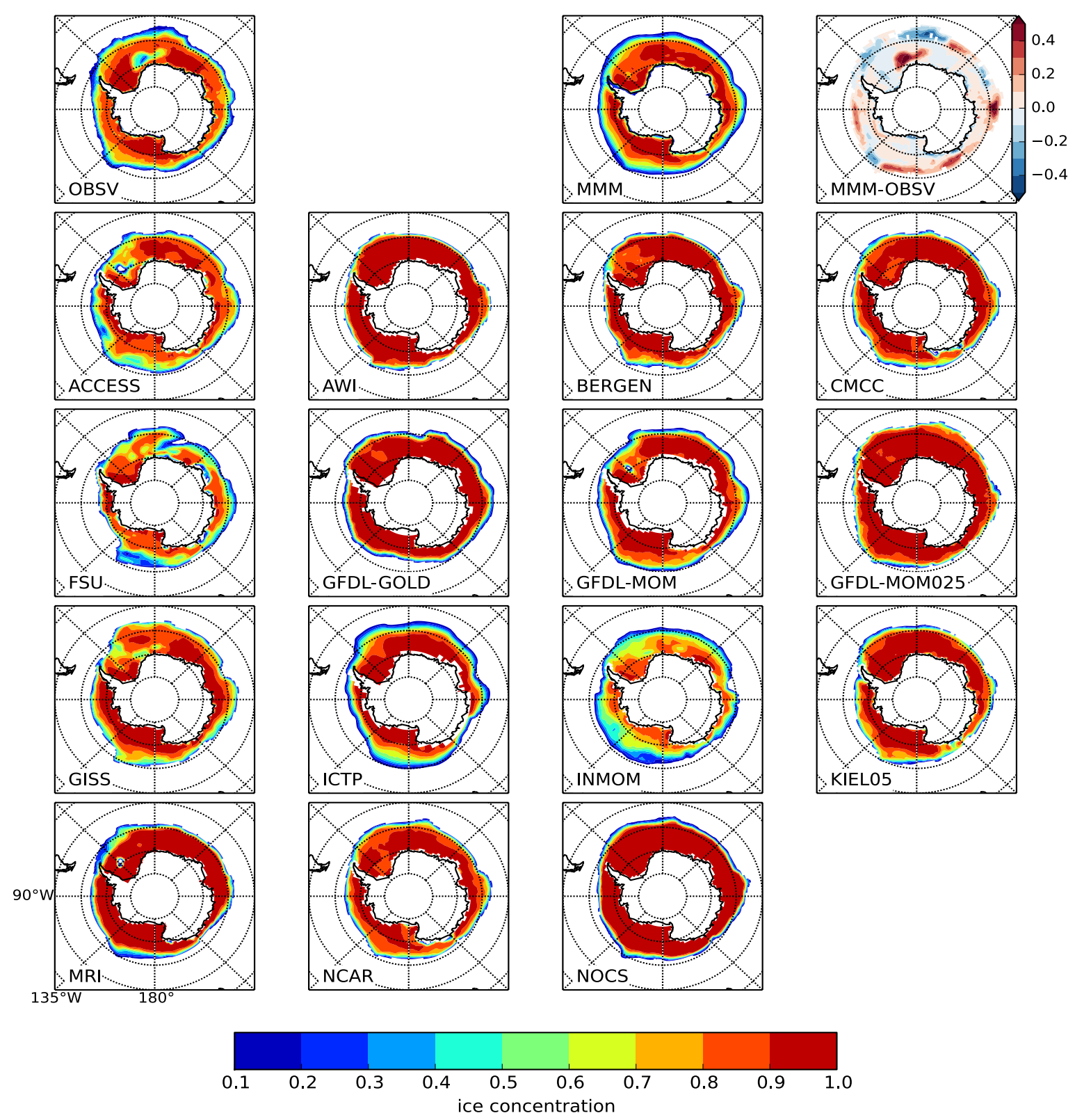

Figure 27: Minimum monthly mean sea ice concentration per grid cell for September 1974-76 in the CORE-II models and observations (Parkinson et al., 2004). During this period, an ice-free region developed in the thick sea ice within Weddell Sea region, known as the Weddell Sea polynya. There is no clear trend in the Weddell Sea polynya within the CORE-II simulations. 


\section{8 - 2007 MEAN}

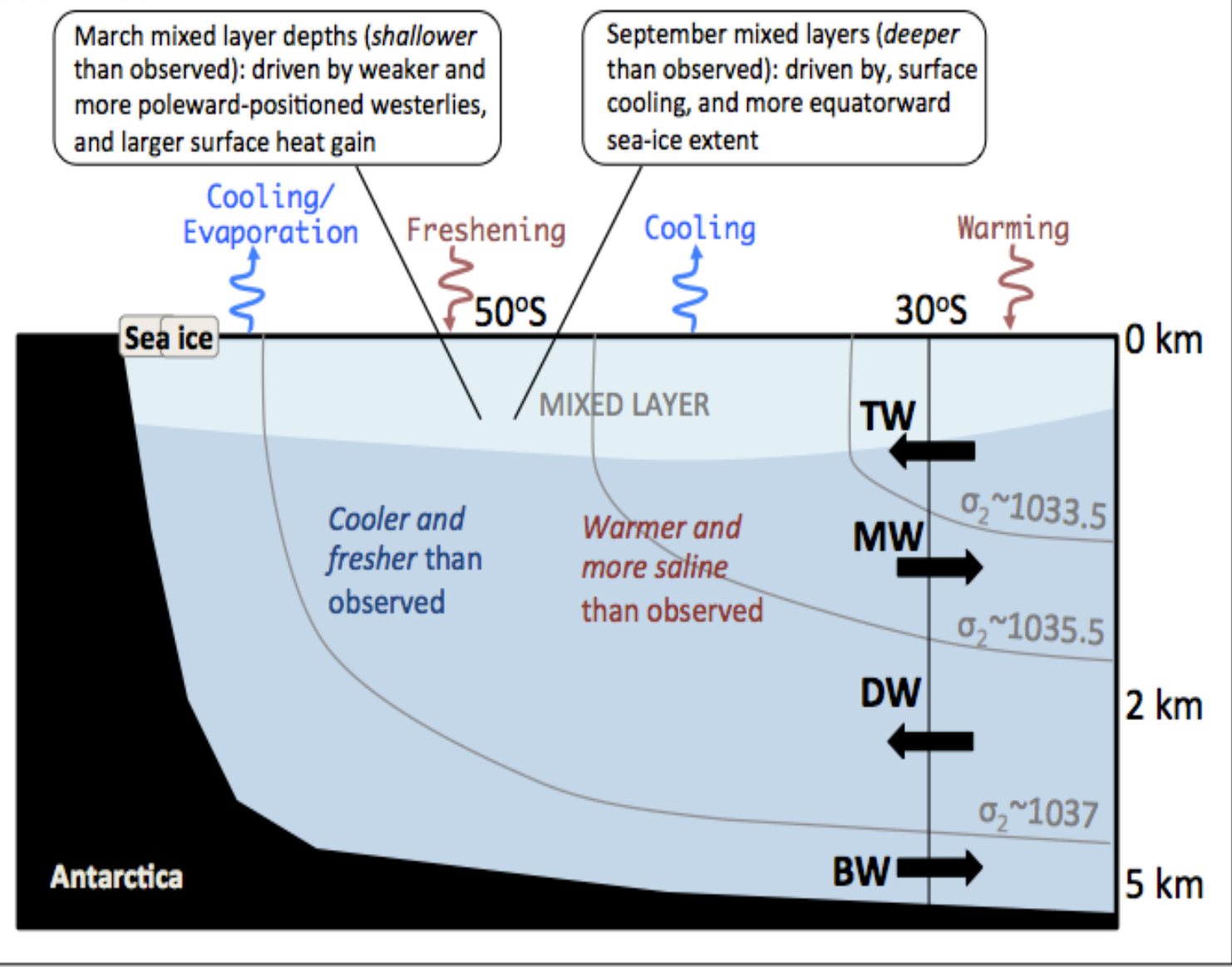

Figure 28: Schematic summarizing the multi model mean biases and oceanic processes coherently represented in the CORE-II models for the 1988-2007 present state. Overlying westerlies and surface heat gain primarily deepen the summer (March) mixed layer depths, with surface heat loss and sea-ice playing are associated with deeper winter (September) mixed layers. In the ocean interior, the models exhibit a cool and fresh bias south of $50^{\circ} \mathrm{S}$, and warm and salty bias to the north. The thick horizontal black arrows are representative of the direction of volume transport across $30^{\circ} \mathrm{S}$ within the approximate density layers $\left(\sigma_{2} ; \mathrm{kg} \mathrm{m}^{-3}\right)$. The water masses in these layers are (top to bottom): southward flowing thermocline waters (TW), northward flowing mode/intermediate waters (MW), southward flowing deep waters (DW), and northward flowing bottom waters (BW). Whilst the March sea-ice concentration is overall lower than observed, the September sea-ice concentration biases vary in sign and strength around the Antarctic continent. 